LBNL-56895

\title{
Strategies for Detecting Hidden Geothermal Systems by Near-Surface Gas Monitoring
}

\author{
Jennifer L. Lewicki \\ Curtis M. Oldenburg
}

\author{
Earth Sciences Division \\ Ernest Orlando Lawrence Berkeley National Laboratory \\ Berkeley, CA 94720
}

December 15, 2004

This work was supported by the Assistant Secretary for Energy Efficiency and Renewable Energy, Office of Geothermal Technologies, of the U.S. Department of Energy, and by the Office of Science, U.S. Department of Energy, under Contract No. DE-AC03-76SF00098. 


\section{DISCLAIMER}

This report was prepared as an account of work sponsored by an agency of the United States Government. Neither the United States Government nor any agency thereof, nor any of their employees, makes any warranty, express or implied, or assumes any legal liability or responsibility for the accuracy, completeness, or usefulness of any information, apparatus, product, or process disclosed, or represents that its use would not infringe privately held rights. Reference herein to any specific commercial product, process, or service by trade name, trademark, manufacturer, or otherwise does not necessarily constitute or imply its endorsement, recommendation, or favoring by the United States Government or any agency thereof. The views and opinions of authors expressed herein do not necessarily state or reflect those of the United States Government or any agency thereof. 


\section{TABLE OF CONTENTS}

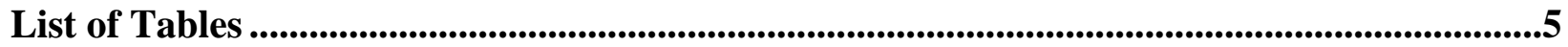

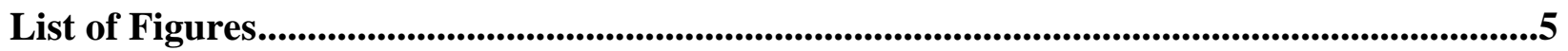

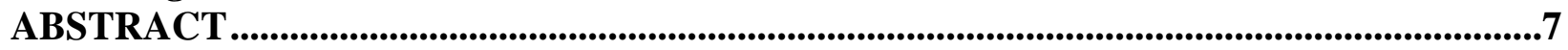

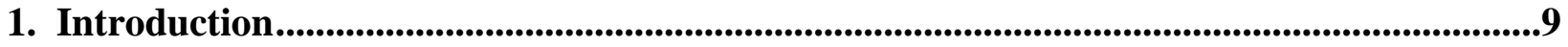

2. Fluxes and Concentrations of $\mathrm{CO}_{2}$ in Known Volcanic and Hydrothermal Systems .......10

3. Physical Properties of $\mathrm{CO}_{2}$ in the Near Surface ..........................................................11

4. Simulations of $\mathrm{CO}_{2}$ Migration .................................................................................................11

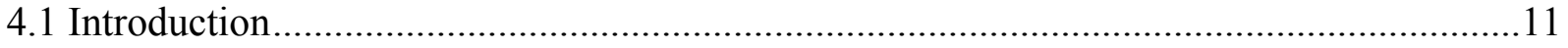

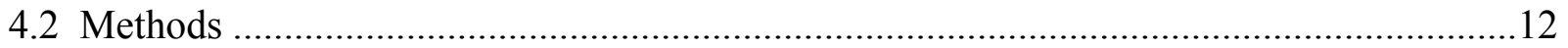

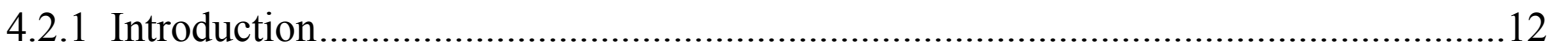

4.2.2 Logarithmic Velocity Profile ................................................................................ 12

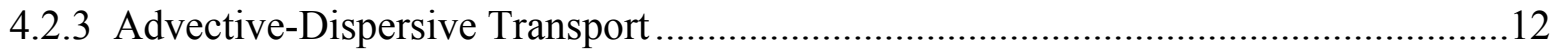

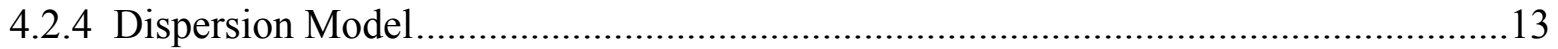

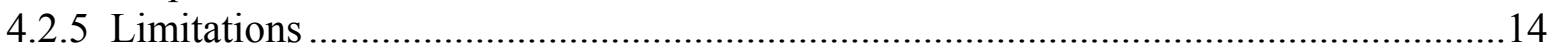

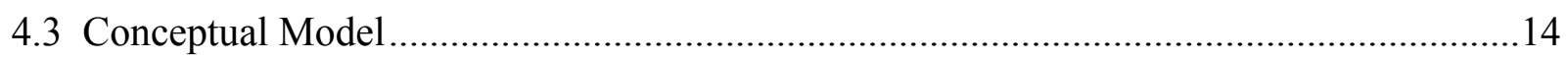

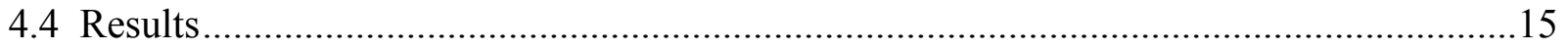

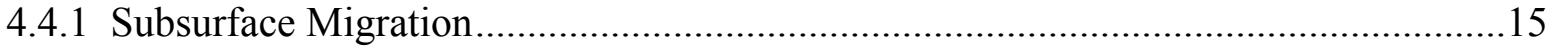

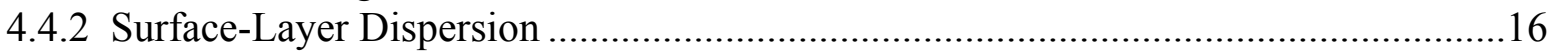

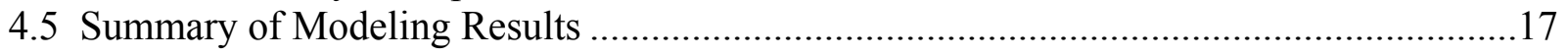

5. Background $\mathrm{CO}_{2}$ Fluxes and Concentrations .........................................................17

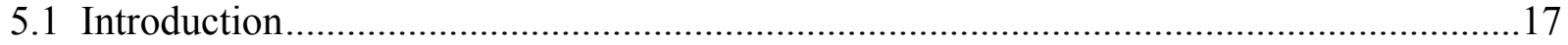

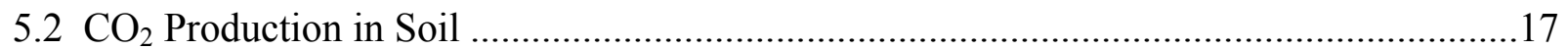

$5.3 \mathrm{CO}_{2}$ from Sub-Soil Sources ................................................................................... 18

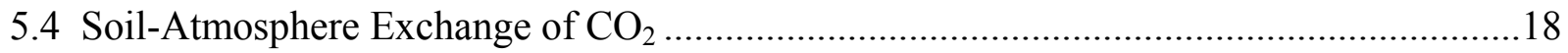

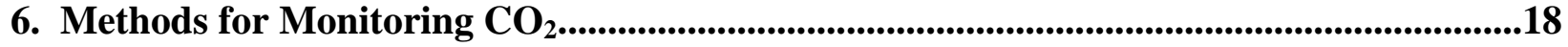

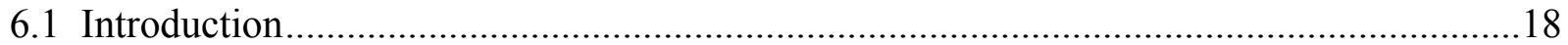

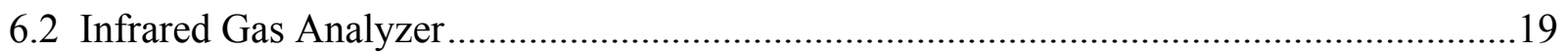

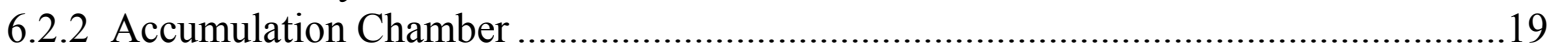

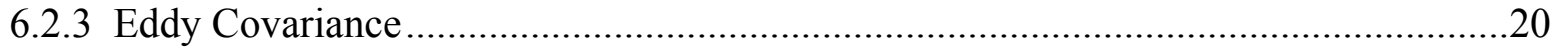

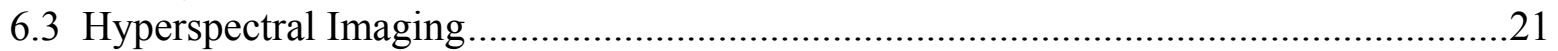

6.4 Light Detection and Ranging ..........................................................................22

6.5 Long Open Path IR and Tunable Lasers .............................................................23

6.6 Micro-Electronic Mechanical Systems, Smart Dust, Motes ......................................23

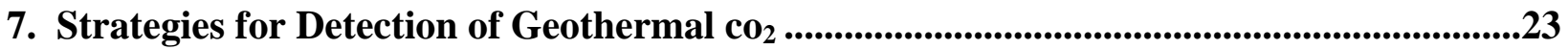

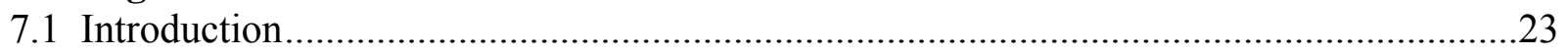

7.2 Sub-Surface Gas Geochemistry ...........................................................................24

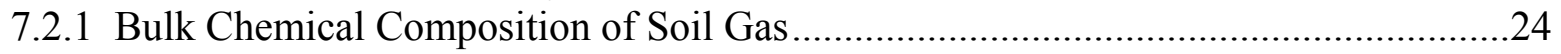

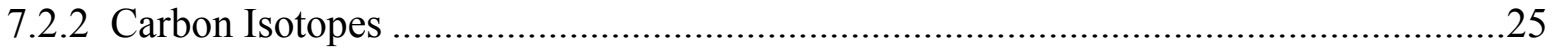

7.2.3 Measurement Strategies .................................................................................26

7.3 Surface and Atmospheric $\mathrm{CO}_{2}$ Concentrations and Fluxes .......................................27

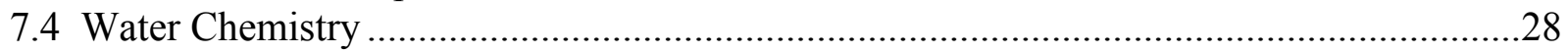

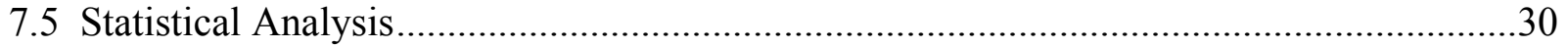

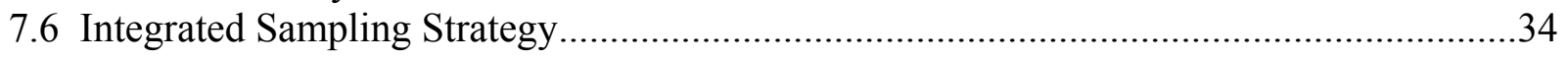




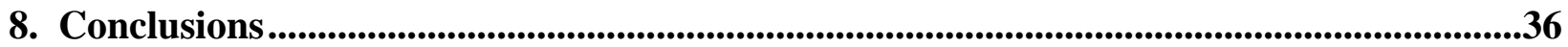

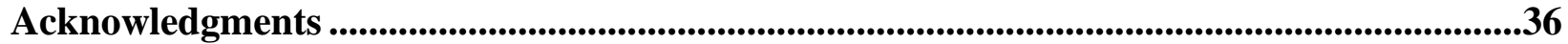

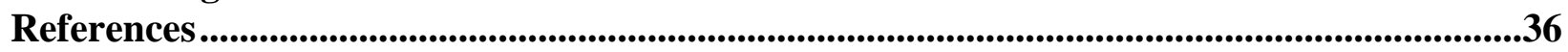

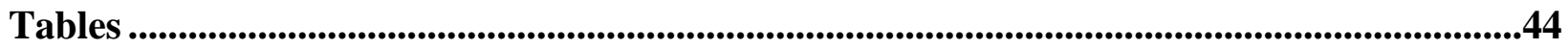

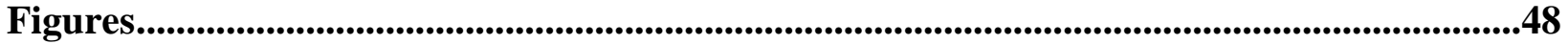




\section{LIST OF TABLES}

Table 4.1. Properties of the coupled subsurface-surface-layer model system. ……....................44

Table 7.1. Chemical and isotopic signatures related to $\mathrm{CO}_{2}$ derived from different sources........45

Table 7.2. Properties of different case scenarios used in Monte Carlo simulations. ......................46

Table 7.3. Mean $(\mu)$ and standard deviation $(\sigma)$ of number of measurements $(\mathrm{n})$........................47

\section{LIST OF FIGURES}

Figure 3.1. Density as a function of concentration (mole fraction) in the system $\mathrm{CO}_{2}$-air. .........48

Figure 3.2. Viscosity as a function of concentration (mole fraction) in the system $\mathrm{CO}_{2}$-air........49

Figure 3.3. Solubility of $\mathrm{CO}_{2}$ and $\mathrm{N}_{2}$ in water (mole fraction) in gas and aqueous phases..........50

Figure 4.1 Logarithmic velocity profile for atmospheric surface layer......................................51

Figure 4.2. Conceptual model for gas migration from a deep hidden geothermal system. ..........52

Figure 4.3. Grid and boundary conditions for the subsurface model system. .............................53

Figure 4.4. Five realizations (A-E) of permeability heterogeneity for the alluvial fan system. ..54

Figure 4.5. Initial liquid saturation for the five realizations (A-E) .........................................55

Figure 4.6. Subsurface $\mathrm{CO}_{2}$ concentrations (mole fraction) for the homogeneous permeability. 56

Figure 4.7. Subsurface $\mathrm{CO}_{2}$ concentrations (mole fraction) for permeability realization A ........57

Figure 4.8. Subsurface $\mathrm{CO}_{2}$ concentrations (mole fraction) for five permeability realizations ...58

Figure 4.9. Horizontal profiles of shallow $\mathrm{CO}_{2}$ concentration for homogeneous permeability ....59

Figure 4.10. Horizontal profiles of $\mathrm{CO}_{2}$ concentration for realizations A-E low flux ................60

Figure 4.11. Horizontal profiles of $\mathrm{CO}_{2}$ concentration for realizations A-E medium flux .........61

Figure 4.12. Horizontal profiles of $\mathrm{CO}_{2}$ concentration for realizations A-E high flux ................62

Figure 4.13. Initial liquid saturation and wind velocity for the coupled system ........................63

Figure 4.14. Coupled $\mathrm{CO}_{2}$ subsurface migration and surface-layer mixing for wind $3 \mathrm{~m} \mathrm{~s}^{-1}$.....64

Figure 4.15. Coupled $\mathrm{CO}_{2}$ subsurface migration and surface-layer mixing for wind $1 \mathrm{~m} \mathrm{~s}^{-1} \ldots \ldots 65$

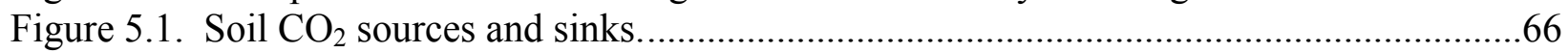

Figure 5.2. Repeated measurements of a soil $\mathrm{CO}_{2}$ concentration profile in central California....67

Figure 5.3. Profiles (A and $\mathrm{B}$ ) of $\mathrm{CO}_{2}$ concentration above the Ogallala aquifer system ............68

Figure 6.1. Schematic diagram of an accumulation chamber (AC) ...........................................69

Figure 6.2. Schematic diagram of an eddy correlation (EC) tower .............................................

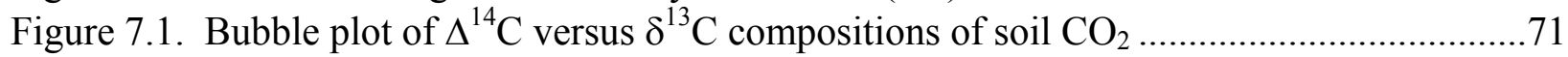

Figure 7.2. Probability density functions of background central California soil $\mathrm{CO}_{2}$ flux ...........72

Figure 7.3. Probability image plots for Cases 1 and 2 Monte Carlo simulations..........................73

Figure 7.4. Probability image plots for Cases 4 and 5 Monte Carlo simulations..........................74

Figure 7.5. Probability image plots for Cases 7 and 10 Monte Carlo simulations........................75

Figure 7.6. Probability image plots for Case 11 Monte Carlo simulation.....................................76 
This page left intentionally blank. 


\begin{abstract}
"Hidden" geothermal systems are those systems above which hydrothermal surface features (e.g., hot springs, fumaroles, elevated ground temperatures, hydrothermal alteration) are lacking. Emissions of moderate to low solubility gases (e.g., $\mathrm{CO}_{2}, \mathrm{CH}_{4}, \mathrm{He}$ ) may be one of the primary near-surface signals from these systems. Detection of anomalous gas emissions related to hidden geothermal systems may therefore be an important tool to discover new geothermal resources. This study investigates the potential for $\mathrm{CO}_{2}$ detection and monitoring in the subsurface and above ground in the near-surface environment to serve as a tool to discover hidden geothermal systems. We focus the investigation on $\mathrm{CO}_{2}$ due to (1) its abundance in geothermal systems, (2) its moderate solubility in water, and (3) the wide range of technologies available to monitor $\mathrm{CO}_{2}$ in the near-surface environment. However, monitoring in the near-surface environment for $\mathrm{CO}_{2}$ derived from hidden geothermal reservoirs is complicated by the large variation in $\mathrm{CO}_{2}$ fluxes and concentrations arising from natural biological and hydrologic processes.
\end{abstract}

In the near-surface environment, the flow and transport of $\mathrm{CO}_{2}$ at high concentrations will be controlled by its high density, low viscosity, and high solubility in water relative to air. Numerical simulations of $\mathrm{CO}_{2}$ migration show that $\mathrm{CO}_{2}$ concentrations can reach very high levels in the shallow subsurface even for relatively low geothermal source $\mathrm{CO}_{2}$ fluxes. However, once $\mathrm{CO}_{2}$ seeps out of the ground into the atmospheric surface layer, surface winds are effective at dispersing $\mathrm{CO}_{2}$ seepage.

In natural ecological systems in the absence of geothermal gas emissions, near-surface $\mathrm{CO}_{2}$ fluxes and concentrations are primarily controlled by $\mathrm{CO}_{2}$ uptake by photosynthesis, production by root respiration, and microbial decomposition of soil/subsoil organic matter, groundwater degassing, and exchange with the atmosphere. Available technologies for monitoring $\mathrm{CO}_{2}$ in the near-surface environment include (1) the infrared gas analyzer (IRGA) for measurement of concentrations at point locations, (2) the accumulation chamber (AC) method for measuring soil $\mathrm{CO}_{2}$ fluxes at point locations, (3) the eddy covariance (EC) method for measuring net $\mathrm{CO}_{2}$ flux over a given area, (4) hyperspectral imaging of vegetative stress resulting from elevated $\mathrm{CO}_{2}$ concentrations, and (5) light detection and ranging (LIDAR) that can measure $\mathrm{CO}_{2}$ concentrations over an integrated path. Technologies currently in developmental stages that have the potential to be used for $\mathrm{CO}_{2}$ monitoring include tunable lasers for long distance integrated concentration measurements and micro-electronic mechanical systems (MEMS) that can make widespread point measurements.

To address the challenge of detecting potentially small-magnitude geothermal $\mathrm{CO}_{2}$ emissions within the natural background variability of $\mathrm{CO}_{2}$, we propose an approach that integrates available detection and monitoring methodologies with statistical analysis and modeling strategies. Within the area targeted for geothermal exploration, point measurements of soil $\mathrm{CO}_{2}$ fluxes and concentrations using the $\mathrm{AC}$ method and a portable IRGA, respectively, and measurements of net surface flux using EC should be made. Also, the natural spatial and temporal variability of surface $\mathrm{CO}_{2}$ fluxes and subsurface $\mathrm{CO}_{2}$ concentrations should be quantified within a background area with similar geologic, climatic, and ecosystem 
characteristics to the area targeted for geothermal exploration. Statistical analyses of data collected from both areas should be used to guide sampling strategy, discern spatial patterns that may be indicative of geothermal $\mathrm{CO}_{2}$ emissions, and assess the presence (or absence) of geothermal $\mathrm{CO}_{2}$ within the natural background variability with a desired confidence level. Once measured $\mathrm{CO}_{2}$ concentrations and fluxes have been determined to be of anomalous geothermal origin with high confidence, more expensive vertical subsurface gas sampling and chemical and isotopic analyses can be undertaken. Integrated analysis of all measurements will determine definitively if $\mathrm{CO}_{2}$ derived from a deep geothermal source is present, and if so, the spatial extent of the anomaly. The appropriateness of further geophysical measurements, installation of deep wells, and geochemical analyses of deep fluids can then be decided based on the results of the near surface $\mathrm{CO}_{2}$ monitoring program. 


\section{INTRODUCTION}

Most commercial geothermal projects have been developed near previously known resources, for example, near hot springs or areas of historic use. Also, the majority of hydrothermal systems with obvious surface expressions in the U.S. have already been explored for geothermal development potential. Discovery of new geothermal systems will therefore require exploration of areas where the reservoirs are either hidden or lie at greater depths than presently known reservoirs. As a result, research must be geared toward the development of novel exploration techniques to locate these new geothermal resources.

Here, we define "hidden" geothermal systems as those systems above which hydrothermal surface features (e.g., hot springs, fumaroles, elevated ground temperatures, hydrothermal alteration) are lacking. Emissions of moderate to low solubility gases (e.g., $\mathrm{CO}_{2}, \mathrm{CH}_{4}, \mathrm{He}$ ) may be one of the primary near-surface signals from these systems. Detection of anomalous gas emissions related to hidden geothermal systems may therefore be an important tool to discover new resources (Klusman et al., 2000). We will focus our discussion specifically on the detection and monitoring of $\mathrm{CO}_{2}$ in the subsurface and above ground in the near-surface environment as a tool to discover hidden geothermal systems because (1) $\mathrm{CO}_{2}$ is the major non-condensable gas present in geothermal reservoirs (e.g., Ellis and Mahon, 1977), (2) due to its moderate solubility in water, $\mathrm{CO}_{2}$ from volcanic-hydrothermal sources tends to migrate to the near-surface in the gaseous phase in equal or greater proportion than dissolved in the aqueous phase in groundwater (e.g., Cruz et al., 1999; Favara et al., 2001; Evans et al., 2002), and (3) a broad range of technologies are available to monitor $\mathrm{CO}_{2}$ in the near-surface environment. Importantly, however, $\mathrm{CO}_{2}$ is produced in the near surface by a variety of biological processes, and monitoring of $\mathrm{CO}_{2}$ from hidden geothermal reservoirs will involve monitoring a system with large variation in $\mathrm{CO}_{2}$ fluxes and concentrations arising from natural biological and hydrologic processes. The detection of anomalous $\mathrm{CO}_{2}$ will therefore require searching for potential geothermal $\mathrm{CO}_{2}$ anomalies, likely of small magnitude, over areas of tens of $\mathrm{km}^{2}$ or more within the naturally varying background $\mathrm{CO}_{2}$ fluxes and concentrations.

The objective of this report is to discuss geothermal $\mathrm{CO}_{2}$ monitoring in the near surface as a tool to discover hidden geothermal reservoirs. To this end, we present (1) the physical properties of $\mathrm{CO}_{2}$ key to its transport in the near-surface environment, (2) model simulations of geothermal $\mathrm{CO}_{2}$ migration and seepage that highlight fundamental features of these processes, (3) a discussion of the processes that affect natural background $\mathrm{CO}_{2}$ fluxes and concentrations within which anomalous geothermal $\mathrm{CO}_{2}$ must be discerned, (4) technologies that are currently available or will be potentially available in the future to monitor $\mathrm{CO}_{2}$ migration and seepage in the near surface, and (5) potential strategies to detect geothermal $\mathrm{CO}_{2}$ seepage fluxes and concentrations within the naturally varying background fluxes and concentrations. 


\section{FLUXES AND CONCENTRATIONS OF $\mathrm{CO}_{2}$ IN KNOWN VOLCANIC AND HYDROTHERMAL SYSTEMS}

Over the past several decades, numerous diffuse $\mathrm{CO}_{2}$ degassing studies have been conducted in known (i.e., "visible") volcanic and hydrothermal environments, many of which focused on characterizing the magnitude and spatial distribution of $\mathrm{CO}_{2}$ emissions. While surface $\mathrm{CO}_{2}$ emission rates from hidden geothermal systems will likely be lower than those measured in known volcanic and hydrothermal systems, the preferential pathways for $\mathrm{CO}_{2}$ flow from depth to the near surface will likely be similar. As discussed below, the magnitudes and styles of diffuse $\mathrm{CO}_{2}$ emissions vary from site to site. Here, we briefly review the surface $\mathrm{CO}_{2}$ fluxes and soil $\mathrm{CO}_{2}$ concentrations measured in these systems. In most cases, the AC method (see section 6.2.2 below) was used to measure surface $\mathrm{CO}_{2}$ fluxes and the $\mathrm{CO}_{2}$ concentrations of soil gases were measured using a portable IRGA (see section 6.2 ) or by laboratory gas chromatography.

At Solfatara crater, Campi Flegrei caldera, Italy, surface $\mathrm{CO}_{2}$ fluxes up to $75,000 \mathrm{~g} \mathrm{~m}^{-2} \mathrm{~d}^{-1}$ were measured (e.g., Cardellini et al., 2003), with average flux estimated to be $1520 \mathrm{~g} \mathrm{~m}^{-2} \mathrm{~d}^{-1}$ (Chiodini et al., 2001). Elevated fluxes here were primarily focused along faults and fractures. At Vulcano Island, Italy, $\mathrm{CO}_{2}$ fluxes up to $12,000 \mathrm{~g} \mathrm{~m}^{-2} \mathrm{~d}^{-1}$ were measured (Cardellini et al., 2003). $\mathrm{CO}_{2}$ fluxes up to $22,000 \mathrm{~g} \mathrm{~m}^{-2} \mathrm{~d}^{-1}$ were measured at Poggio dell'Ulivo, an area of cold $\mathrm{CO}_{2}$ degassing in the Central Italian magmatic province (Cardellini et al., 2003). At the Central American volcanoes of Masaya (Nicaragua), Cerro Negro (Nicaragua), Poas (Costa Rica), and Arenal (Costa Rica), fluxes up to 50,000 (average =2750, Lewicki et al., 2003), 35,000 (Salazar et al., 2001), 140 (Williams-Jones et al., 2000), and $291 \mathrm{~g} \mathrm{~m}^{-2} \mathrm{~d}^{-1}$ (Williams-Jones et al., 2000), respectively, were measured. Elevated fluxes at these volcanoes were predominantly measured along eruptive fissures and faults. Koepenick et al. (1996) reported fluxes up to $1350 \mathrm{~g} \mathrm{~m}^{-2} \mathrm{~d}^{-1}$ (average $=166 \mathrm{~g} \mathrm{~m}^{-2} \mathrm{~d}^{-1}$ ) near fumaroles and fractures on Oldoinyo Lengai volcano, Tanzania, whereas Hernandez et al. (2001) reported fluxes up to $18,150 \mathrm{~g} \mathrm{~m}^{-2} \mathrm{~d}^{-1}$ at Miyakejima, Japan, mainly focused along flank fissures and on the main volcanic cone. At Mammoth Mountain, USA, average measured $\mathrm{CO}_{2}$ flux ranged from $1500-2100 \mathrm{~g} \mathrm{~m}^{-2} \mathrm{~d}^{-1}$, with maximum values of $>10,000 \mathrm{~g} \mathrm{~m}^{-2} \mathrm{~d}^{-1}$ (Gerlach et al., 2001). $\mathrm{CO}_{2}$ flow here was hypothesized to be controlled by faulting. At the Dixie Valley Geothermal Field, USA, $\mathrm{CO}_{2}$ fluxes up to $570 \mathrm{~g} \mathrm{~m}^{-2} \mathrm{~d}^{-1}$ were measured near faults and fumaroles (Bergfeld et al., 2001). Werner et al. (2000) reported $\mathrm{CO}_{2}$ fluxes up to $30,000 \mathrm{~g} \mathrm{~m}^{-2} \mathrm{~d}^{-1}$ in the Yellowstone volcanic system, with average fluxes of $89 \mathrm{~g} \mathrm{~m}^{-}$ ${ }^{2} \mathrm{~d}^{-1}$ in travertine depositing areas to $1200 \mathrm{~g} \mathrm{~m}^{-2} \mathrm{~d}^{-1}$ in acid-sulfate areas. Elevated fluxes here were mainly focussed along faults and fractures.

Soil $\mathrm{CO}_{2}$ concentrations measured in volcanic and hydrothermal environments have also varied widely, depending on the study area and proximity to geologic features (e.g., faults, eruptive fissures) influencing gas flow. At Poas volcano, concentrations up to 16 vol.\% were measured by Williams-Jones et al. (2000). At Arenal and Galeras (Colombia) volcanoes, Willams-Jones et al. (2000) reported concentrations up to 7.3 and 13 vol.\%, respectively. Soil $\mathrm{CO}_{2}$ concentrations up to 90 vol.\% were measured at Oldoinyo Lengai volcano (average $=14$ vol.\%, Koepenick et al., 1996), Mammoth Mountain (Sorey et al., 1998), and the Yellowstone volcanic system (Werner et al., 2000). Similar to surface $\mathrm{CO}_{2}$ fluxes, elevated soil $\mathrm{CO}_{2}$ concentrations were commonly associated with faults, fractures, eruptive fissures, and vents in these study areas. 


\section{PHYSICAL PROPERTIES OF $\mathrm{CO}_{2}$ IN THE NEAR SURFACE}

Pressures and temperatures in the shallow subsurface (e.g., within the vadose zone and close to the water table) are close to those in the atmosphere near the ground surface. Figure 3.1 shows the density of $\mathrm{CO}_{2}$-air mixtures as a function of concentration (mole fraction) at three different temperatures (Magee et al., 1994; NIST, 1992) where air is dry and composed of $79 \%$ nitrogen $\left(\mathrm{N}_{2}\right)$ and $21 \%$ oxygen $\left(\mathrm{O}_{2}\right)$ by volume. As shown in Figure 3.1, $\mathrm{CO}_{2}$ has greater density than dry air, and the gases mix approximately ideally at atmospheric pressure. Note that the density contrast between $\mathrm{CO}_{2}$ and air will be larger in the vadose zone than indicated in Figure 3.1 due to the presence of water vapor with lower density relative to dry air. Figure 3.2 shows that under the same pressure and temperature conditions, $\mathrm{CO}_{2}$ is less viscous than air (Magee et al., 1994; NIST, 1992).

Figure 3.3 shows the solubility of $\mathrm{CO}_{2}$ and $\mathrm{N}_{2}$ (where $\mathrm{N}_{2}$ is a proxy for air) in water as a function of gas composition (mole fraction) at three different temperatures (Spycher et al., 2003). In these model calculations, the partial pressure of $\mathrm{CO}_{2}$ is significantly in excess of atmospheric partial pressure. Thus, the $\mathrm{pH}$ of the solution is maintained below $\sim 6$ and $\mathrm{H}_{2} \mathrm{CO}_{3}$ is the dominant aqueous carbon species present. Carbon dioxide has greater solubility (approximately 50x) in water than does $\mathrm{N}_{2}$ (air). The solubility of $\mathrm{CO}_{2}$ decreases as temperature increases and as its partial pressure decreases. Carbon dioxide gas bubbles are usually formed when $\mathrm{CO}_{2}$-saturated ground water migrates upwards in the subsurface and pressure decreases.

The transport of $\mathrm{CO}_{2}$ in the shallow subsurface is also controlled by its molecular diffusivity, which is comparable to that of other components in air (e.g., $\mathrm{N}_{2}, \mathrm{O}_{2}, \mathrm{H}_{2} \mathrm{O}$ ) and is approximately $1.65 \times 10^{-5} \mathrm{~m}^{2} \mathrm{~s}^{-1}$ at $25{ }^{\circ} \mathrm{C}, 1$ bar (Vargaftik et al., 1996). Pressure and temperature have compensating effects on molecular diffusion, as described for solubility; diffusivity tends to decrease as pressure increases with depth and increase with increasing temperature.

In summary, $\mathrm{CO}_{2}$ is a dense and inviscid gas relative to air. Carbon dioxide will therefore tend to be mobile and sink due to buoyancy effects. However, because $\mathrm{CO}_{2}$ and other gases in the near surface are fully miscible, no significant density segregation is expected to occur in gas mixtures unless there is relative flow between the gas and liquid water. This flow may cause $\mathrm{CO}_{2}$ to preferentially dissolve in groundwater and leave behind a gas mixture enriched in the less soluble components. If groundwater pressure decreases and/or temperature increases, exsolution may occur, releasing $\mathrm{CO}_{2}$ back to the gas phase.

\section{SIMULATIONS OF $\mathrm{CO}_{2}$ MIGRATION}

\subsection{Introduction}

In this section we present numerical simulations of $\mathrm{CO}_{2}$ migration, seepage, and atmospheric dispersion. The purpose of these simulations is to evaluate the magnitudes and form of anomalous $\mathrm{CO}_{2}$ concentrations and fluxes that might be expected to emanate from a given model 
hidden geothermal system. From this information, we can design and evaluate potential monitoring and detection methods.

\subsection{Methods}

\subsubsection{Introduction}

We use the simulator T2CA (Oldenburg and Unger, 2004), a research module of TOUGH2 (Pruess et al., 1999). T2CA retains the fundamental porous media flow and transport capabilities of TOUGH2, and models five components (water, brine, $\mathrm{CO}_{2}$, a gas tracer, and air) under isothermal or non-isothermal conditions. The main advance in T2CA is the implementation of a simple atmospheric transport and dispersion capability for dilute gases based on variable-K theory (Arya, 1999). In variable-K theory, a constant time-averaged wind velocity profile is specified for advection, and atmospheric dispersion is modeled as a diffusion process with variable diffusivity as a function of height above the ground surface. In this way, T2CA models coupled subsurface and atmospheric surface layer gas flow and transport. Because the subsurface methods in TOUGH2 are well documented and described elsewhere (e.g., Pruess et al., 1999), we focus here on describing briefly the atmospheric dispersion methods, for which more detail can be found in Oldenburg and Unger (2004).

\subsubsection{Logarithmic Velocity Profile}

The ambient time-averaged wind profile near the ground surface follows a logarithmic profile (e.g., Slade, 1968, p. 73). The logarithmic wind profile is valid over approximately the lower one-tenth of the atmospheric boundary layer, or approximately a few tens of meters above the ground surface. The logarithmic wind profile as shown on Figure 4.1 is given as:

$$
u(z)=\frac{u_{*}}{k} \ln \left(\frac{z}{z_{0}}\right)
$$

where $u(z)$ is the ambient wind velocity as a function of height above the ground surface, $u *$ is the friction velocity (a parameter that governs the shape of the wind profile near the ground surface for various surface types), $k$ is von Karman's constant $(k=0.4), z$ is the elevation, and $z_{0}$ is a roughness height that is a function of various surface types and for which $u(z)=0$ for $z \leq z_{o}$ (Slade, 1968). The logarithmic wind profile is strictly applicable to neutral stability conditions.

\subsubsection{Advective-Dispersive Transport}

The mean turbulent transport of $\mathrm{CO}_{2}$ as a passive gas in the surface layer can be described by the advective-dispersive transport equation with variable eddy diffusivities $\left(K_{x}, K_{y}, K_{z}\right)$ (Arya, 1999, p. 137). For the three-dimensional $(x, y, z)$ transport of a component (e.g., $\left.\mathrm{CO}_{2}\right)$ at concentration $c$, this equation is

$$
\frac{\partial c}{\partial t}+u \frac{\partial c}{\partial x}+v \frac{\partial c}{\partial y}+w \frac{\partial c}{\partial z}-\frac{\partial}{\partial x}\left(K_{x} \frac{\partial c}{\partial x}\right)-\frac{\partial}{\partial y}\left(K_{y} \frac{\partial c}{\partial y}\right)-\frac{\partial}{\partial z}\left(K_{z} \frac{\partial c}{\partial z}\right)=0
$$


For convenience in surface-layer transport modeling, the coordinate system can be arranged so that $x$ is aligned in the downwind direction, making $v=w=0$ where $u$ is the ambient wind. We assume that the seeping gas concentration is low enough that it does not affect the velocity field, i.e., we make a dilute gas assumption.

\subsubsection{Dispersion Model}

For the special case of constant eddy diffusivities and a uniform wind velocity $(u)$ with no shear (i.e., no velocity gradient), and assuming that advection dominates diffusion in the $x$-direction, solutions to Eq. 4.2 are given by the well-known Gaussian plume dispersion model, with constant eddy diffusivities $D_{x x}, D_{y y}$, and $D_{z z}$ given by

$$
D_{x x}=\frac{\sigma_{x}^{2}}{2 t}, D_{y y}=\frac{\sigma_{y}^{2}}{2 t}, D_{z z}=\frac{\sigma_{z}^{2}}{2 t}
$$

where $\sigma_{x}, \sigma_{y}, \sigma_{z}$ are the standard deviations of concentration distributions at an observation or receptor point, and $t$ is the travel time to the point (e.g., Arya, 1999, p. 132).

Although attractive for its simplicity and widely used in pollutant transport applications, the Gaussian plume model is not valid for situations with wind shear (i.e., a non-zero gradient of $u$ with height), as appropriate for winds near the ground surface that affect $\mathrm{CO}_{2}$ seepage (Arya, 1999, p. 197-199). Theory and data point to the need for variable eddy diffusivities $\left(K_{x}, K_{y}, K_{z}\right)$, an approach called variable-K theory. The variable-K theory is recommended for cases with wind shear and non-homogeneous turbulence such as will be found in the surface layer (Arya, 1999, p. 143). For our surface-layer applications involving $\mathrm{CO}_{2}$ seepage, we have used variable K-theory and the assumption that $K_{z}$ increases linearly with height as

$$
K_{Z}=k u * Z
$$

(Arya, 1999, p. 143). This model assumes neutral stability in the surface layer, allows for a variable wind speed with height, and models the larger dispersion that occurs as the plume moves upward. Because there is no analogous formulation of $K_{y}$ (transverse dispersion) valid for short travel distances $(<10 \mathrm{~km}$ ) in variable-K theory (Arya, 1999, p. 151), we adopt here a 2-D configuration for our test problem that models only vertical dispersion and downwind advection. Because $\mathrm{CO}_{2}$ dispersion will occur only in the vertical direction, this represents a conservative model in that actual $\mathrm{CO}_{2}$ concentrations downwind will be lower for emissions from any realistic areal source for which lateral dispersion occurs. The neglect of lateral dispersion is not an inherent limitation of T2CA, which is in fact three-dimensional, and can include lateral dispersion assuming a reasonable parameterization is available.

In summary, T2CA uses a logarithmic velocity profile and variable- $\mathrm{K}$ theory to model multicomponent gaseous $\left(\mathrm{CO}_{2}\right.$, gas tracer, and air) transport in a 2-D surface layer that is directly coupled with a porous medium subsurface region. In this approach, we calculate eddy diffusivities from the variable-K diffusivity of Eq. 4.4 to produce an effective atmospheric dispersivity at every gridblock in the surface layer, a convenient approach in the discretized framework of T2CA. Although it is normally negligible in the surface layer, the molecular diffusion coefficient is added to the eddy diffusivity with the largest term controlling the 
dispersion process. The single effective dispersivity is then used in the advective-dispersive transport equation for each chemical component to model surface-layer transport.

\subsubsection{Limitations}

In general, $\mathrm{CO}_{2}$ dispersion can occur either as a dense or a passive gas, depending on the local $\mathrm{CO}_{2}$ concentration. Our approach is applicable only to passive gas transport in the surface layer (Oldenburg and Unger, 2004). Therefore, this approach is applicable only to cases of small $\mathrm{CO}_{2}$ seepage flux in which the ambient winds are not affected by $\mathrm{CO}_{2}$ seepage. This assumption is easily met for windy conditions and for the small seepage fluxes expected from hidden geothermal systems.

Time-averaged winds are assumed in the logarithmic velocity profile, and no account is made of daily changes in winds, temperature, or weather. We assume the time scale of interest is on the order of 1 mo. to 10 years, time scales over which averaging is defensible. Length scales for mixing are on the order of $10 \mathrm{~m}$ to $1 \mathrm{~km}$.

Numerical dispersion in the implicit and upstream-weighted TOUGH2 framework is on the order of one-half the grid spacing multiplied by the velocity. Because of the alignment of the grid with the unidirectional wind, numerical dispersion occurs only in the flow direction (i.e., $x$-direction) in the surface layer. In the quasi-steady cases we are considering, advection dominates transport in the flow direction. In the vertical direction, the velocity is zero $(w=0)$. Thus, vertical eddy diffusion is unaffected by numerical dispersion. If $\mathrm{CO}_{2}$ front tracking in the surface layer ever arises as a focus of interest, special weighting schemes can be implemented to diminish numerical dispersion in the flow direction (e.g., Oldenburg and Pruess, 2000).

\subsection{Conceptual Model}

The geologic framework of the model hidden geothermal system we consider is based loosely on an arid basin and range system like the Dixie Valley geothermal system (e.g., Benoit, 1999; McKenna and Blackwell, 2004), only without any surface manifestations. In particular, we consider a model in which a growing alluvial fan covers a geothermal anomaly created by deep range-bounding faults so that it is essentially invisible at the surface. Within this system, we model the migration of $\mathrm{CO}_{2}$ upward from a small $\left(15 \mathrm{~m}^{2}\right)$ region that represents the top of a conductive fault, located near the water table. The $\mathrm{CO}_{2}$ spreads in the heterogeneous system as it migrates upward until it seeps out at the ground surface. A conceptual model of the system is shown in Figure 4.2, along with the outline (dashed) of the model domain. We present results from the start of $\mathrm{CO}_{2}$ migration up to 200 years, at which point the gas seepage flux and concentrations are nearly steady. The grid and boundary conditions for the subsurface region are shown in Figure 4.3. The grid consists of $6715-\mathrm{m}$ gridblocks in the $x$-direction, and $314-\mathrm{m}$ gridblocks in the $z$-direction, with the grid tilted at six degrees. We do not consider the effects of infiltration of meteoric water to simplify models and focus attention on arid basin and range-type environments. Additional properties of the system are presented in Table 4.1.

We consider both a homogeneous permeability case, along with five realizations of heterogeneous permeability. The heterogeneous permeability cases are significant because gas migration will tend to follow high-permeability pathways. We present in Figure 4.4 five realizations (referred to as realizations A-E) of a heterogeneous permeability field generated 
using simulated annealing to represent an alluvial fan deposit (note the vertical exaggeration). The permeability is characterized by a mean value of $10^{-12} \mathrm{~m}^{2}$, and varies by four orders of magnitude. There is a $45-\mathrm{m}$ correlation length in the $Y$-direction (sub-horizontal), and no correlation in the vertical direction, thereby creating a layered structure intended to represent an alluvial fan.

\subsection{Results}

\subsubsection{Subsurface Migration}

We simulated the subsurface migration of $\mathrm{CO}_{2}$ from a $15 \mathrm{~m}^{2}$ source area near the water table at three different source strength rates $\left(\mathrm{q}_{\mathrm{CO} 2}=1 \times 10^{-6}, 1 \times 10^{-5}\right.$ and $1 \times 10^{-4} \mathrm{~kg} \mathrm{~s}^{-1}$, Table 4.1). These rates are equivalent to source $\mathrm{CO}_{2}$ fluxes of 5.76, 57.6 and $576 \mathrm{~g} \mathrm{~m}^{-2} \mathrm{~d}^{-1}$, respectively, when normalized by the source emission area. These $\mathrm{CO}_{2}$ fluxes were arbitrarily chosen to produce small $\mathrm{CO}_{2}$ seepage fluxes, and are significantly lower (i.e., up to four orders of magnitude) than surface $\mathrm{CO}_{2}$ fluxes measured in known/visible volcanic and hydrothermal systems. While we do not know the range of source $\mathrm{CO}_{2}$ fluxes that will be expected from a hidden geothermal system, we chose to model this low range of values to test the capability limits of available technologies for near-surface $\mathrm{CO}_{2}$ detection. For reference, the largest source $\mathrm{CO}_{2}$ flux we consider is similar to the highest surface $\mathrm{CO}_{2}$ fluxes measured at the Dixie Valley Geothermal Field, Nevada (Bergfeld et al., 2001). First, to illustrate the two-dimensional flow behavior of $\mathrm{CO}_{2}$ in the subsurface, we present the results for high source $\mathrm{CO}_{2}$ flux $\left(576 \mathrm{~g} \mathrm{~m}^{-2} \mathrm{~d}^{-1}\right)$ and heterogeneous subsurface permeability (realizations A-E). To illustrate the expected near-surface $\mathrm{CO}_{2}$ signals for the purpose of detection analysis (see Sections 6 and 7), we then present one-dimensional horizontal profiles of shallow subsurface $\mathrm{CO}_{2}$ concentrations and surface $\mathrm{CO}_{2}$ fluxes associated with the three source strengths for (1) homogeneous subsurface permeability and (2) heterogeneous permeability (realizations A-E). To facilitate comparison of $\mathrm{CO}_{2}$ concentration results, $1 \mathrm{vol} \%=10^{-2}$ mole fraction $=10^{4} \mathrm{ppmv}$. The initial condition for the simulations is a static unsaturated-saturated system as shown in Figure 4.5 by the liquid saturation fields.

The $\mathrm{CO}_{2}$ plume after $0.5,1$, and 10 years of migration for the homogeneous permeability case is presented in Figure 4.6. As shown, $\mathrm{CO}_{2}$ migrates upward and outward from the source and reaches the ground surface in approximately one year. Results for heterogeneous systems (heterogeneity realization A) are presented in Figure 4.7. As shown, there is a slight preferential migration in the sub-horizontal direction reflecting the permeability structure of the alluvial fan. However, the plume seeps out of the ground after only slightly more than one year. As observed in prior work (Oldenburg and Unger, 2003), at late times (after 10 years) the $\mathrm{CO}_{2}$ concentration in the shallow subsurface can become very high even though the $\mathrm{CO}_{2}$ flux is quite small. $\mathrm{CO}_{2}$ plumes after 200 years of migration for permeability realizations A-E are shown in Figure 4.8. At 200 years, the $\mathrm{CO}_{2}$ plumes for the different permeability fields are similar in general shape and $\mathrm{CO}_{2}$ concentration distribution.

Figure 4.9 shows the horizontal profiles of $\mathrm{CO}_{2}$ concentration at $3 \mathrm{~m}$ depth and surface $\mathrm{CO}_{2}$ flux associated with a subsurface with homogeneous isotropic permeability and low, medium, and high source $\mathrm{CO}_{2}$ source fluxes $(t=200$ years). These profiles all show a similar smooth increase and then decrease in concentration and flux crossing the $\mathrm{CO}_{2}$ plume. Maximum $\mathrm{CO}_{2}$ 
concentrations for the low, medium, and high source strengths are about $2 \times 10^{4}, 1 \times 10^{5}$ and $6 \mathrm{x}$ $10^{5}$ ppmv, respectively, whereas maximum surface $\mathrm{CO}_{2}$ fluxes are about $2 \times 10^{-4}, 0.2$, and $40 \mathrm{~g}$ $\mathrm{m}^{-2} \mathrm{~d}^{-1}$, respectively. These profiles also show that the width of the $\mathrm{CO}_{2}$ plume increases with increasing source strength. If the source area of $\mathrm{CO}_{2}$ emission were increased (i.e., to simulate more diffuse, rather than focused $\mathrm{CO}_{2}$ flow), the magnitude of the near-surface $\mathrm{CO}_{2}$ concentration and flux signals would decrease, while the width of the anomaly would increase.

Profiles of $\mathrm{CO}_{2}$ concentration at $3 \mathrm{~m}$ depth and surface $\mathrm{CO}_{2}$ flux associated with a subsurface with heterogeneous permeability (realizations A-E) and low $\mathrm{CO}_{2}$ source flux $(t=200$ years) are shown on Figure 4.10. Figures 4.11 and 4.12 present results for medium and high $\mathrm{CO}_{2}$ source strengths, respectively. At low source flux, $\mathrm{CO}_{2}$ concentration profiles associated with the heterogeneous permeability realizations are broadly similar to those associated with homogeneous permeability. In other words, both heterogeneous and homogeneous permeability profiles display a similar relatively smooth increase then decrease in concentration across the plume maximum concentrations (although these concentrations vary somewhat between realizations A-E) and similar width of the $\mathrm{CO}_{2}$ anomaly. For profiles corresponding to the low source flux and both homogeneous and heterogeneous permeabilities, the $\mathrm{CO}_{2}$ concentrations at $3 \mathrm{~m}$ depth fall within the range of natural background $\mathrm{CO}_{2}$ concentrations arising from biological processes (see Section 7.2.1). At medium and high source fluxes, the concentration profiles for heterogeneous permeability realizations A-E diverge from profiles associated with homogeneous permeability, showing greater spatial variability of concentrations. These changes are likely due to an increasing contribution of advective transport of $\mathrm{CO}_{2}$ through relatively high permeability pathways at elevated source fluxes. For all source $\mathrm{CO}_{2}$ fluxes, profiles of surface $\mathrm{CO}_{2}$ fluxes associated with heterogeneous permeability differ from those associated with homogeneous permeability at the same source strengths. Relative to the homogeneous permeability cases, fluxes along the heterogeneous profiles are more spatially variable and maximum observed fluxes may be greater or less, depending on the presence of high or low permeability pathways, respectively.

\subsubsection{Surface-Layer Dispersion}

In this section, we present results of the coupled subsurface-surface layer system to investigate above-ground $\mathrm{CO}_{2}$ concentrations for the model system. The methods in T2CA assume a horizontal ground surface, above which a constant logarithmic wind profile exists. To accommodate this assumption, we simulated a horizontal system rather than the tilted system used for the subsurface simulations discussed in the Section 4.4.1. Otherwise, we used the same permeability structure (realization A), water table depth at source location, and source strength $\left(q_{\mathrm{CO} 2}=1 . \times 10^{-4} \mathrm{~kg} \mathrm{~s}^{-1}\right)$. Figure 4.13 shows the initial liquid saturation field in the subsurface and the surface-layer winds for the $3 \mathrm{~m} \mathrm{~s}^{-1}$ case.

Shown in Figures 4.14 and 4.15 are results after 1, 10, and 200 years for the high $\mathrm{CO}_{2}$ source strength of $1 \times 10^{-4} \mathrm{~kg} \mathrm{~s}^{-1}$ and ambient winds of $3 \mathrm{~m} \mathrm{~s}^{-1}$ and $1 \mathrm{~m} \mathrm{~s}^{-1}$. As shown, dilution in the atmospheric surface layer is very strong. Surface layer $\mathrm{CO}_{2}$ concentrations due to seepage are of order $10^{-8}$ or smaller by mole fraction. This strong dilution occurs because the $\mathrm{CO}_{2}$ mixes with ambient air very effectively by turbulence as modeled by variable-K theory.

As an aside, we note that relative to Figure 4.8a (permeability realization A, high source $\mathrm{CO}_{2}$ flux, and 200-year simulation, tilted system), Figure 4.14c shows a greater extent of lateral 
subsurface $\mathrm{CO}_{2}$ flow. This difference can be attributed to the effects of the down-dip decreases in (1) vertical path length for $\mathrm{CO}_{2}$ flow, and (2) size of the unsaturated zone (Figure 4.8a). In addition, the horizontal system of Figure $4.14 \mathrm{c}$ allows upward $\mathrm{CO}_{2}$ flow only along vertical connections in the numerical grid, whereas the dipping system allows a vertical component of flow along both coordinate-axis directions.

\subsection{Summary of Modeling Results}

$\mathrm{CO}_{2}$ migrates upward with little lateral diversion, even in a tilted heterogeneous permeability system. The travel time from approximately $100 \mathrm{~m}$ depth to the ground surface is approximately one year. The gas in the $\mathrm{CO}_{2}$ plume is essentially pure $\mathrm{CO}_{2}$ in the subsurface, even though the $\mathrm{CO}_{2}$ flux is quite small. Surface-layer winds are capable of diluting $\mathrm{CO}_{2}$ concentrations to very small values above the ground surface. These results have neglected lateral dispersion (transverse to wind velocity direction) and therefore somewhat overpredict actual surface-layer $\mathrm{CO}_{2}$ concentrations. The high $\mathrm{CO}_{2}$ concentrations observed in simulations at the ground surface and in the subsurface, relative to the atmospheric surface layer suggest that monitoring of $\mathrm{CO}_{2}$ in the subsurface or at the ground surface may have greater potential to detect anomalous $\mathrm{CO}_{2}$ of geothermal origin than above-ground techniques.

\section{BACKGROUND $\mathrm{CO}_{2}$ FLUXES AND CONCENTRATIONS}

\subsection{Introduction}

We define "background" $\mathrm{CO}_{2}$ as $\mathrm{CO}_{2}$ derived mainly from the atmosphere and biologically mediated oxidation of organic carbon (respiration). We will not discuss $\mathrm{CO}_{2}$ derived from leaking natural fossil hydrocarbon reservoirs here. Background soil $\mathrm{CO}_{2}$ fluxes and concentrations are primarily dependent on three factors: (1) $\mathrm{CO}_{2}$ production in the soil by biological processes, (2) flow of $\mathrm{CO}_{2}$ from sub-soil sources into the soil column, and (3) exchange of $\mathrm{CO}_{2}$ with the atmosphere by concentration and pressure-driven transport processes. Background soil $\mathrm{CO}_{2}$ sources and exchanges are shown schematically in Figure 5.1 and are discussed in detail below.

\section{2 $\mathrm{CO}_{2}$ Production in Soil}

Production of $\mathrm{CO}_{2}$ in soils occurs primarily by root respiration and decay of organic matter (aerobic microbial respiration). The rate of root respiration is strongly dependent on the vitality of the plant (e.g., Mogensen, 1977). While litter and root exudates provide the source of carbon for decay processes, the decay rate and associated $\mathrm{CO}_{2}$ production are largely dependent on soil temperature and moisture, substrate quality and availability, soil aeration, and pH (e.g., Wiant, 1967a; Wiant 1967b; Edwards, 1975; Singh and Gupta, 1977; Amundson et al., 1989; Wood et al., 1993). Both diurnal and seasonal temperature changes have been shown to strongly influence the rate of $\mathrm{CO}_{2}$ production by root and microbial respiration processes, and related concentrations and fluxes; production in the soil generally increases with temperature (e.g., Parada et al., 1983; Amundson and Smith, 1988; Osozawa and Hasegawa, 1995). Soil water 
content also strongly controls soil $\mathrm{CO}_{2}$ production rate and it has been observed that between the permanent wilting point and 60-80\% saturation, increasing water content increases the rates of soil $\mathrm{CO}_{2}$ production (Alexander, 1977), whereas at higher or lower moisture contents, production rates can decrease (Kucera and Kirkham, 1971). Figure 5.2 shows repeated measurements of soil $\mathrm{CO}_{2}$ concentration as a function of depth (hereafter referred to as $\mathrm{CO}_{2}$ concentration profiles) at one site in central California. This time series of profiles demonstrates how soil $\mathrm{CO}_{2}$ production and related concentrations can vary over time due to changes in soil temperature and water content (Lewicki et al., 2003a).

\section{$5.3 \mathrm{CO}_{2}$ from Sub-Soil Sources}

Carbon dioxide may also enter soils from sources below at depth. Increasing $\mathrm{CO}_{2}$ concentrations with depth down to the water table have been observed in a number of studies, indicating $\mathrm{CO}_{2}$ production in the sub-soil (e.g., Wood and Petraitis, 1984; Keller, 1991; Keller and Bacon, 1998). This sub-soil production of $\mathrm{CO}_{2}$ can occur by groundwater degassing of $\mathrm{CO}_{2}$ that was originally derived from soil respiration or atmospheric sources and then dissolved in infiltration moving through the vadose zone. In addition, particulate organic carbon can be transported to depth by recharging groundwater and can be oxidized to $\mathrm{CO}_{2}$ by microbes under aerobic conditions (e.g., Wood and Petraitis, 1984). Furthermore, if soil parent material contains ancient organic carbon and is exposed to aerobic conditions in the vadose zone, oxidation of this carbon will produce $\mathrm{CO}_{2}$ (e.g., Keller and Bacon, 1998). $\mathrm{CO}_{2}$ concentration profiles resulting from any of these processes will show increasing concentration with depth below the soil (e.g., Figure 5.3) and the $\mathrm{CO}_{2}$ may then be transported upwards into the soil column.

\subsection{Soil-Atmosphere Exchange of $\mathrm{CO}_{2}$}

Two main gas transport processes control exchange of soil $\mathrm{CO}_{2}$ with the atmosphere, namely concentration-gradient-driven flow (diffusion) and total pressure-gradient-driven flow (advection). Diffusive flow is driven by the rate of gas production and the temperature, water content, porosity, and tortuosity of the soil. Advective transport can be driven by (1) atmospheric pressure effects whereby changes in atmospheric pressure can cause "pumping" of gas into and out of the soil (e.g., Massmann and Farrier, 1992), (2) temperature effects whereby changes in temperature may cause expansion or contraction of soil gas (e.g., Hinkle, 1994), (3) wind effects whereby changes in wind speed may promote gas flow through the soil (e.g., Reimer, 1980; Schery et al., 1984; Lewicki et al., 2003a), and (4) rainfall. Flow of rainwater through the soil can displace gas and "flush" $\mathrm{CO}_{2}$ from the soil, leading to a temporary increase in soil $\mathrm{CO}_{2}$ flux. Alternatively, precipitation may have a "capping" effect, slowing transport of $\mathrm{CO}_{2}$ to the atmosphere and leading to rise of soil $\mathrm{CO}_{2}$ concentrations (e.g., Hinkle, 1994).

\section{METHODS FOR MONITORING $\mathrm{CO}_{2}$}

\subsection{Introduction}

A broad range of technologies is available to measure near-surface $\mathrm{CO}_{2}$ concentrations and fluxes and determine the source of this $\mathrm{CO}_{2}$ with the goal of detecting anomalous $\mathrm{CO}_{2}$ of 
geothermal origin. However, these techniques differ from one another in terms of the spatial and temporal scales of the measurement, measurement sensitivity and error, and cost. Overviews of $\mathrm{CO}_{2}$ detection technologies can also be found in Shuler and Tang (2002) and Oldenburg et al. (2003).

\subsection{Infrared Gas Analyzer}

The infrared gas analyzer (IRGA) is an instrument commonly used to measure $\mathrm{CO}_{2}$ concentration in subsurface or atmospheric air. The measurement is based on $\mathrm{CO}_{2}$ absorption of infrared radiation within a gas sample cell. Portable IRGAs are available for use in the field and require only one person to operate. These IRGAs can be used to make single measurements or continuous measurements over time. Also, small IRGAs are available for installation in the subsurface or above ground and can be used for continuous monitoring of $\mathrm{CO}_{2}$ concentration at fixed locations over time. Portable instrument set up and calibration usually require less than one hour and a single measurement can be made in seconds. The IRGA measurement range is variable; depending on the model and calibration, IRGAs are available to measure $\mathrm{CO}_{2}$ concentration over a low range (e.g., 0-1000 ppmv $\mathrm{CO}_{2}$ ) or over a high range (e.g., 0-100 vol\% $\mathrm{CO}_{2}$ ). The precision and accuracy of IRGAs can be as good as $\pm 0.2 \mathrm{ppmv}$ at $350 \mathrm{ppmv}$ (near atmospheric concentration) and $\pm 1 \%$, respectively. The cost of equipment can be as low as about $\$ 500$, but typically ranges from $\$ 5,000$ to $\$ 30,000$.

IRGAs are reliable instruments, reasonably priced, straightforward to use, and portable. As a result, IRGAs have been applied to a wide range of studies including occupational health and safety, ecosystem, volcanic/geothermal, micrometeorological, agricultural, and human physiology research. Although IRGAs make measurements of $\mathrm{CO}_{2}$ concentrations at point locations, they can be coupled with additional instrumentation to measure surface $\mathrm{CO}_{2}$ fluxes from small to large areas (see Accumulation Chamber and Eddy Covariance sections below). Additional information regarding commercially available IRGAs and their applications in research can be found in: Li-COR (2003); Oskarsson et al. (1999); Shuler and Tang (2002); Sorey et al. (1996); and USGS (2000a, 2000b).

\subsubsection{Accumulation Chamber}

The accumulation chamber (AC) method is used to measure soil $\mathrm{CO}_{2}$ flux using an $\mathrm{AC}$ and an IRGA (Figure 6.1). Using this technique, an AC with an open bottom ( $\mathrm{cm}^{2}$ scale) is placed either directly on the soil surface or on a collar installed on the ground surface, the contained air is circulated through the $\mathrm{AC}$ and an IRGA, and the rate of change of $\mathrm{CO}_{2}$ concentration in the chamber $\left(d\left[\mathrm{CO}_{2}\right] / d t\right)$ is measured by the IRGA and recorded. The flux of $\mathrm{CO}_{2}(\mathrm{~F})$ is then calculated according to

$$
F=\left(\frac{\rho V}{A}\right)\left(\frac{d\left[C O_{2}\right]}{d t}\right)
$$

where $\rho$ is the molar density of air, $V$ is the volume of the measurement system, and $A$ is the area of the AC footprint. The accuracy and precision of the $\mathrm{AC}$ method have been estimated to be - 
$12.5 \%$ (Evans et al., 2002) and $\pm 10 \%$ (Chiodini et al., 1998), respectively. Each AC measurement typically is made within several minutes and one person is required to operate the instrumentation. The AC method has been applied in volcanic and geothermal studies where relatively high magnitude fluxes (up to $5 \times 10^{4} \mathrm{~g} \mathrm{~m}^{-2} \mathrm{~d}^{-1}$ ) are present (e.g., Farrar et al., 1995; Chiodini et al., 2001; Salazar et al., 2001; Lewicki et al., 2003b), as well as in ecological studies (e.g., Rolston, 1986; Mosier, 1989; Norman et al., 1992, Gouldin et al., 1996) where relatively small magnitude $\mathrm{CO}_{2}$ fluxes on the order of $40 \mathrm{~g} \mathrm{~m}^{-2} \mathrm{~d}^{-1}$ are typical.

Because the $\mathrm{AC} \mathrm{CO}_{2}$ flux measurement is regarded as a point measurement, many measurements are required to characterize the spatial variability of fluxes and to delineate spatial trends within a study area. To estimate the total $\mathrm{CO}_{2}$ emissions from an area of interest, flux measurements are made at evenly spaced intervals along grids and the mean flux is multiplied by the surveyed area, or fluxes are measured at uneven spacing within the area, geostatistical methods are used to interpolate a flux grid, and volume and area integration algorithms are applied to this grid. It can be difficult with the $\mathrm{AC}$ method to evaluate the temporal variability of soil $\mathrm{CO}_{2}$ fluxes that is typical for an area of interest and the influence of atmospheric parameters (temperature, pressure, wind, precipitation) on this variability. To characterize this temporal variability, researchers commonly install automated $\mathrm{CO}_{2}$ flux measurement stations where single or multiple chambers measure flux repeatedly over time at point locations (e.g., Gouldin and Crill, 1997; Rogie et al., 2001; Lewicki et al., 2003a; Edwards and Riggs, 2003). The cost of the portable AC instrumentation typically ranges from $\$ 15,000$ to $\$ 25,000$.

\subsubsection{Eddy Covariance}

Eddy covariance (EC), or eddy correlation, is a technique whereby high frequency measurements of atmospheric $\mathrm{CO}_{2}$ concentrations at a height $(\mathrm{z})$ above the ground are made by an IRGA (Figure 6.2), along with measurements of micrometeorological variables such as wind velocity, relative humidity, and temperature. Integration of these measurements provides a gross conservation of energy and mass over an area of land (the $\mathrm{EC}$ footprint) from which the net $\mathrm{CO}_{2}$ flux is derived. The equations and algorithms used to estimate the $\mathrm{EC} \mathrm{CO}_{2}$ flux are under constant development; however, the method essentially involves time-averaging the product of the time series of fluctuating $\mathrm{CO}_{2}$ concentration $(c(x, y, z, t))$, and the time series of fluctuating vertical wind velocity $(w(x, y, z, t))$. Under steady-state conditions and for sufficiently long averaging time (typically 30 minutes to several hours), this converges to the ensemble mean flux, the average of the product of $w$ and $c$. The measured vertical $\mathrm{CO}_{2}$ flux is an integral of the surface flux over the upwind footprint. The size of this footprint (typically $\mathrm{m}^{2}$ to $\mathrm{km}^{2}$ ) scales with the measurement height and is also dependent on meteorological conditions during the time of measurement.

One advantage of EC is that it provides a spatially and temporally averaged measurement and therefore inherently filters out small-scale spatial and temporal variability in the surface flux, potentially providing a more representative measurement of the surface flux. Spatial and temporal averaging over large land areas also allows for more efficient measurement strategies. One limitation of the EC measurement is that it assumes a horizontal and homogeneous surface. Violations of this assumption include varying density of plant cover, land use, and topography and can introduce significant error into the measurement. In general, measurements should be 
made over terrain with less than 8 to 15\% slope (Baldocchi et al., 1988). Also, if surface heterogeneity occurs on a small scale and is randomly distributed or can be organized into regions of uniform surface conditions within which the EC measurement is made, measurement error can be reduced (e.g., Lenschow, 1995). Furthermore, the EC measurement should be made under statistically steady meteorologic conditions; morning and evening periods, as well as times of changing weather conditions should be avoided. Due to the significant error that can be introduced into the EC measurement from meteorological and terrain conditions at the study site, EC typically cannot provide temporally and spatially continuous measurements. Rather, gaps in time and space must be tolerated. Also, it is generally not possible to delineate spatial trends in surface $\mathrm{CO}_{2}$ flux within the EC measurement footprint. A method such as $\mathrm{AC}$ must be used to accomplish this.

Typical ecological $\mathrm{CO}_{2}$ fluxes in nature are $38 \mathrm{~g} \mathrm{~m}^{-2} \mathrm{~d}^{-1}$ efflux and $112 \mathrm{~g} \mathrm{~m}^{-2} \mathrm{~d}^{-1}$ uptake. The absolute range and minimum resolvable flux for EC have not been documented in the literature. Under favorable meteorologic and terrain conditions, the resolution of the EC method can be as good as $0.4 \mathrm{~g} \mathrm{~m}^{-2} \mathrm{~d}^{-1}$. Estimates of the precision of EC vary from \pm 5 to $30 \%$. Short-term error has been estimated to be $\pm 7 \%$ during the daytime and $\pm 12 \%$ during the nighttime; long-term error is on the order of $\pm 5 \%$. The capital cost for EC equipment typically ranges from $\$ 15,000$ to $\$ 40,000$, depending on tower size and meteorological instrumentation. The operating costs are primarily the power supply, labor, and time for a survey. EC has mainly been applied in meteorological, ecological, and terrestrial carbon cycle investigations, but has also been tested in volcanic environments. For detailed information on the theory of EC and its applications, readers are referred to Anderson and Farrar (2001), Baldocchi et al. (2001), Baldocchi and Wilson (2001), Foken and Wichura (1996), Gouldin et al. (1996), Li-Cor (2003), Massman and Lee (2002), and the USGS (2000a, b).

\subsection{Hyperspectral Imaging}

Hyperspectral imaging refers to the imaging of a region of interest over a large number of discrete, contiguous spectral bands, typically in the visible and near-IR. A complete reflectance spectrum is then derived for each pixel in the hyperspectral image. The reflectance spectra of most materials on the Earth's surface contain characteristic or diagnostic absorption features; these absorption features can therefore provide a means to identify surface materials. Hyperspectral data have been used in a wide range of studies, including mineral and geothermal exploration, vegetation mapping, hazardous material remediation, ecosystem monitoring, and agricultural problems. One important application of hyperspectral imaging to monitoring for $\mathrm{CO}_{2}$ migration from hidden geothermal systems is the ability to detect changes in plant health and communities related to elevated soil $\mathrm{CO}_{2}$ concentration (e.g., Martini et al., 2000).

The spectroradiometers used in hyperspectral imaging can be hand-held, truck-mounted, planemounted, or satellite-based and related survey areas vary from sub $\mathrm{m}^{2}$ to greater than $\mathrm{km}^{2}$. The material detection range depends on the signal to noise ratio of the acquired data and the strength of the material's spectral signature. Hyperspectral imaging can reconstruct net energy exchange, net primary production, or gross primary production with $20 \%$ error or less. Although individual measurements are rapid, the time required for data processing and analysis may range from days to weeks. However, high spatial resolution, high signal-to-noise, geo-rectified hyperspectral 
data are currently available from commercial vendors. The cost of imaging an area of interest varies by orders of magnitude depending upon the platform for deployment. The main advantage of hyperspectral imaging to detection of hidden geothermal systems is the potential for remote sensing of $\mathrm{CO}_{2}$ migration by proxy over large land areas. The main disadvantages are the potentially high cost of obtaining imagery and that the methodologies are still evolving. Further information on hyperspectral imaging, can be found the following websites: http://aviris.jpl.nasa.gov/ (JPL AVIRIS), www.earthsearch.com (Earth Search Sciences, Inc.).

\subsection{Light Detection and Ranging}

Light detection and ranging (LIDAR) can be used measure the concentrations of trace gases in the atmosphere (e.g., $\mathrm{N}_{2} \mathrm{O}, \mathrm{SO}_{2}, \mathrm{O}_{3}, \mathrm{H}_{2} \mathrm{O}, \mathrm{CH}_{4}, \mathrm{CO}_{2}$ ) with laser light. While there are a range of LIDAR techniques in use, atmospheric $\mathrm{CO}_{2}$ concentration can be measured by differential absorption LIDAR (DIAL) or Raman LIDAR.

In the DIAL technique, a tunable laser is used at two wavelengths to estimate the concentration of a target-absorbing species. In the case of $\mathrm{CO}_{2}$, one laser wavelength is selected to coincide with the center of a $\mathrm{CO}_{2}$ absorption line and the second wavelength is selected to fall in a nearby non-absorbing region. Laser power at both wavelengths is transmitted over the same path in the atmosphere and is elastically scattered into the field of view of the LIDAR receiver. The average $\mathrm{CO}_{2}$ concentration over the path length is then determined from the ratio of the backscatter signals for the two laser wavelengths.

In the Raman LIDAR method, laser light is transmitted into the atmosphere, the laser radiation is shifted in wavelength due to interaction with the target scattering molecules along the resolved path length, and this wavelength-shifted signal is detected by the LIDAR receiver. Raman scattering provides wavelength shifts that are unique to the target molecules, according to the vibrational energy states of the molecules. In the case of $\mathrm{CO}_{2}$, the backscattered power of the wavelength-shifted signal is proportional to the average $\mathrm{CO}_{2}$ concentration over the laser path length. By comparing the Raman signal of the $\mathrm{CO}_{2}$ to the Raman signal of $\mathrm{N}_{2}$ or $\mathrm{O}_{2}, \mathrm{CO}_{2}$ concentration can be quantified.

DIAL and Raman LIDAR can be deployed from a truck- or plane-based platform. Truck-based surveys can cover up to $10 \mathrm{~s}$ of $\mathrm{km}^{2}$ per day, whereas a given plane-mounted survey can potentially cover $10 \mathrm{~s}$ to $100 \mathrm{~s}$ of $\mathrm{km}^{2}$. The detection range of DIAL and Raman LIDAR depends upon the wavelength and strength of absorption and typically ranges from $<1$ ppmv to several percent for $\mathrm{CO}_{2}$. The precision for truck mounted or airborne measurements is generally from $1 \%$ to $5 \%$ of maximum range; from 3.4 to $27 \mathrm{ppmv}$ at $1 \mathrm{~km}$ path length and from 14 to $86 \mathrm{ppmv}$ at $2 \mathrm{~km}$ path length at $330 \mathrm{ppmv}$ in clean air. The cost of DIAL and Raman LIDAR ranges from hundreds of dollars for a truck-mounted survey to thousands of dollars for an airborne survey. The advantages of Raman LIDAR and DIAL are that these are rapidly developing technologies with the potential to measure atmospheric $\mathrm{CO}_{2}$ concentrations over multiple spatial scales, thus increasing the efficiency of the $\mathrm{CO}_{2}$ survey. The main disadvantages are that they have the potential to be expensive and measure average concentration over a path length. Additional measurements are therefore required to locate the source(s) of $\mathrm{CO}_{2}$ emissions along the path length. For a more detailed description of these methods, the reader is referred to Schlessinger (1995), Radziemski et al. (1987), Shuler and Tang (2002); Jet Propulsion Laboratory, National 
Aeronautics and Space Administration, http://lidar.jpl.nasa.gov/, $\underline{\text { http://asd- }}$ www.larc.nasa.gov/lidar/lidar.html.

\subsection{Long Open Path IR and Tunable Lasers}

Measurement of atmospheric surface layer $\mathrm{CO}_{2}$ concentration by long open path IR and tunable lasers occurs as a fixed laser sends pulses to one or more reflectors within a study area and the signal is returned to a detector at the beginning of the laser path. The infrared absorption is measured at $\mathrm{CO}_{2}$-specific wavelengths and the cumulative $\mathrm{CO}_{2}$ concentration over the laser path length is then determined. While still under development, a single instrument set-up has the potential to provide continuous monitoring of atmospheric surface layer $\mathrm{CO}_{2}$ over several $\mathrm{km}^{2}$. The detection range currently ranges from less than 1 ppmv to several percent $\mathrm{CO}_{2}$ and measurement precision is expected to be $\pm 3 \%$ or better. Although these instruments are not yet developed to the point of commercial viability, the costs are projected to be thousands of dollars per unit. The primary advantage of long open path IR and tunable laser technology is the potential to monitor $\mathrm{CO}_{2}$ concentration over a large area with automated, continuous measurement, and the main disadvantage is that it is still under development. Also, because it provides a measurement of cumulative $\mathrm{CO}_{2}$ along the path length, additional point measurements are required to locate the source(s) of $\mathrm{CO}_{2}$ along the path. For further description of long open path IR and tunable laser technology, see Shuler and Tang (2002) and Duarte (1995).

\subsection{Micro-Electronic Mechanical Systems, Smart Dust, Motes}

Micro-electronic mechanical systems (MEMS), Smart Dust, and Motes are miniaturized $\left(\mathrm{mm}^{3}\right.$ scale) sensing and communications platforms and are currently developing technologies. Applicable to $\mathrm{CO}_{2}$ detection, is the incorporation of miniaturized infrared gas sensors into these platforms to measure absorption of IR radiation at $\mathrm{CO}_{2}$-specific wavelengths. These technologies may therefore have the capability to measure $\mathrm{CO}_{2}$ concentrations in the atmospheric surface layer and the subsurface. The promising aspect of these miniature devices is that numerous measurement systems could be distributed over a large study area to form a network that measures $\mathrm{CO}_{2}$ concentrations and broadcasts the data to a single data recording location. Smart Dust is particularly attractive because it is small, inexpensively fabricated in mass quantities, could be easily scattered around a given area, and self-assembles into a network so that data collection and coverage are simplified. Since MEMS, Smart Dust, and Motes are currently under development; the sensitivity, precision, and time and length scales of the $\mathrm{CO}_{2}$ concentration measurements are uncertain. The main disadvantage of these technologies is that they are currently under development. For more information on MEMS, Smart Dust, and Motes technologies, refer to http://www.ion-optics.com/.

\section{STRATEGIES FOR DETECTION OF GEOTHERMAL $\mathrm{CO}_{2}$}

\subsection{Introduction}

As the previous section shows, a variety of technologies is available to measure $\mathrm{CO}_{2}$ concentrations and fluxes in the subsurface and atmospheric surface layer, several of which are 
rapidly developing and will extend our current capabilities and potentially lower the cost of $\mathrm{CO}_{2}$ monitoring. However, successful application of these technologies to detect the signal of $\mathrm{CO}_{2}$ from hidden geothermal systems within natural background variability is challenging when the geothermal $\mathrm{CO}_{2}$ fluxes are very small. To meet the challenge of geothermal $\mathrm{CO}_{2}$ detection, novel procedures and/or technologies may have to be developed. In this section, we present potential strategies based on currently available conventional technologies that could be applied toward the detection and quantification of geothermal $\mathrm{CO}_{2}$.

\subsection{Sub-Surface Gas Geochemistry}

Relative to atmospheric gases, sub-surface gases are less prone to dilution of the geothermal $\mathrm{CO}_{2}$ signal by background ecological and meteorological processes. As a result, monitoring for $\mathrm{CO}_{2}$ migration from geothermal reservoirs should be focused on the subsurface. Both the carbon isotopic composition of $\mathrm{CO}_{2}$ and bulk gas chemistry can be used to determine the origin of $\mathrm{CO}_{2}$ and thereby potentially detect migration of $\mathrm{CO}_{2}$ from a geothermal reservoir. For reference, Table 7.1 shows typical chemical and isotopic signatures related to $\mathrm{CO}_{2}$ derived from different sources.

\subsubsection{Bulk Chemical Composition of Soil Gas}

The bulk chemical composition of gases collected at soil and sub-soil depths provides information on $\mathrm{CO}_{2}$ production and the source of this $\mathrm{CO}_{2}$ (i.e., whether it is derived from respiration or non-respiration sources). $\mathrm{CO}_{2}$ concentration profiles measured with depth in the vadose zone can yield valuable information about $\mathrm{CO}_{2}$ production. For example, an increase in $\mathrm{CO}_{2}$ concentration with depth below the soil indicates $\mathrm{CO}_{2}$ production at sub-soil depths. Production of $\mathrm{CO}_{2}$ by oxidative decay of organic matter tends to consume $\mathrm{O}_{2}$ at a similar rate. Also, atmospheric $\mathrm{O}_{2}$ will diffuse down into the soil and sub-soil as sub-surface $\mathrm{CO}_{2}$ diffuses to the atmosphere. A flux of geothermal $\mathrm{CO}_{2}$ would produce elevated $\mathrm{CO}_{2}$ concentration at depth, relative to the atmosphere, but would not be accompanied by $\mathrm{O}_{2}$ consumption, although atmospheric $\mathrm{O}_{2}$ would diffuse down into the soil. Based on these general processes, the $\mathrm{CO}_{2}$ concentration and $\mathrm{O}_{2}$ concentration profiles generated should be different, depending on whether a geothermal flux is present. Assuming that diffusion is the dominant gas transport process in the absence of a geothermal $\mathrm{CO}_{2}$ flux, diffusion models could be used to predict the $\mathrm{CO}_{2}$ concentration and $\mathrm{O}_{2}$ concentration-depth profiles that result from expected background $\mathrm{CO}_{2}$ respiration and $\mathrm{O}_{2}$ consumption rates. One might expect groundwater degassing of respiration and atmospheric-derived $\mathrm{CO}_{2}$ to show similar chemical trends within the vadose zone to degassing of geothermal $\mathrm{CO}_{2}$. However, vadose zone $\mathrm{CO}_{2}$ concentrations produced by groundwater degassing and biological respiration processes have generally been reported to be less than 13 vol.\% $\mathrm{CO}_{2}$ (e.g., Wood and Petraitis, 1984; Amundson and Davidson, 1990; Wood et al., 1993), whereas near-surface $\mathrm{CO}_{2}$ concentrations associated with geothermal emissions could be much higher. For example, simulated geothermal source $\mathrm{CO}_{2}$ fluxes of 57.6 to $576 \mathrm{~g} \mathrm{~m}^{-}$ ${ }^{2} \mathrm{~d}^{-1}$ produce maximum near-surface $\mathrm{CO}_{2}$ concentrations of $\sim 10-80$ vol.\% $\left(1 \times 10^{5}\right.$ to $8 \times 10^{5}$ ppmv, Figures 4.9, 4.11, and 4.12). Importantly, however, the maximum near-surface $\mathrm{CO}_{2}$ concentration produced by a source $\mathrm{CO}_{2}$ flux of $5.76 \mathrm{~g} \mathrm{~m}^{-2} \mathrm{~d}^{-1}$ is only predicted to be $\sim 2$ vol.\% $\left(2 \times 10^{4}\right.$ ppmv, Figures 4.9 and 4.10$)$, which could be problematic to distinguish from background $\mathrm{CO}_{2}$ concentrations. The spatial and temporal variability of background $\mathrm{CO}_{2}$ concentrations typical of the ecosystem and geology of the study area should therefore be well characterized in 
order to identify anomalously high $\mathrm{CO}_{2}$ concentrations that may be related to migration of $\mathrm{CO}_{2}$ from geothermal reservoirs.

\subsubsection{Carbon Isotopes}

Carbon isotopic compositions of $\mathrm{CO}_{2}$ reflect the compositions and relative proportions of the contributing sources and therefore can serve as tracers of the origin of $\mathrm{CO}_{2}$. Hereafter, carbon13 values will be reported as $\delta^{13} \mathrm{C}$, the deviation in parts per thousand (\%o) of the ${ }^{13} \mathrm{C} /{ }^{12} \mathrm{C}$ ratio in the sample from that of the Pee Dee Belemnite (PDB) reference standard. Carbon-14 values will be reported as $\Delta^{14} \mathrm{C}$, the deviation, in parts per thousand of the ${ }^{14} \mathrm{C} /{ }^{12} \mathrm{C}$ ratio in the sample from that of the reference standard (oxalic acid decay corrected to 1950). The stable carbon isotopic composition of $\mathrm{CO}_{2}$ is measured by a lab-based mass spectrometer, whereas ${ }^{14} \mathrm{C}$ in $\mathrm{CO}_{2}$ is measured by an accelerator mass spectrometer (AMS). Carbon isotopic analyses can occur following laboratory preparation of gases collected in the field using standard geochemical methods. The cost of $\delta^{13} \mathrm{C}$ analysis typically ranges from $\$ 10$ to $\$ 30$ per sample, and $\Delta^{14} \mathrm{C}$ analysis typically ranges from $\$ 200$ to $\$ 600$ per sample.

The background isotopic composition of $\mathrm{CO}_{2}$ in the soil is typically affected by contributions of $\mathrm{CO}_{2}$ from respiration (root and microbial) and the atmosphere. $\mathrm{CO}_{2}$ in the present atmosphere has $\delta^{13} \mathrm{C}$ and $\Delta^{14} \mathrm{C}$ values close to -7 and $70 \%$, respectively. The $\delta^{13} \mathrm{C}$ composition of $\mathrm{CO}_{2}$ respired from plant roots is isotopically depleted relative to the atmosphere due to isotopic fractionation associated with photosynthesis and will have an isotopic composition similar to that of the plant. Likewise, the $\delta^{13} \mathrm{C}$ composition of $\mathrm{CO}_{2}$ derived from decay of soil organic material will be similar to the plant material. This composition will largely depend on the photosynthetic pathway (e.g., $\mathrm{C}_{3}$ or $\mathrm{C}_{4}$ ) of the plant. The bulk $\delta^{13} \mathrm{C}$ compositions of $\mathrm{C}_{3}$ plants (e.g., woody shrubs) range from -24 to $-38 \%$, but are typically about $-28 \%$ (O'Leary, 1988). $\mathrm{C}_{4}$ plants (e.g., grasses that have evolved to conserve water) have $\delta^{13} \mathrm{C}$ values from -6 to $-19 \%$, but are typically near $-14 \%$ (O’Leary, 1988).

The $\Delta^{14} \mathrm{C}$ composition of soil-respired $\mathrm{CO}_{2}$ is primarily affected by root-respired $\mathrm{CO}_{2}, \mathrm{CO}_{2}$ produced by decay of organic matter on time scales of less than one year, and $\mathrm{CO}_{2}$ produced by decay of organic matter on several year to decadal time scales (e.g., Trumbore, 2000). $\mathrm{CO}_{2}$ derived from the first two sources will have $\Delta^{14} \mathrm{C}$ values similar to that of the present atmosphere, $\mathrm{CO}_{2}$ derived from decay of organic matter on decadal time scales may be ${ }^{14} \mathrm{C}$ enriched relative to the atmosphere due to the increase in ${ }^{14} \mathrm{C}$ in soil organic matter since nuclear weapons testing in the 1960's. With the exception of oxidation or warming of wetland or frozen soils, respectively, decay of ancient organic matter with depleted $\Delta^{14} \mathrm{C}$ values contributes relatively little to the decomposition $\mathrm{CO}_{2}$ flux in most soils (e.g., Trumbore, 2000). Seasonal variations in the $\Delta^{14} \mathrm{C}$ values of soil-respired $\mathrm{CO}_{2}$ have also been observed, with the highest values measured during the growing season (e.g., Keller and Bacon, 1998; Trumbore, 2000).

In most cases, respiration occurs predominantly in the soil zone (i.e., typically the upper one to two meters of the subsurface). For example, Keller and Bacon (1998) showed that in a Canadian pastureland, $98 \%$ of all subsurface respiration occurred in the soil. Therefore, the isotopic compositions of sub-soil $\mathrm{CO}_{2}$ should be influenced by respiration to a significantly lesser degree than isotopic compositions of soil $\mathrm{CO}_{2}$. However, $\mathrm{CO}_{2}$ can be produced at lower rates at sub-soil 
depths by various processes such as oxidation of organic matter. The $\delta^{13} \mathrm{C}$ value of this $\mathrm{CO}_{2}$ will be similar to the source material and may not vary significantly from those for soil-respired $\mathrm{CO}_{2}$. Also, groundwater degassing of $\mathrm{CO}_{2}$ derived from atmospheric and soil-respired sources can occur and the $\delta^{13} \mathrm{C}$ value of this $\mathrm{CO}_{2}$ will be controlled by the relative proportions of the $\mathrm{CO}_{2}$ from these sources. The ${ }^{14} \mathrm{C}$ values of $\mathrm{CO}_{2}$ produced by these sub-soil processes will depend on factors such as the age of the organic matter and the residence time of dissolved $\mathrm{CO}_{2}$ in the groundwater. For example, oxidation of ancient organic matter (e.g., peat, kerogen) will produce $\mathrm{CO}_{2}$ that is highly depleted or free of ${ }^{14} \mathrm{C}$.

The $\delta^{13} \mathrm{C}$ signature of $\mathrm{CO}_{2}$ derived from geothermal sources (e.g., magmatic/metamorphic) typically ranges from -2 to $-6 \%$ (Faure, 1986) and therefore will distinguish it from $\mathrm{CO}_{2}$ derived from $\mathrm{C}_{3}$, and many $\mathrm{C}_{4}$ plants. However, it is similar to that of atmospheric $\mathrm{CO}_{2}$ and therefore, when considered alone, will be problematic in distinguishing these sources. In addition, if groundwaters containing dissolved $\mathrm{CO}_{2}$ of biologic origin circulate through areas of high heat flow and subsequently degas this $\mathrm{CO}_{2}$, the $\delta^{13} \mathrm{C}$ signature will be similar to the biologic source(s). Geothermal $\mathrm{CO}_{2}$ derived from deep magmatic/metamorphic sources is ${ }^{14} \mathrm{C}$-free. Leaking geothermal $\mathrm{CO}_{2}$ will therefore have a ${ }^{14} \mathrm{C}$ signal that is distinct from atmospheric and most biogenic respiration sources. This signal should be easily distinguishable from dominant background $\mathrm{CO}_{2}$ sources. For example, geothermal source $\mathrm{CO}_{2}$ fluxes of 5.76, 57.6, and $576 \mathrm{~g}$ $\mathrm{m}^{-2} \mathrm{~d}^{-1}$ were described in Section 3. Given a background soil $\mathrm{CO}_{2}$ respiration rate and $\Delta^{14} \mathrm{C}$ composition typical of a temperate forest (i.e., $7.2 \mathrm{~g} \mathrm{~m}^{-2} \mathrm{~d}^{-1}$ and $128 \%$, respectively (Trumbore, 2000)), by mass balance, the $\Delta^{14} \mathrm{C}$ values of soil $\mathrm{CO}_{2}$ samples will be $-371,-874$, and $-986 \%$ for geothermal source fluxes of $5.76,57.6$, and $576 \mathrm{~g} \mathrm{~m}^{-2} \mathrm{~d}^{-1}$, respectively. The differences between these values and the isotopic composition of background soil $\mathrm{CO}_{2}$ are much greater than the precision of the ${ }^{14} \mathrm{C}$ analysis (e.g., $\pm 4-8 \%$ depending on the laboratory method used (Southon et al., 1993)); geothermal fluxes over this range of magnitudes would therefore be easily detectable by ${ }^{14} \mathrm{C}$ analyses of soil $\mathrm{CO}_{2}$.

Production rates of $\mathrm{CO}_{2}$ from background sub-soil sources should be significantly lower than those in the soil column (e.g., Wood and Patraitis, 1984; Keller and Bacon, 1998). Therefore, the range of geothermal fluxes of $\mathrm{CO}_{2}$ discussed above should be readily detectable using carbon-13, and in the absence of a large source of $\mathrm{CO}_{2}$ derived from respiration of ancient sedimentary organic carbon, carbon-14, isotopic analyses of $\mathrm{CO}_{2}$ collected from sub-soil depths. Furthermore, if soil and sub-soil gas samples contain a contribution of $\mathrm{CO}_{2}$ from a deep geothermal source, plots of $\delta^{13} \mathrm{C}$ or $\Delta^{14} \mathrm{C}$ of $\mathrm{CO}_{2}$ versus $\mathrm{CO}_{2}$ concentration can be examined for mixing trends between deep geothermal and shallow respiration derived $\mathrm{CO}_{2}$. In other words, the chemical compositions of the soil and sub-soil gases should lie on a trend between gases with relatively low $\mathrm{CO}_{2}$ concentration and high $\Delta^{14} \mathrm{C}$ or low $\delta^{13} \mathrm{C}$ (young biogenic-carbon dominated) and those with relatively high $\mathrm{CO}_{2}$ concentration and low $\Delta^{14} \mathrm{C}$ or high $\delta^{13} \mathrm{C}$ (geothermal-carbon dominated). Figure 7.1 shows an idealized mixing trend between soil gases derived from these two end-member sources.

\subsubsection{Measurement Strategies}

Soil gas $\mathrm{CO}_{2}$ concentrations can be measured at many locations within a large area using a soil probe and a portable IRGA. Using this method, a soil probe is driven down to the depth of interest (usually within the soil zone), gas is pumped from the soil to the IRGA by an internal 
pump, and $\mathrm{CO}_{2}$ concentration is measured, typically to \pm 100 ppmv or $0.01 \%$. Alternatively, a gas sample can be collected from the probe using a syringe and vial for chemical analysis by standard gas chromatographic methods. Each IRGA measurement or collection of a gas sample can be conducted within minutes, and as a result, many measurements can be made over relatively short periods of time within the measurement area. Importantly, $\mathrm{CO}_{2}$ concentrations in the soil zone will be strongly influenced by background respiration processes, which could render detection of $\mathrm{CO}_{2}$ concentration anomalies related to very small geothermal fluxes difficult. The spatial and temporal variability of background $\mathrm{CO}_{2}$ concentrations should therefore be characterized in areas with similar climate, vegetation, and soil type to that being explored for geothermal $\mathrm{CO}_{2}$ flow. Sampling of gases at sub-soil depths would be valuable to avoid large respiration signals. However, this sampling would require installation of numerous sampling wells to install permanent $\mathrm{CO}_{2}$ concentration sensors or provide locations at which to collect gas samples for chemical analyses. Unless multiple sampling wells were previously in place throughout the study area, sub-soil gas sampling could be impractical.

Due to the time and cost involved in making numerous (e.g., hundreds to thousands) closely spaced measurements within a large measurement area, the researcher commonly makes fewer measurements at widely and unevenly spaced intervals. A range of geostatistical methods, for example, kriging (e.g., Isaaks and Srivatava, 1989) or sequential Gaussian simulation (Deutsch and Journel, 1998) can then be used to estimate $\mathrm{CO}_{2}$ concentrations at unsampled locations within a grid. This grid can then be contoured to search for spatial trends in the data. Autocorrelation analysis of a spatial data set involves the calculation of correlation coefficients for the data as a function of separation distance between the measurements. Thus, contouring and autocorrelation analysis together can be used to look for spatial trends in the data that may be related to $\mathrm{CO}_{2}$ migration from a hidden geothermal reservoir. For example, elevated $\mathrm{CO}_{2}$ concentrations and a high degree of spatial autocorrelation of these concentrations along a linear trend may indicate $\mathrm{CO}_{2}$ flow along a geologic structure and would require further (e.g., isotopic) evaluation of the origin of the $\mathrm{CO}_{2}$.

\subsection{Surface and Atmospheric $\mathrm{CO}_{2}$ Concentrations and Fluxes}

Seepage of $\mathrm{CO}_{2}$ from a hidden geothermal reservoir may result in surface $\mathrm{CO}_{2}$ fluxes and atmospheric surface layer $\mathrm{CO}_{2}$ concentrations of high enough magnitude to detect within background variability of $\mathrm{CO}_{2}$. The magnitude of these seepage $\mathrm{CO}_{2}$ fluxes and atmospheric $\mathrm{CO}_{2}$ concentrations will be determined by a range of factors such as the mode of $\mathrm{CO}_{2}$ emission (e.g., focused versus diffuse flow) and atmospheric effects (e.g., wind and density-driven atmospheric dispersion).

Several methods are available to detect anomalous $\mathrm{CO}_{2}$ concentrations related to geothermal seepage in the atmospheric surface layer. For example, fixed or portable IRGAs or fixed solidstate sensors could be used to measure $\mathrm{CO}_{2}$ concentrations. Because these measurements would be made at point locations, numerous measurements over a potentially large study area would be required. In addition, due to the significant atmospheric dispersion and dilution of seeping $\mathrm{CO}_{2}$ that is expected under normal wind speed conditions, anomalous $\mathrm{CO}_{2}$ concentrations may only be a few 10's of ppmv above average ambient air ( $370 \mathrm{ppmv})$ downwind from the source (Figure 3.13). The precision of fixed detectors (typically \pm 1 ppmv or better) would allow the detection of these anomalous $\mathrm{CO}_{2}$ concentrations; however, the cost of each detector would 
likely preclude use of the many detectors required within a study area. The use of one or a few portable IRGAs would be much lower in cost. However, due to the precision of portable IRGAs (typically \pm 100 ppmv at best), it would not be possible to detect low anomalous $\mathrm{CO}_{2}$ concentrations within background variability. Point measurements of $\mathrm{CO}_{2}$ concentrations in the soil and sub-soil avoid several of the primary limitations of atmospheric $\mathrm{CO}_{2}$ detection methods, and as a result, would likely be a preferred method to detect $\mathrm{CO}_{2}$ migrating from geothermal sources.

One method available to detect anomalous soil $\mathrm{CO}_{2}$ flux is the $\mathrm{AC}$ technique. Successful detection, however, will strongly depend on the magnitude of the geothermal source flux at depth. For example, for a simulated source flux of $576 \mathrm{~g} \mathrm{CO}_{2} \mathrm{~m}^{-2} \mathrm{~d}^{-1}$, the maximum predicted surface $\mathrm{CO}_{2}$ flux is about 30 to $100 \mathrm{~g} \mathrm{~m}^{-2} \mathrm{~d}^{-1}$ (Figures 4.9 and 4.12). This flux should be detectable within natural background variability of surface $\mathrm{CO}_{2}$ fluxes using the $\mathrm{AC}$ method. However, in the case of moderate to low geothermal source fluxes of 57.6 and $5.76 \mathrm{~g} \mathrm{CO}_{2} \mathrm{~m}^{-2} \mathrm{~d}^{-}$ ${ }^{1}$, maximum predicted surface $\mathrm{CO}_{2}$ fluxes are only about $10^{-4}$ to $10^{-1}$ (Figures $4.9-4.11$ ), which would not be detectable using the $\mathrm{AC}$ method, given the measurement error.

Because the AC method essentially provides a "point" flux measurement (i.e., a measurement on the $\mathrm{cm}^{2}$ scale), numerous measurements are required to characterize the spatial trends and variability of fluxes within a study area. However, the AC method offers the benefit over the EC method in that spatial trends in surface fluxes can be mapped, allowing for the location and geometry of potential areas of anomalously high $\mathrm{CO}_{2}$ flux to be delineated, as described above for soil $\mathrm{CO}_{2}$ concentrations. Also, the $\mathrm{AC}$ technique is generally more flexible than the $\mathrm{EC}$ method because it requires few terrain or atmospheric conditions to be met. Because the AC technique provides a point measurement in time and space (as opposed to the spatially and temporally averaged EC measurement), it can be difficult to evaluate the temporal variability of soil $\mathrm{CO}_{2}$ fluxes that is typical for the study area and the influence of atmospheric parameters (temperature, pressure, wind, precipitation) on this variability. Therefore, automated $\mathrm{CO}_{2}$ flux measurement stations must be deployed where single or multiple chambers measure flux repeatedly over time, along with meteorological parameters. The relationship between surface $\mathrm{CO}_{2}$ flux and these meteorological parameters can then be evaluated using correlation analysis.

The EC method provides a spatially and temporally averaged surface $\mathrm{CO}_{2}$ flux measurement that could be used to detect anomalous $\mathrm{CO}_{2}$ emissions related to seepage of geothermal $\mathrm{CO}_{2}$. To successfully detect anomalous $\mathrm{CO}_{2}$ flux, however, EC instrumentation must be deployed under the meteorological and terrain conditions required to minimize the error of the measurement. Also, the magnitude of the $\mathrm{CO}_{2}$ flux anomaly must be large enough such that it can be detected above background variability (which should be characterized for an ecosystem similar to that at the study site), given the error of the measurement. Additional point measurement (e.g., with the $\mathrm{AC}$ method) would also be required to delineate the location and geometry of the $\mathrm{CO}_{2}$ flux anomaly within the EC footprint.

\subsection{Water Chemistry}

Geothermal $\mathrm{CO}_{2}$ may also seep and dissolve into ground and surface waters. This $\mathrm{CO}_{2}$ could be detected by ground and surface water sampling and chemical analysis. As $\mathrm{CO}_{2}$ dissolves in 
ground and surface waters, the acidity of the waters will tend to increase (i.e., the $\mathrm{pH}$ will decrease). A relatively large magnitude $\mathrm{CO}_{2}$ seepage flux into ground or surface water could produce $\mathrm{CO}_{2}$ gas bubbles and this $\mathrm{CO}_{2}$ could be sampled for isotopic analyses $\left(\delta^{13} \mathrm{C}, \Delta^{14} \mathrm{C}\right)$ to constrain its source, as described above for vadose zone $\mathrm{CO}_{2}$. However, if seepage fluxes are small to moderate, $\mathrm{CO}_{2}$ should be mainly present in the aqueous phase as dissolved inorganic carbon, DIC (i.e., $\mathrm{CO}_{2}(\mathrm{aq}), \mathrm{H}_{2} \mathrm{CO}_{3}, \mathrm{HCO}_{3}^{-}, \mathrm{CO}_{3}{ }^{2-}$ ). With increasing seepage of $\mathrm{CO}_{2}$ into waters, DIC should increase. Alkalinity is the ability of water to accept protons $\left(\mathrm{H}^{+}\right)$and is predominantly due to the presence of $\mathrm{HCO}_{3}{ }^{-}$and $\mathrm{CO}_{3}{ }^{2-}$ in most potable natural waters. The DIC concentration can be directly determined or can be calculated if both alkalinity and $\mathrm{pH}$ are determined for a given water sample. Plots of DIC concentration versus $\Delta^{14} \mathrm{C}$ or $\delta^{13} \mathrm{C}$ of the DIC can then be used to trace the addition of deep magmatic/hydrothermal carbon to groundwaters that contain respiration-derived carbon from infiltration (e.g., Chiodini et al., 2000; Evans et al., 2002). The chemical trends in these waters indicate mixing between waters with relatively low DIC and high $\Delta^{14} \mathrm{C}$ or low $\delta^{13} \mathrm{C}$ (young biogenic-carbon dominated) and those with relatively high DIC and low $\Delta^{14} \mathrm{C}$ or high $\delta^{13} \mathrm{C}$ (magmatic/hydrothermal-carbon dominated). If the concentration of DIC derived from the deep source and water flow rate are known for sample locations within the study area, the discharge of deeply derived DIC can be estimated.

In order to successfully detect geothermal $\mathrm{CO}_{2}$, a variety of factors must be considered in the interpretation of ground and surface water geochemistry. To evaluate the influence of residence time on the ${ }^{14} \mathrm{C}$ compositions of DIC, groundwater age should be assessed (e.g., by tritium analyses). Also, interactions between water and host rocks along flow paths can affect the concentration and isotopic composition of DIC, concentrations of major and minor cations in solution, and $\mathrm{pH}$. For example, dissolution of calcium carbonate $\left(\mathrm{CaCO}_{3}\right)$ by the reaction $\mathrm{CO}_{2}+$ $\mathrm{H}_{2} \mathrm{O}+\mathrm{CaCO}_{3}=\mathrm{Ca}^{2+}+2 \mathrm{HCO}_{3}{ }^{-}$results in the doubling of DIC (i.e., one mole of $\mathrm{CO}_{2}$ reacts to produce two moles of $\mathrm{HCO}_{3}^{-}$) and a release of $\mathrm{Ca}^{2+}$ to solution. Also, the DIC produced will have $\delta^{13} \mathrm{C}$ and $\Delta^{14} \mathrm{C}$ compositions reflecting contributions from both the $\mathrm{CO}_{2}$ and the carbonate mineral. Therefore, the contribution of DIC derived from dissolution of ${ }^{14} \mathrm{C}$-free and ${ }^{13} \mathrm{C}$ enriched carbonate rocks along flow paths will decrease $\Delta^{14} \mathrm{C}$ values and increase $\delta^{13} \mathrm{C}$ values similarly to geothermal $\mathrm{CO}_{2}$ and could complicate interpretation of DIC concentration-carbon isotopic composition plots.

Single or continuous aqueous geochemical measurements are usually made at fixed locations. These measurements can be made using portable field equipment (e.g., $\mathrm{pH}$ electrode, field alkalinity titration kit) or by analysis of water samples in a standard geochemical laboratory. Carbon isotopic compositions of water samples are determined as described above for soil gas samples. The detection range and precision are variable, depending on the measurement. Aqueous geochemical sampling and analytical techniques are well established, and relatively inexpensive (i.e., dollars to hundreds of dollars per sample). However, the spatial coverage of groundwater sampling is limited by the presence of wells or springs. Also, source water chemical composition, rock-water interactions along flow paths, and residence time can complicate interpretation of the groundwater geochemistry. In the case of surface waters, interpretations can be complicated by source water chemical composition, surface hydrology, and weather. 


\subsection{Statistical Analysis}

\subsubsection{Background}

Statistical analysis can be used to refine sampling strategy and reduce the number of high-cost measurements made in the search for hidden geothermal systems. Assuming that the sampling method (e.g., IRGA for $\mathrm{CO}_{2}$ concentration, $\mathrm{AC}$ method for soil $\mathrm{CO}_{2}$ flux) has $100 \%$ capability to detect a gas anomaly, the probability $(P)$ of sampling at least once a gas anomaly of area $x$ at least once within a study area $A$ with $n$ number of randomly distributed point measurements is given by

$$
P=1-\left[1-\frac{x}{A}\right]^{n}
$$

Therefore, if $x / A=0.1, \sim 30$ measurements are required to sample a gas anomaly at least once with $95 \%$ confidence. If $x / A=0.01$ and $0.001, \sim 300$ and 3000 samples, respectively, are required to sample the anomaly at least once. Importantly, application of Eq. 7.2 assumes that a gas anomaly exists within area $A$. However, in the case we are particularly interested in, the researcher will search for a hidden geothermal system within an area where there is no evidence of surface hydrothermal features and there is likely a relatively low probability of the existence of a gas anomaly within this area. With Bayesian statistics, we are then able to answer the question: "Given that we have failed to detect $(\sim d)$ a gas anomaly of area $x$ within the sampling area $A$ with one randomly located point measurement, what is the confidence level $(P)$ that it is actually there $(H)$ ?" For this case,

$$
P(H \mid \sim d)=\frac{\left(1-\frac{x}{A}\right) P(H)}{P(H)\left[1-\frac{x}{A}\right]+[1-P(H)]}
$$

(Bayes, 1763). To solve this equation, $P(H)$ is set equal to an initial confidence (e.g., 0.1 if the researcher is realistically pessimistic or 0.9 if realistically optimistic, that the anomaly is present within the study area), given some prior information about the study area. To estimate the number of randomly distributed point measurements $(n)$ necessary for there to be, e.g., only a $5 \%$ chance that an anomaly exists, given that we have not detected it, the calculated $P(H \mid \sim d)$ is substituted for $P(H)$, the equation is solved iteratively until $P(H \mid \sim d)=0.05$, and $n=$ the number of iterations. If the researcher strongly suspects that there is an anomaly within the study area, and $P(H)=0.9, n \approx 50,500,5000$, and 50,000 for $x / A=0.1,0.01,0.001$, and 0.0001, respectively. If $P(H)=0.1, n \approx 7,70,700$, and 7000 for $x / A=0.1,0.01,0.001$, and 0.0001 , respectively. 
Although any number of $x / A$ scenarios may be possible, these examples demonstrate that in the case of preliminary gas sampling and analysis, rapid and economical methods should be used in order to accommodate a potentially large number of measurements. It is also necessary to collect site-specific geologic information prior to sampling to delineate the most probable locations of gas migration (e.g., near geologic structures) to minimize $A$ and maximize $x / A$.

It is important to recognize that Eq. 7.3 assumes that the sampling methodology is $100 \%$ capable of detecting the gas anomaly. In other words, the detection method does not give false positives (i.e., it detects an anomaly that is not there) or negatives (i.e., it fails to detect an anomaly that is there). In reality, the methods used to detect a $\mathrm{CO}_{2}$ anomaly within background $\mathrm{CO}_{2}$ will likely give both false positives and negatives. In this case,

$$
P(H \mid \sim d)=\frac{\left[\left(1-\frac{x}{A}\right)(1-\alpha(m))+\frac{x}{A} \beta(m)\right] P(H)}{\left[\left(1-\frac{x}{A}\right)(1-\alpha(m))+\frac{x}{A} \beta(m)\right] P(H)+[1-\alpha(m)][1-P(H)]}
$$

where $\alpha(m)$ and $\beta(m)$ are the false positive and negative rates, respectively, as a function of the magnitude $(m)$ of the anomaly. The confidence that once an anomaly has been detected it is a true anomaly $(P(H \mid \sim d)$, given $\alpha(m)$ and $\beta(m)$ of the detection method, is then given by

$$
P(H \mid d)=\frac{\left\lfloor\frac{x}{A}(1-\beta(m))+\left(1-\frac{x}{A}\right) \alpha(m)\right\rfloor P(H)}{\left\lfloor\frac{x}{A}(1-\beta(m))+\left(1-\frac{x}{A}\right) \alpha(m)\right\rfloor P(H)+\alpha(m)[1-P(H)]}
$$

In order to apply Eqs. 7.4 and 7.5, $\alpha(\mathrm{m})$ and $\beta(\mathrm{m})$ must be estimated. For a given measurement method, for example, soil $\mathrm{CO}_{2}$ flux measurement by $\mathrm{AC}, \alpha(m)$ and $\beta(m)$ are related to the probability density functions (PDFs) of the background and anomalous $\mathrm{CO}_{2}$ fluxes, respectively, and the chosen threshold above which $\mathrm{CO}_{2}$ flux is considered anomalous. In other words, $\alpha(m)$ is the fraction of the background PDF that lies above the threshold value and $\beta(m)$ is the fraction of the anomaly PDF that lies below the threshold value. The PDFs of the background and anomalous $\mathrm{CO}_{2}$ flux can be estimated from background field characterization and numerical modeling of geothermal $\mathrm{CO}_{2}$ flow \pm laboratory experiments, respectively. The threshold value is then found where the influence of $\alpha(m)$ and $\beta(m)$ on $n$ is minimized. Monte Carlo simulation taking $P(H), x / A, \alpha(m)$, and $\beta(m)$ into account can be used to estimate the number of measurements that will be required to determine with a desired confidence level that a gas anomaly exists in the sampling area (see Examples section below). In the field, the researcher would apply Eqs. 7.4 and 7.5 by beginning with an initial confidence that a geothermal anomaly exists within study area $A$. Measurements would be made within this area and Eqs. 7.4 or 7.5 would be solved repeatedly, depending on whether an anomaly is not detected or detected, 
respectively. If the number of measurements that do not detect an anomaly increases, then the confidence that an anomaly exists decreases (Eq. 7.4). Conversely, if the number of measurements that detect an anomaly increases, then so does the confidence that the anomaly exists (Eq. 7.5). Measurements could be made until the desired confidence level is met that an anomaly exists in the sampling area.

Eqs. 7.4 and 7.5 have the potential to guide sampling strategy and reduce the number of highcost (e.g., isotopic) measurements made. For example, when measured $\mathrm{CO}_{2}$ fluxes and/or concentrations have been determined with high confidence to be anomalous, these sites can then be further sampled for isotopic analyses to determine if the $\mathrm{CO}_{2}$ source is geothermal. Or, if a sufficiently low confidence level that an anomaly exists is reached, then further geochemical analyses can be avoided. While we describe the application of Eqs. 7.2-5 in the context of randomly distributed measurements, these equations can also be applied if measurements are made at evenly spaced intervals along a grid. However, if measurements are spatially clustered, Eqs. 7.2-5 cannot be used.

\subsubsection{Examples}

Introduction. In this section, we describe several cases where we use the PDFs of a background soil $\mathrm{CO}_{2}$ flux data set measured by the AC method in central California (Lewicki et al., 2003a) and of anomalous geothermal $\mathrm{CO}_{2}$ flux estimated based on numerical modeling (see Section 4, above) to estimate the $n$ required to determine with a confidence level of $99 \%$ that a gas anomaly exists within a hypothetical sampling area. This hypothetical sampling area is assumed to have vegetation type and sub-surface physical properties similar to that at the background central California site, so that the measured soil $\mathrm{CO}_{2}$ fluxes can be considered typical of background fluxes at the hypothetical site.

In each of the cases explored, we use Monte Carlo simulations to determine the threshold $\mathrm{CO}_{2}$ flux where the influence of $\alpha(m)$ and $\beta(m)$ on $n$ is minimized, and therefore, the minimum $n$ required to detect a $\mathrm{CO}_{2}$ anomaly with a confidence level of $99 \%$. First, $\alpha(m)$ and $\beta(m)$ are calculated based on the background and anomaly PDFs, respectively, for threshold values from 1 to $50 \mathrm{~g} \mathrm{~m}^{-2} \mathrm{~d}^{-1}$. Then, for each of the $\alpha(m)-\beta(m)$ value sets associated with each of the 50 threshold values and assuming given $x / A$ and $P(H)$ values, 500 Monte Carlo simulations are conducted. Each of these Monte Carlo simulations estimates $n$ by random sampling of an initial $\mathrm{CO}_{2}$ flux value and iteratively solving Eqs. 7.4 and 7.5 until a confidence level of $99 \%$ is met that the $\mathrm{CO}_{2}$ anomaly exists. Because cases where extreme numbers of samples are needed to detect an anomaly are unrealistic based on the time and cost required for the sampling, a cutoff of $n=20,001$ is assigned. Based on the 500 simulations, a PDF of $n$ is constructed for each threshold value. The PDFs for all threshold values are compiled in an image plot (i.e., probability density as a function of threshold value and $n$ ) and used to determine the minimum $n$ required to detect the $\mathrm{CO}_{2}$ anomaly, and its associated threshold value. To explore the influences of (1) near-surface permeability structure, (2) $P(H)$, and (3) $x / A$ on $n$, we vary each of these parameters individually, while holding the remaining parameters constant in the Monte Carlo simulations for Cases 1-12 (Table 7.2). Also, we only consider the high modeled geothermal source $\mathrm{CO}_{2}$ flux because the surface fluxes associated with the low and medium source fluxes are below the detection limits of the AC method, as discussed above. 
Homogeneous and isotropic permeability. Figure 7.2a shows the PDFs of measured background soil $\mathrm{CO}_{2}$ flux (Lewicki et al., 2003a) and modeled anomalous surface $\mathrm{CO}_{2}$ flux associated with homogeneous and isotropic permeability structure and high source $\mathrm{CO}_{2}$ flux (see Figure 4.9 for the anomalous $\mathrm{CO}_{2}$ flux profile). Based on these PDFs, $\alpha(m)$ and $\beta(m)$ were calculated for threshold values from 1 to $50 \mathrm{~g} \mathrm{~m}^{-2} \mathrm{~d}^{-1}$. Holding $P(H)=0.1$ (indicating realistic pessimism that an anomaly exists), $x / A$ was varied from 0.1 to 0.001 (Cases 1-3, Table 7.2) for Monte Carlo simulations. Then, $x / A$ was varied from 0.1 to 0.001 , holding $P(H)=0.9$ (Cases 46, Table 7.2), indicating realistic optimism that an anomaly exists. Figure 7.3 shows PDF image plots for Cases 1 and 2. For a given threshold value on these plots, high probability indicates that the $n$ is appropriate to detect a $\mathrm{CO}_{2}$ anomaly with $99 \%$ confidence. Also, the goal here is to determine the minimum $n$ required to detect an anomaly. Therefore, we are specifically interested to find the location on the plot where probability is maximized and $n$ is minimized.

On the Case 1 plot corresponding to $P(H)=0.1$ and $x / A=0.1$ (Figure 7.3), high probabilities corresponding to minimum $n$ values are evident at threshold values $<8 \mathrm{~g} \mathrm{~m}^{-2} \mathrm{~d}^{-1}$ and $\sim 28 \mathrm{~g} \mathrm{~m}^{-2}$ $\mathrm{d}^{-1}$. These threshold values approximately correspond to the "cross-over" points between the background and anomaly PDFs (Figure 7.2a). In other words, relative to measured background $\mathrm{CO}_{2}$ flux, there is a high probability of occurrence of anomalous $\mathrm{CO}_{2}$ flux at $<8$ and $\sim 30 \mathrm{~g} \mathrm{~m}^{-2} \mathrm{~d}^{-}$ 1 , while there is a relatively high probability of occurrence of background $\mathrm{CO}_{2}$ flux at intermediate values. However, because (1) the low anomalous $\mathrm{CO}_{2}$ fluxes would not likely be detectable using the $\mathrm{AC}$ method, and (2) the measured background soil $\mathrm{CO}_{2}$ flux data set may not accurately represent the occurrence of low $\mathrm{CO}_{2}$ flux values at the study site, the portion of the probability image plots at threshold values $<8 \mathrm{~g} \mathrm{~m}^{-2} \mathrm{~d}^{-1}$ will hereafter be ignored. The threshold value of $26 \mathrm{~g} \mathrm{~m}^{-2} \mathrm{~d}^{-1}$ therefore likely represents the value where the influence of $\alpha(\mathrm{m})$ and $\beta(m)$ on $n$ is minimized for Case 1. The mean $(\mu)$ and standard deviation $(\sigma)$ of $n$ at a threshold value $=28 \mathrm{~g} \mathrm{~m}^{-2} \mathrm{~d}^{-1}$ are shown on Table 7.3. The mean $(\mu)$ and $\sigma$ are taken to be the minimum number of measurements required to detect a $\mathrm{CO}_{2}$ anomaly within the sampling area and its uncertainty, respectively. For Case 1, $n=5415 \pm 3029$ (Table 7.3).

Also shown on Figure 7.2 is the Case $2(x / A=0.01)$ probability image plot. This plot indicates that $>20,000$ samples are required to detect an anomaly associated with $x / A=0.01$. For $x / A=$ 0.001 (Case 3), $>20,000$ samples are also required to detect an anomaly. Figure 7.4 shows probability image plots for Cases 4 and 5, where $P(H)=0.9$ and $x / A=0.1$ and 0.01 , respectively. For Case 4, $n=1869 \pm 1784$ (threshold $=29 \mathrm{~g} \mathrm{~m}^{-2} \mathrm{~d}^{-1}$ ) and for Case $5 n=19,984 \pm 256$ (threshold $\left.=28 \mathrm{~g} \mathrm{~m}^{-2} \mathrm{~d}^{-1}\right)$ (Table 7.3). For Case $6(x / A=0.001), n>20,000$. Increasing the initial confidence level that an anomaly exists in the study area therefore leads to a decrease in $n$.

Heterogeneous and isotropic permeability. Figure 7.2b shows the PDFs of background central California soil $\mathrm{CO}_{2}$ flux (Lewicki et al., 2003a) and anomalous $\mathrm{CO}_{2}$ flux associated with the heterogeneous and isotropic permeability realizations $\mathrm{A}-\mathrm{E}$ and high source $\mathrm{CO}_{2}$ flux (see Figure 4.12 for the anomalous $\mathrm{CO}_{2}$ flux profiles that were combined to produce the anomalous PDF). Based on these PDFs, $\alpha(m)$ and $\beta(m)$ were calculated for threshold values from 1 to $50 \mathrm{~g} \mathrm{~m}^{-2} \mathrm{~d}^{-1}$. Holding $P(H)=0.1, x / A$ was varied from 0.1 to 0.001 (Cases 7-9, Table 7.2) for Monte Carlo simulations. Then, $x / A$ was varied from 0.1 to 0.001 , holding $P(H)=0.9$ (Cases $10-12$, Table 7.2). Figure 7.5 shows probability image plots for Cases 7 and 10. For Case $7(x / A=0.1), n=$ $3407 \pm 1919$ for a threshold value of $38 \mathrm{~g} \mathrm{~m}^{-2} \mathrm{~d}^{-1}$. Relative to the Case 1 simulations for homogeneous permeability, fewer samples are required for detection of a $\mathrm{CO}_{2}$ anomaly 
associated with heterogeneous permeability. This can be attributed to the greater occurrence probability of high (i.e., $>38 \mathrm{~g} \mathrm{~m}^{-2} \mathrm{~d}^{-1}$ ) anomalous $\mathrm{CO}_{2}$ fluxes associated with the heterogeneous subsurface permeability (Figure 7.2b), relative to homogeneous permeability (Figure 7.2a). For Cases 8 and $9(x / A=0.01$ and 0.001 , respectively $),>20,000$ samples are required to detect a $\mathrm{CO}_{2}$ anomaly. When $P(H)=0.9, n$ decreases; $n=1267 \pm 1253$ for a threshold value of $38 \mathrm{~g} \mathrm{~m}^{-2} \mathrm{~d}^{-1}$ and $x / A=0.1$ (Case 10, Figure 7.4). Decreasing $x / A$ to 0.01 and 0.001 , results in $n=19,984 \pm$ 256 (Case 11, Figure 7.6) and $>20,000$, respectively.

It is likely that "real-world" study areas will be characterized by heterogeneous permeability structure. As a result, fewer samples will likely be required, relative to the simulated cases with homogeneous permeability, with all else being equal (i.e., $x / A$, geothermal source $\mathrm{CO}_{2}$ flux, $P(H)$ ). Overall, however, all Monte Carlo simulations demonstrate that, even for anomalous surface $\mathrm{CO}_{2}$ fluxes associated with the high source $\mathrm{CO}_{2}$ flux and heterogeneous permeability, a large number of measurements are required to detect anomalous flux with high confidence. It therefore will become critical to limit $A$ in order to maximize $x / A$ and reduce the number of required samples by detailed site characterization (e.g., by identification of structural features likely to provide high permeability pathways for gas transport and limitation of study area $A$ to these features).

\subsection{Integrated Sampling Strategy}

The selection of a study area targeted for geothermal exploration will depend on a variety of geologic, geographic, and ecological factors. For example, the site may be located adjacent to a known geothermal resource. Or, the site may be selected because it possesses similar geologic and tectonic features to a known geothermal resource. Furthermore, recent vegetation kill potentially related to elevated soil- $\mathrm{CO}_{2}$ concentrations may provide the impetus to conduct a survey to search for geothermal $\mathrm{CO}_{2}$.

Importantly, the natural spatial and temporal variability of near-surface $\mathrm{CO}_{2}$ should also be characterized in a background area with similar geologic, climatic, and ecosystem characteristics to the area targeted for geothermal exploration. To evaluate the overall spatial distribution of soil $\mathrm{CO}_{2}$ fluxes and concentrations within the background area, these parameters should be measured using the AC method and a portable IRGA within the area along a large grid at widely spaced sampling intervals. Also, to understand the small-scale spatial heterogeneity of soil $\mathrm{CO}_{2}$ fluxes and concentrations, measurements should be made along a smaller grid at closely spaced sampling intervals. To capture diurnal and seasonal variations in $\mathrm{CO}_{2}$, measurements of soil $\mathrm{CO}_{2}$ concentration, flux, and isotopic composition should be made repeatedly over time at several fixed "representative" sites. If feasible, atmospheric temperature, pressure, and wind speed and direction should be measured at a weather station contemporaneously with $\mathrm{AC}^{\mathrm{CO}_{2}}$ fluxes. Soil temperature and moisture should also be monitored concurrently with soil $\mathrm{CO}_{2}$ fluxes. Correlation analysis of soil $\mathrm{CO}_{2}$ flux and environmental parameters should be performed. Using regression analysis, empirical relationships between correlated parameters could be established and used to predict the background $\mathrm{CO}_{2}$ fluxes expected under a given set of environmental conditions. If the background study area meets the terrain conditions required by the EC method, then an EC station should be deployed during times of optimal meteorological conditions to measure spatially averaged net $\mathrm{CO}_{2}$ fluxes. 
A broad range of measurements should be made within the area targeted for geothermal exploration. However, as demonstrated by our modeling results, elevated sub-soil and soil $\mathrm{CO}_{2}$ concentrations are expected to be the strongest and most easily detected signals related to $\mathrm{CO}_{2}$ migration away from a hidden geothermal reservoir. As a result, initial sampling priority should be given to the measurement of these concentrations. In particular, the collection of sub-soil gas and water samples from wells for geochemical analyses promises a relatively high potential to detect leaking geothermal $\mathrm{CO}_{2}$. Therefore, if previously installed wells exist within the study area, these wells should be sampled for analysis. However, because there is likely to be a relatively low density of pre-existing wells within the study area, a strong emphasis should also be put on rapid, economical, low-error measurements of soil $\mathrm{CO}_{2}$ concentration and surface $\mathrm{CO}_{2}$ fluxes along grids at evenly spaced intervals. These measurements should be focused during seasonal times of low ecological productivity to minimize biological respiration and maximize potential deep geothermal contribution of $\mathrm{CO}_{2}$.

The two primary goals of soil $\mathrm{CO}_{2}$ concentration and flux sampling are to minimize the number of these measurements $(n)$, and to locate "high-probability" anomalies (Eqs. 7.4 and 7.5) where more costly deep sampling and isotopic measurements will then be conducted. To accomplish these goals, $x / A$ (Eqs. 7.4 and 7.5, in the case where measurement methods are not 100\% capable of detecting anomalous $\mathrm{CO}_{2}$ ) should be maximized by focusing soil $\mathrm{CO}_{2}$ concentration and $\mathrm{AC}$ $\mathrm{CO}_{2}$ flux sampling in areas where geothermal $\mathrm{CO}_{2}$ migration is most likely (e.g., near geologic structures). Secondly, the probability distributions of the background and anomalous soil $\mathrm{CO}_{2}$ concentration (or flux) should be estimated from background field characterization and numerical modeling of geothermal $\mathrm{CO}_{2}$ migration, respectively, and threshold values should be defined above which these parameters are considered anomalous. These $\mathrm{CO}_{2}$ concentration and flux threshold values are chosen based on minimization of $\alpha(m)$ and $\beta(m)$ and therefore $n$ (Eqs. 7.4 and 7.5). Equations 7.4 and 7.5 should then be used to determine the presence (or absence) of $\mathrm{CO}_{2}$ anomalies with high confidence. The information provided on the locations of highprobability gas anomalies should be integrated with maps contoured for soil $\mathrm{CO}_{2}$ concentration and flux magnitude and autocorrelation and cross-correlation coefficients of these parameters. Based on these combined analyses, the locations of more costly and time-intensive sampling can be determined.

Where anomalously high soil $\mathrm{CO}_{2}$ concentration and flux are located, new wells should be installed and gases should be sampled at regular intervals from the surface to the water table for chemical and isotopic compositions. A source of $\mathrm{CO}_{2}$ at depth would be accompanied by an increase in $\mathrm{CO}_{2}$ concentration with depth. To check for a biological respiration source of $\mathrm{CO}_{2}$ at (sub-soil) depth, measured $\mathrm{CO}_{2}$ and $\mathrm{O}_{2}$ concentration-depth profiles should be compared to profiles generated by diffusion models of background $\mathrm{CO}_{2}$ respiration and $\mathrm{O}_{2}$ consumption. Profiles of $\delta^{13} \mathrm{C}$ and $\Delta^{14} \mathrm{C}$ should be measured. Relatively low $\Delta^{14} \mathrm{C}$ and high $\delta^{13} \mathrm{C}$ values would be expected at depth with a leaking geothermal $\mathrm{CO}_{2}$ source and mass balance calculations could be used to estimate the fraction contribution of this component to sampled $\mathrm{CO}_{2}$. In sum, the observations of $\mathrm{CO}_{2}$ and $\mathrm{O}_{2}$ concentration gradients, $\mathrm{CO}_{2}$ production distribution, surface $\mathrm{CO}_{2}$ fluxes, and carbon isotopic compositions must be consistent with the $\mathrm{CO}_{2}$ source.

If the terrain conditions in the study area are such that the errors of EC measurements are low enough to detect potentially small geothermal seepage fluxes, EC could be used as an additional tool to search for $\mathrm{CO}_{2}$ seepage. Then, if the measured EC flux is sufficiently higher than the flux 
variability measured at the background site to be considered anomalous, $\mathrm{AC}$ and soil $\mathrm{CO}_{2}$ concentration measurements should be used detect the location and geometry of the anomaly within the $\mathrm{EC}$ footprint. To minimize $\mathrm{x} / \mathrm{A}$ and the number of necessary $\mathrm{AC}$ and $\mathrm{CO}_{2}$ concentration measurements, the EC instrumentation (e.g., tower height) should be configured to yield small footprint areas.

\section{CONCLUSIONS}

The properties of $\mathrm{CO}_{2}$ and the methods for detection and monitoring of $\mathrm{CO}_{2}$ are generally well known. We are also able to obtain a better understanding of near-surface $\mathrm{CO}_{2}$ concentrations and fluxes resulting from $\mathrm{CO}_{2}$ migration and seepage from hidden geothermal reservoirs using numerical simulation of $\mathrm{CO}_{2}$ flow and transport. Yet despite this understanding, detecting small anomalous geothermal $\mathrm{CO}_{2}$ fluxes and concentrations within natural background variations of $\mathrm{CO}_{2}$ poses a challenge. The strategy that we propose involves integrated monitoring, modeling, and statistical analysis to understand the natural system. Once this understanding is achieved, integrated measurement, monitoring, and sampling technologies can be applied toward the characterization of $\mathrm{CO}_{2}$ within the area potentially hosting a hidden geothermal reservoir. If measurements of $\mathrm{CO}_{2}$ concentrations and fluxes within this area are suggestive of the presence of $\mathrm{CO}_{2}$ derived from a geothermal source, the area should be investigated further by more costand time-intensive vertical profile sampling and isotopic analyses. Integrated analysis of all measurements will determine definitively if $\mathrm{CO}_{2}$ derived from a deep geothermal source is present, and if so, the spatial extent of the anomaly. The appropriateness of further geophysical measurements, installation of deep wells, and geochemical analyses of deep fluids can then be decided based on the results of the near surface $\mathrm{CO}_{2}$ monitoring program.

\section{ACKNOWLEDGMENTS}

We thank Pat Dobson and Mark Conrad (LBNL) for constructive comments and thorough reviews of this report. This work was supported by the Assistant Secretary for Energy Efficiency and Renewable Energy, Office of Geothermal Technologies, of the U.S. Department of Energy, and by the Office of Science, U.S. Department of Energy, under Contract No. DE-AC03-76SF00098.

\section{REFERENCES}

Alexander, M., Introduction to Soil Microbiology, $2^{\text {nd }}$ ed., John Wiley and Sons, New York, 467 pp., 1977. 
Amundson, R.G. and V.S. Smith, Annual cycles of physical and biological properties in an uncultivated and irrigated soil in the San Joaquin Valley of California, Agriculture, Ecosystems, Env., 20, 195-208, 1988.

Amundson, R.G., O.A. Chadwick, and J.M. Sowers, A comparison of soil climate and biological activity along an elevation gradient in the eastern Mojave Desert, Oecologia, 80, 395-400, 1989.

Amundson, R.G. and E.A. Davidson, Carbon and nitrogeneous gases in the soil atmosphere, J. Geochem. Explor., 38, 13-41, 1990.

Anderson, D.E. and C.D. Farrar, Eddy covariance measurement of $\mathrm{CO}_{2}$ flux to the atmosphere from an area of high volcanogenic emissions, Mammoth Mountain, California, Chem. Geology, 177, 31-42, 2001.

Arya, S.P., Air Pollution Meteorology and Dispersion, Oxford University Press, 1999.

Baldocchi, D.D., Hicks, B.B. and Meyers, T.P., Measuring biosphere-atmosphere exchanges of biologically related gases with micrometeorological methods, Ecology, 69, 1331-1340, 1988.

Baldocchi, D.D. and K.B. Wilson, Modeling $\mathrm{CO}_{2}$ and water vapor exchange of a temperate broadleaved forest across hourly to decadal time scales, Ecological Modelling, 142, 155$184,2001$.

Baldocchi, D.D, E. Falge, L., Gu, , R. Olson, D. Hollinger, S. Running, P. Anthoni, Ch. Bernhofer, K. Davis, J. Fuentes, A. Goldstein, G. Katul, B. Law, X. Lee, Y. Malhi, T. Meyers, J.W. Munger, W. Oechel, K. Pilegaard, H.P. Schmid, R. Valentini, S. Verma, T. Vesala, K. Wilson and S. Wofsy, 2001, FLUXNET: A New Tool to Study the Temporal and Spatial Variability of Ecosystem-Scale Carbon Dioxide, Water Vapor and Energy Flux Densities, Bull. Am. Meteorol. Soc., 82, 2415-2435, 2001.

Bayes, T., An essay towards solving a problem in the doctrine of Chances, Philosophical Transactions of the Royal Society of London, 53, 370-418, 1763.

Benoit, D., Conceptual models of the Dixie Valley, Nevada Geothermal Field, Geoth. Resour. Council Trans., 23, 505-511, 1999.

Bergfeld, D., F. Goff, and C.J. Janik, Elevated carbon dioxide flux at the Dixie Valley geothermal field, Nevada; relations between surface phenomena and the geothermal reservoir, Chem. Geol., 177, 43-66, 2001.

Britter, R.E., Atmospheric dispersion of dense gases, Ann. Rev. Fluid Mech., 21, 317-344, 1989.

Cardellini, C., G. Chiodini, F. Frondini, D. Granieri, J. Lewicki, and L. Peruzzi, Accumulation 
chamber measurements of methane fluxes: application to volcanic-geothermal areas and landfills, Appl. Geochem., 18, 45-54, 2003.

Chiodini, G., G. R. Cioni, M. Guidi, B. Raco, and L. Marini, Soil $\mathrm{CO}_{2}$ flux measurements in volcanic and geothermal areas, Appl. Geochem., 13, 543-552, 1998.

Chiodini, G., F. Frondini, C. Cardellini, F. Parello, and L. Peruzzi, Rate of diffuse carbon dioxide earth degassing from carbon balance of regional aquifers: The case of the central Apennine, Italy, J. Geophys. Res., 105, 8423-8434, 2000.

Chiodini, G., C. Cardellini, F. Frondini, D. Granieri, L. Marini, and G. Ventura, $\mathrm{CO}_{2}$ degassing and energy release at Solfatara Volcano, Campi Flegrei, Italy, J. Geophys. Res., 106, 16,213$16,221,2001$.

Cruz, J.V., R.M. Couthinho, M.R. Carvalho, N. Oskarrson, and S.R. Gislason, Chemistry of waters from furnas volcano, Sao Miguel, Azores: fluxes of volcanic carbon dioxide and leached materials, J. Volcanol. Geotherm. Res., 92, 151-167, 1999.

Deutsch, C.V. and A.G. Journel, GSLIB, Geostatistical Software User's Guide, Oxford Univ. Press, New York, NY, 1998.

Duarte, F.J., Tunable Laser Applications, Optical Engineering Series No.50, Marcek Dekker, Inc., New York, NY, 1995.

Edwards, N.T., Effects of temperature and moisture on carbon dioxide evolution in a mixed deciduous forest floor, Soil Sci. Soc. Am. Proc., 39, 361-365, 1975.

Edwards, N.T. and B.M. Ross-Todd, Soil carbon dynamics in a mixed deciduous forest following clear-cutting with and without residual removal, Soil Sci. Soc. Am. J., 47, 1014$1021,1983$.

Edwards, N.T. and J.S. Riggs, Automated monitoring of soil respiration: a moving chamber design, Soil Sci. Soc. Am. J., 67, 1266-1271, 2003.

Ellis, A.J. and W.A.J. Mahon, Chemistry and Geothermal Systems, Academic Press, New York, 1977.

Evans, W. C., M. L. Sorey, A. C. Cook, B. M. Kennedy, D. L. Shuster, E. M. Colvard, L. D. Wjite, and M. L. Huebner, Tracing and quantifying magmatic carbon discharge in cold groundwaters: lessons learned from Mammoth Mountain, USA, J. Volcanol. Geother, Res., 114, 291-312, 2002.

Farrar, C. D., M. L. Sorey, W. C. Evans, J. F. Howle, B. D. Kerr, B. M. Kennedy, Y. King, and J. R. Southon, Forest-killing diffuse $\mathrm{CO}_{2}$ emission at Mammoth Mountain as a sign of magmatic unrest, Nature, 376, 675-678, 1995. 
Faure, G., Principles of Isotope Geochemistry, John Wiley and Sons, New York, NY, 1986.

Favara, R. S. Giammanco, S. Inguaggiatio, G. Pecoraino, Preliminary estimate of $\mathrm{CO}_{2}$ output from Pantelleria Island volcano (Sicily, Italy): evidence of active mantle degassing, Appl. Geochem., 16, 883-894, 2001.

Foken, Th. and B. Wichura, Tools for quality assessment of surface-based flux measurements, Agric. For. Meteorol., 78, 83-105, 1996.

Gerlach, T.M., M.P. Doukas, K.A. McGee, and R. Kessler, Soil efflux and total emission rates of magmatic $\mathrm{CO}_{2}$ at the Horseshoe Lake tree kill, Mammoth Mountain, California, Chem Geol., 177, 101-116, 2001.

Gouldin, M.L., J.W. Munger, S.-M. Fan, B.C. Daube, and S.C. Wofsy, Measurements of carbon sequestration by long-term eddy covariance: methods and a critical evaluation of accuracy, Global Change Biology, 2, 169-182, 1996.

Gouldin, M.L. and P.M. Crill, Automated measurements of $\mathrm{CO}_{2}$ exchange at the moss surface of a black spruce forest, Tree Physiology, 17, 537-542, 1997.

Hernandez, P.A., J.M. Salazar, Y. Shimoike, T. Mori, K. Notsu, and N. Perez, Diffuse emission of $\mathrm{CO}_{2}$ from Miyakejima volcano, Japan, Chem. Geol., 177, 175-185, 2001.

Hinkle, M.E., Environmental conditions affecting concentrations of $\mathrm{He}, \mathrm{CO}_{2}, \mathrm{O}_{2}$, and $\mathrm{N}_{2}$ in soil gases, Appl. Geochem., 9, 53-63, 1994.

Isaaks, E.H. and R.M. Srivastava, An Introduction to Applied Geostatistics, Oxford University Press, New York, NY, 1989.

Keller, C.K., Hydrogeochemistry of a clayey till, 2, Sources of $\mathrm{CO}_{2}$, Water Resour. Res., 27, 2555-2564, 1991.

Keller, C.K. and D.H. Bacon, Soil respiration and georespiration distinguished by transport analyses of vadose $\mathrm{CO}_{2},{ }^{13} \mathrm{CO}_{2}$, and ${ }^{14} \mathrm{CO}_{2}$, Global Biogeochem. Cycles, 12, 361-372, 1998.

Klusman, R.W., J.N. Moore, and M.P. LeRoy, Potential for surface gas flux measurements in exploration and surface evaluation of geothermal resources, Geothermics, 29, 637-670, 2000.

Koepenick, K.W., S.L. Brantley, J.M. Thompson, G.L. Rowe, A.A. Nyblade, and C. Moshy, Volatile emissions from the crater and flank of Oldoinyo Lengai volcano, Tanzania, $J$. Geophys. Res., 101, 13,819-13,830, 1996.

Kucera, C.L. and D.L. Kirkham, Soil respiration studies in tallgrass prairie in Missouri, Ecology, 52, 912-915, 1971.

Lenschow, D.L., Micrometeorological techniques for measuring biosphere-atmosphere trace gas 
exchange. In Biogenic Trace Gases: Measuring Emissions from Soil and Water edited by P.A. Matson and R.C. Harriss, Blackwell Science, Cambridge, 126-163, 1995.

Lewicki, J.L., W.C. Evans, G.E. Hilley, M.L. Sorey, J.D. Rogie, and S.L. Brantley, Shallow soil $\mathrm{CO}_{2}$ flow along the San Andreas and Calaveras faults, California, J. Geophys. Res., 108, ECV 3-1 - ECV 3-14, 2003a.

Lewicki, J.L., C. Connor, K. St-Amand, J. Stix, and W. Spinner, Self-potential, soil $\mathrm{CO}_{2}$ flux, and temperature on Masaya volcano, Nicaragua, Geophys. Res. Lett., 30, 1817, 2003 b.

LI-COR Product Information Brochure, 2003. http://env.licor.com.

Magee, J.W., J.A. Howley, and J.F. Ely, A predictive model for the thermophysical properties of carbon dioxide rich mixtures, Research Report RR-136, Gas Processors Assoc., Tulsa OK, 35 pp., 1994.

Martini, B.A., D.C. Potts, E.A. Silver, and W.L. Pickles, Hyperspectral Remote Sensing for Research and Monitoring in Active Volcanic Regions: Long Valley Caldera, CA. EOS Trans. Am. Geophys. Union, Fall Meeting p. F1385, 2000.

Massmann, J., and D. Farrier, Effects of atmospheric pressures on gas transport in the vadose zone, Water Resour. Res., 28, 777-791, 1992.

Massmann, W.J. and X. Lee, Eddy covariance flux corrections and uncertainties in long term studies of carbon and energy exchanges, Agric-For-Meteorol., 113, 121-144, 2002.

McKenna, J.R., and D.D. Blackwell, Numerical modeling of transient Basin and Range extensional geothermal systems, Geothermics, 33, 457-476, 2004.

Mogensen, V.O., Field measurements of dark respiration rates of roots and aerial parts in Italian ryegrass and barley, J. Appl. Ecol., 14, 243-252, 1977.

Mosier, A.R., Chamber and isotope techniques, in Exchange of trace gases between ecosystems and the atmosphere, edited by M.O. Andreae, and D.S. Schimel, J. Wiley and Sons, 1989.

Norman, J.M., R. Garcia, and S.B. Verma, Soil surface $\mathrm{CO}_{2}$ fluxes and the carbon budget of a grassland, J. Geophys. Res., 97, 18,845-18,853, 1992.

NIST (National Institute of Science and Technology), NIST Database 14 Mixture Property Database, version 9.08, U.S. Department of Commerce, Oct. 1992.

Oldenburg, C.M., and K. Pruess, Simulation of propagating fronts in geothermal reservoirs with the implicit Leonard total variation diminishing scheme, Geothermics, 29, 1125, 2000.

Oldenburg, C.M., J.L. Lewicki, and R.P. Hepple, Near-surface monitoring strategies for carbon dioxide storage verification, Lawrence Berkeley National Laboratory Report LBNL-54089, 
2003.

Oldenburg, C.M., and A.J.A. Unger, On leakage and seepage from geologic carbon sequestration sites: unsaturated zone attenuation, Vadose Zone Journal, 2, 287-296, 2003.

Oldenburg, C.M., and A.J.A. Unger, Coupled vadose zone and atmospheric surface-layer transport of $\mathrm{CO}_{2}$ from geologic carbon sequestration seepage simulation, Vadose Zone Journal, 3, 848-857, 2004.

O’Leary, M.H., Carbon isotopes in photosynthesis, Bioscience, 38, 328-336, 1988.

Oskarsson, N., K. Palsson, H. Olafsson, and T. Ferreira, Experimental monitoring of carbon dioxide by low power IR-sensors: Soil degassing in the Funas Volcanic Centre, Azores, J. Volcanol. Geotherm. Res., 92, 195-207, 1999.

Osozawa, S. and S. Hasegawa, Diel and seasonal changes in carbon dioxide concentration and flux in an andisol, Soil Science, 160, 117-124, 1995.

Parada, C.B., A. Long, and S.N. Davis, Stable-isotopic compositions of soil carbon dioxide in the Tucson Basin, Arizona, U.S.A., Isot. Geosci., 1, 219-236, 1983.

Pruess, K., C. Oldenburg, and G. Moridis, TOUGH2 User's Guide Version 2.0, Lawrence Berkeley National Laboratory Report LBNL-43134, 197 pp., November 1999.

Radziemski, L. J., Richard W. Solarz, and Jeffrey A. Paisner, Laser Spectroscopy and Its Applications, Optical Engineering Series No. 11, Marcel Dekker, NY, 1987.

Reimer, G.M. Use of soil-gas helium concentrations for earthquake prediction: Limitations imposed by diurnal variation, J. Geophys. Res., 85, 3107-3114, 1980.

Rogie, J.D., D.M. Kerrick, M.L. Sorey, G. Chiodini, and D.L. Galloway, Dynamics of carbon dioxide emission at Mammoth Mountain, California, Earth Planet. Sci. Lett., 188, 535-541, 2001.

Rolston, D.E., Gas flux, in "Methods of Soil Analysis, 1, Physical and Mineralogical Methods," edited by A. Klute, Am. Soc. Agron. Monogr., 9, 1103-1119, 1986.

Salazar, J. M., P. A. Hernandez, N. M. Perez, G. Melian, J. Alvarez, F. Segura, and K. Notsu, Diffuse emission of carbon dioxide from Cerro Negro volcano, Nicaragua, Central America, Geophys. Res. Lett., 22, 4275-4278, 2001.

Schery, S. D., D. H. Gaeddert, and M. H. Wilkening, Factors affecting exhalation of radon from a gravelly sandy loam, J. Geophys. Res., 89, 7299-7309, 1984.

Schlessinger, M., Infrared Technology Fundamentals, $2^{\text {nd }}$ Ed., Revised and Expanded, Optical Engineering Series No.46, Marcel Dekker, Inc., New York, NY, 1995. 
Shuler, P.J. and Y. Tang, Atmospheric $\mathrm{CO}_{2}$ Monitoring Systems - A Critical Review of Available Techniques and Technology Gaps: Report for SMV Group, The $\mathrm{CO}_{2}$ Capture Project (CCP), The Carbon Capture Project, 2002.

Singh, J.S. and S.R. Gupta, Plant decomposition and soil respiration in terrestrial ecosystems, Bot. Rev., 43, 449-528, 1977.

Slade, D.H., (editor), Meteorology and Atomic Energy 1968, Chapter 2, U.S. Atomic Energy Commission, 1968.

Sorey, M.L., W.C. Evans, B.M. Kennedy, C.D. Farrar, L.J. Hainsworth, and B. Hausback, Carbon dioxide and helium emissions from a reservoir of magmatic gas beneath Mammoth Mountain, California, J. Geophys. Res., 103, 15,303-15,323, 1998.

Sorey, M.L., C.D. Farrar, W.C. Evans, D.P. Hill, R.A. Bailey, J.W. Hendley II, and P.H. Stauffer, Invisible $\mathrm{CO}_{2}$ gas killing trees at Mammoth Mountain, California, U.S. Geological Survey Fact Sheet 172-96, 4pp., 1996. http://wrgis.wr.usgs.gov/fact-sheet/fs172-96/.

Southon, J.R., J.S. Vogel, S.E. Trumbore, J.C. Davis, M.L. Roberts, M.W. Caffee, R.C. Finkel, I.D. Proctor, D.W. Heikkinen, A.J. Berno, and R.S. Hornady, Progress in AMS measurements at the LLNL spectrometer, Radiocarbon, 34, 473-477, 1993.

Spycher, N., K. Pruess, and J. Ennis-King, $\mathrm{CO}_{2}-\mathrm{H}_{2} \mathrm{O}$ mixtures in geological sequestration of $\mathrm{CO}_{2}$. Assesment and calculation of mutual solubilities from 12 to $100{ }^{\circ} \mathrm{C}$ and up to $600 \mathrm{bar}$, Geochimica et Cosmochimica Acta, 67(16), 3015-3031, 2003.

Trumbore, S., Age of soil organic matter and soil respiration: radiocarbon constraints on belowground dynamics, Ecological Applications, 10, 399-411, 2000.

USGS, Measuring volcanic gases: emission rates of sulfur dioxide and carbon dioxide in volcanic plumes, 2000a. http://volcanoes.usgs.gov/About/What/Monitor/Gas/plumes.html.

USGS, Measuring volcanic gases: soil efflux, 2000b. http://volcanoes.usgs.gov/About/What/Monitor/Gas/soil.html.

van Genuchten, M.T., A closed-form equation for predicting the hydraulic conductivity of unsaturated soils, Soil Sci. Soc. Am. J., 44, 892-898, 1980.

Vargaftik, N.B., Y.K. Vinogradov, and V.S. Yargin, Handbook of Physical Properties of Liquids and Gases, Third Edition, Begell House, New York, 1359 pp., 1006, 1996.

Werner, C., S.L. Brantley, and K. Boomer, $\mathrm{CO}_{2}$ emissions related to the Yellowstone volcanic system 2. Statistical sampling, total degassing, and transport mechanisms, J. Geophys. Res., 105, 10,831-10,846, 2000. 
Wiant, H.V., Influence of temperature on the rate of soil respiration, J. For., 65, 489-490, 1967a.

Wiant, H.V., Influence of moisture content on the "soil respiration", J. For., 65, 902-903, 1967b.

Wood, W.W. and M.J. Petraitis, Origin and distribution of carbon dioxide in the unsaturated zone of the southern high plains of Texas, Water Resour. Res., 20, 1193-1208, 1984.

Wood, B.D., C.K. Keller, and D.L. Johnstone, In situ measurement of microbial activity and contrals on microbial $\mathrm{CO}_{2}$ production in the unsaturated zone, Water Resour. Res., 29, 647$659,1993$. 


\section{TABLES}

Table 4.1. Properties of the coupled subsurface-surface-layer model system.

\begin{tabular}{|c|c|}
\hline Property & Value \\
\hline \multicolumn{2}{|l|}{ Subsurface } \\
\hline Subsurface region extent $(x \times y \times z)$ & $1 \mathrm{~km} \times 1 \mathrm{~m} \times 124 \mathrm{~m}$ \\
\hline Discretization $(N x \times N y \times N z)$ & $67 \times 1 \times 31$ \\
\hline Standard deviation of $\log k$ & 0.70 \\
\hline Minimum, maximum $k$ & $1 \times 10^{-14}, 1 \times 10^{-10} \mathrm{~m}^{2}$ \\
\hline Correlation length of $k$ in $Y$-, Z-direction & $45,1 \mathrm{~m}$ \\
\hline Porosity $(\phi)$ & 0.2 \\
\hline Infiltration rate $(i)$ & $0.0 \mathrm{~cm} \mathrm{yr}^{-1}$ \\
\hline Temperature (isothermal) & $15^{\circ} \mathrm{C}$ \\
\hline $\mathrm{CO}_{2}$ source location $(x, y)$ & $293.5 \mathrm{~m},-86 \mathrm{~m}$ \\
\hline Source $\mathrm{CO}_{2}$ migration rate & 1. $\times 10^{-4}, 1 . \times 10^{-5}, 1 . \times 10^{-6} \mathrm{~kg} \mathrm{~s}^{-1}$ \\
\hline Residual water sat. $\left(S_{l r}\right)$ & 0.1 \\
\hline Residual gas sat. $\left(S_{g r}\right)$ & 0.01 \\
\hline van Genuchten (1980) $\alpha$ & $1 \times 10^{-4} \mathrm{~Pa}^{-1}$ \\
\hline van Genuchten (1980) m & 0.2 \\
\hline \multicolumn{2}{|l|}{ Surface Layer } \\
\hline Surface-layer region extent $(x \times y \times z)$ & $1 \mathrm{~km} \times 1 \mathrm{~m} \times 62 \mathrm{~m}$ \\
\hline Discretization $(N x \times N y \times N z)$ & $67 \times 1 \times 31$ \\
\hline Pressure in surface layer & $1 \mathrm{bar}$ \\
\hline Temperature & $15^{\circ} \mathrm{C}$ \\
\hline Velocity profile & Logarithmic \\
\hline Reference velocity at $z=10 \mathrm{~m}$ & 1 or $3 \mathrm{~m} \mathrm{~s}^{-1}$ \\
\hline Friction velocity for $v=1 \mathrm{~m} \mathrm{~s}^{-1}$ & $0.0861 \mathrm{~m} \mathrm{~s}^{-1}$ \\
\hline Friction velocity for $v=3 \mathrm{~m} \mathrm{~s}^{-1}$ & $0.261 \mathrm{~m} \mathrm{~s}^{-1}$ \\
\hline Roughness length $\left(z_{0}\right)$ & $0.1 \mathrm{~m}$ \\
\hline
\end{tabular}


Table 7.1. Chemical and isotopic signatures related to $\mathrm{CO}_{2}$ derived from different sources.

\begin{tabular}{|c|c|c|c|c|c|}
\hline $\mathrm{CO}_{2}$ source & $\begin{array}{c}\delta^{13} \mathrm{C}_{\mathrm{CO} 2} \\
\% 0 \\
\%\end{array}$ & $\begin{array}{c}\Delta{ }^{14} \mathrm{C}_{\mathrm{CO} 2} \\
\% 0\end{array}$ & $\begin{array}{l}\text { Near- } \\
\text { surface } \\
\mathrm{CO}_{2} \text { conc. }\end{array}$ & $\begin{array}{l}\mathrm{CO}_{2} \text { conc. } \\
\text { profile with } \\
\text { depth }\end{array}$ & $\begin{array}{l}\mathrm{O}_{2} \text { conc. } \\
\text { profile with } \\
\text { depth }\end{array}$ \\
\hline Atmosphere & -7 & 70 & Low & - & - \\
\hline $\begin{array}{l}\text { Plant root } \\
\text { respiration and } \\
\text { oxidative decay } \\
\text { of young soil } \\
\text { organic matter }\end{array}$ & $\begin{array}{l}C_{3}:-24 \text { to }-38 \\
C_{4}:-6 \text { to }-19\end{array}$ & $\geq 70$ & $\begin{array}{l}\text { Low to } \\
\text { moderate }\end{array}$ & $\begin{array}{l}\text { Increasing } \\
\text { through soil } \\
\text { zone }\end{array}$ & $\begin{array}{l}\text { Decreasing } \\
\text { through soil } \\
\text { zone }\end{array}$ \\
\hline $\begin{array}{l}\text { Oxidative } \\
\text { decay of } \\
\text { ancient organic } \\
\text { matter }\end{array}$ & $\begin{array}{l}\mathrm{C}_{3}:-24 \text { to }-38 \\
\text { Aquatic/C } \\
-6 \text { to }-19 \\
\text { Also age } \\
\text { dependent }\end{array}$ & $\begin{array}{l}\text { Highly } \\
\text { depleted } \\
\text { to absent, } \\
\text { depending } \\
\text { on age }\end{array}$ & Low & $\begin{array}{l}\text { Increasing } \\
\text { potentially } \\
\text { through } \\
\text { vadose zone }\end{array}$ & $\begin{array}{l}\text { Decreasing } \\
\text { potentially } \\
\text { through } \\
\text { vadose zone }\end{array}$ \\
\hline $\begin{array}{l}\text { Marine } \\
\text { carbonate rocks }\end{array}$ & $0 \pm 4$ & absent & Low & $\begin{array}{l}\text { Increasing } \\
\text { through } \\
\text { vadose zone }\end{array}$ & No effect \\
\hline Geothermal & -2 to -6 & absent & $\begin{array}{l}\text { Moderate } \\
\text { to high }\end{array}$ & $\begin{array}{l}\text { Increasing } \\
\text { through } \\
\text { vadose zone }\end{array}$ & No effect \\
\hline
\end{tabular}

Conc., $\mathrm{C}_{3}$, and $\mathrm{C}_{4}$, refer to concentration, $\mathrm{C}_{3}$ plants, and $\mathrm{C}_{4}$ plants. All near-surface concentrations given are general estimates; these concentrations will be strongly dependent on the magnitude of the $\mathrm{CO}_{2}$ flux. 
Table 7.2. Properties of different case scenarios used in Monte Carlo simulations.

\begin{tabular}{llcc}
\hline & \multicolumn{1}{c}{ Permeability } & $x / A$ & $P(H)$ \\
\hline 1 & Homogeneous/isotropic & 0.1 & 0.1 \\
2 & Homogeneous/isotropic & 0.01 & 0.1 \\
3 & Homogeneous/isotropic & 0.001 & 0.1 \\
4 & Homogeneous/isotropic & 0.1 & 0.9 \\
5 & Homogeneous/isotropic & 0.01 & 0.9 \\
6 & Homogeneous/isotropic & 0.001 & 0.9 \\
7 & Heterogeneous/isotropic & 0.1 & 0.1 \\
8 & Heterogeneous/isotropic & 0.01 & 0.1 \\
9 & Heterogeneous/isotropic & 0.001 & 0.1 \\
10 & Heterogeneous/isotropic & 0.1 & 0.9 \\
11 & Heterogeneous/isotropic & 0.01 & 0.9 \\
12 & Heterogeneous/isotropic & 0.001 & 0.9 \\
\hline
\end{tabular}


Table 7.3. Mean $(\mu)$ and standard deviation $(\sigma)$ of number of measurements $(\mathrm{n})$ required to detect a soil $\mathrm{CO}_{2}$ flux anomaly within a sampling area and the associated $\mathrm{CO}_{2}$ flux threshold for different case scenarios.

\begin{tabular}{cccc}
\hline Case & $\begin{array}{c}\mu \\
\mathrm{g} \mathrm{m}^{-2} \mathrm{~d}^{-1}\end{array}$ & $\begin{array}{c}\sigma \\
\mathrm{g} \mathrm{m}^{-2} \mathrm{~d}^{-1}\end{array}$ & $\begin{array}{c}\text { Threshold } \\
\mathrm{g} \mathrm{m}^{-2} \mathrm{~d}^{-1}\end{array}$ \\
\hline 1 & 5415 & 3029 & 28 \\
2 & $>20,000$ & na & na \\
3 & $>20,000$ & na & 29 \\
4 & 1869 & 1784 & 28 \\
5 & 19,984 & 256 & na \\
6 & $>20,000$ & na & 38 \\
7 & 3407 & 1919 & na \\
8 & $>20,000$ & na & na \\
9 & $>20,000$ & na & 38 \\
10 & 1267 & 1253 & 45 \\
11 & 19,984 & 256 & na \\
12 & $>20,000$ & na & \\
\hline
\end{tabular}




\section{FIGURES}

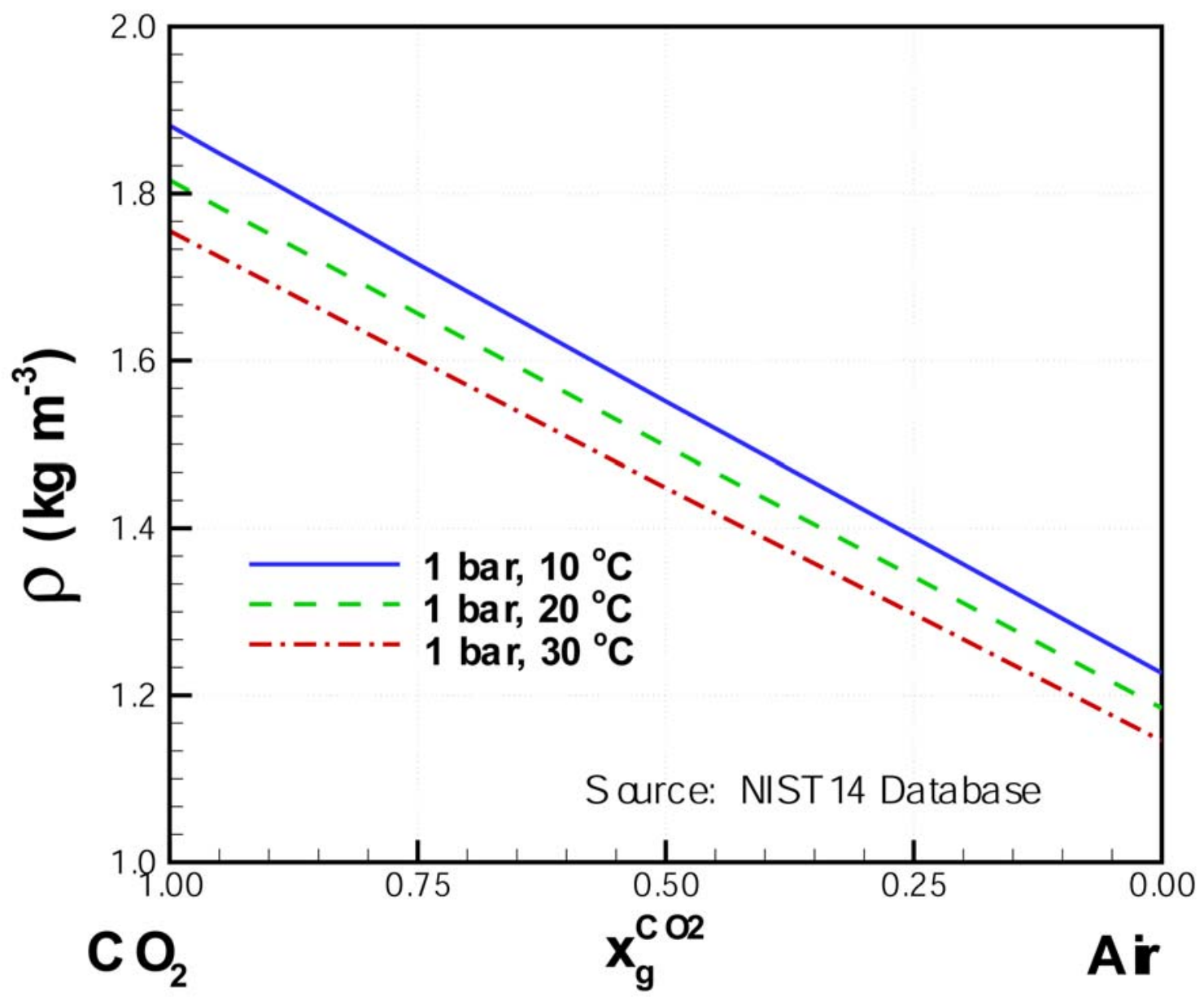

Figure 3.1. Density as a function of concentration (mole fraction) in the system $\mathrm{CO}_{2}$-air. 


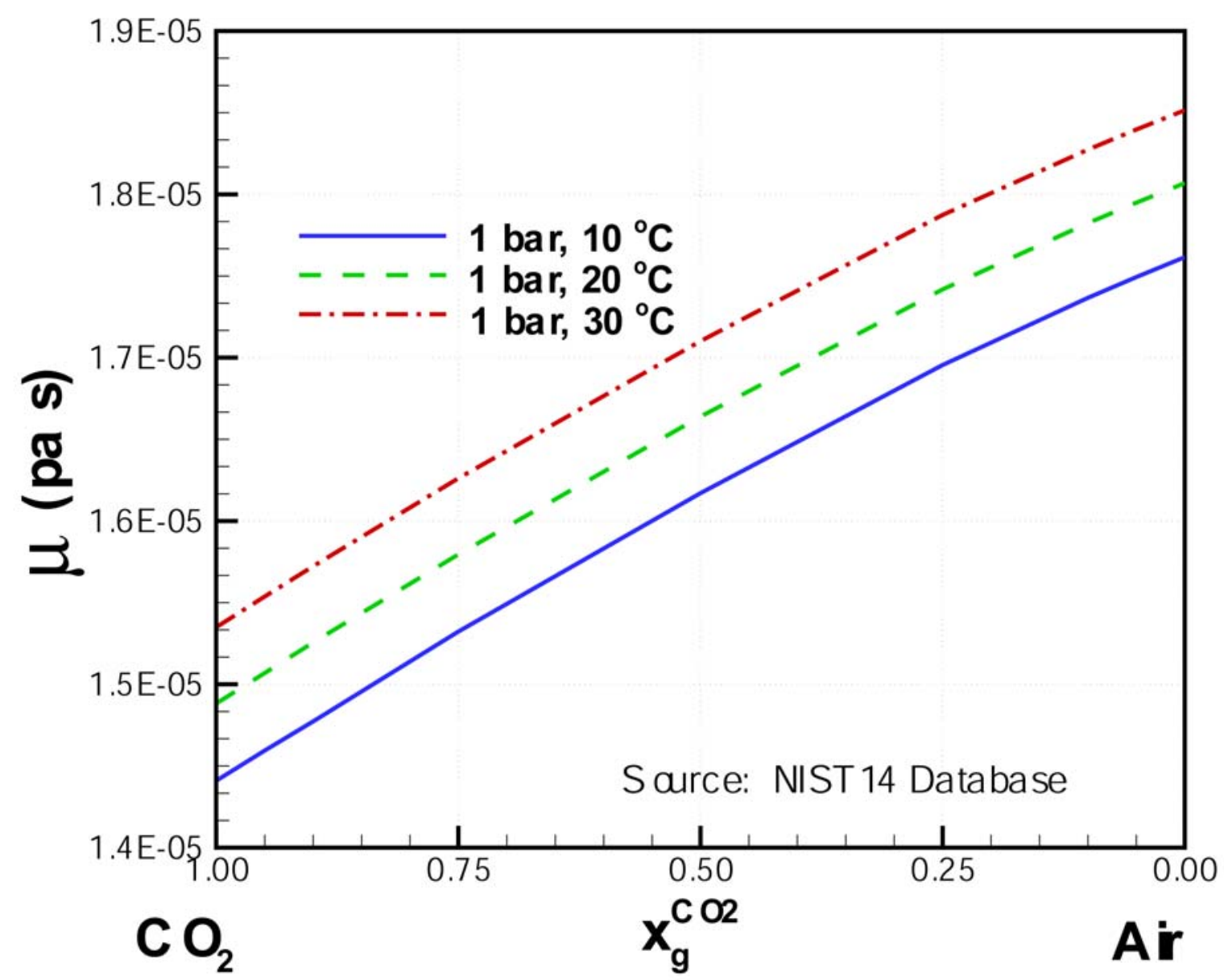

Figure 3.2. Viscosity as a function of concentration (mole fraction) in the system $\mathrm{CO}_{2}$-air. 


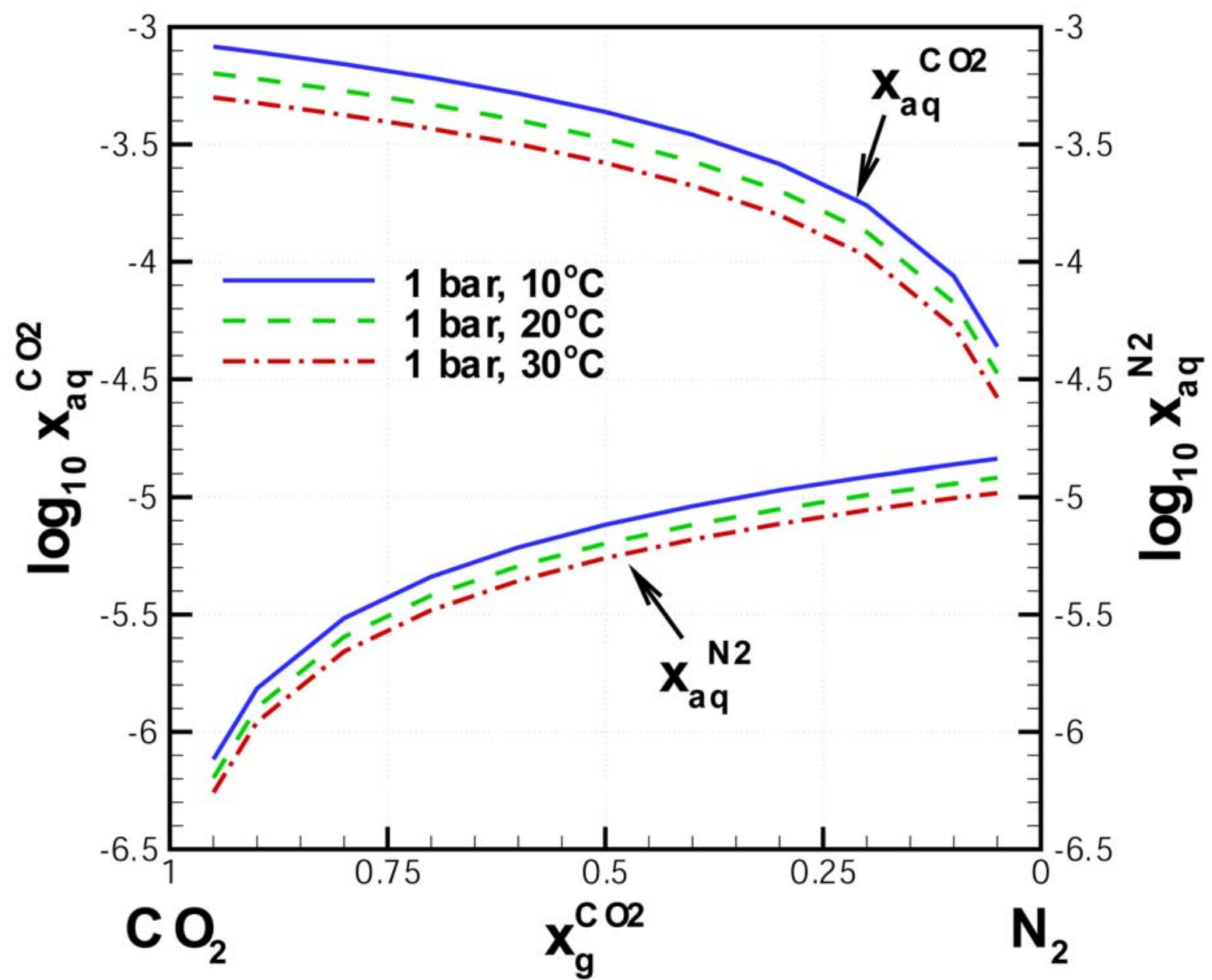

Figure 3.3. Solubility of $\mathrm{CO}_{2}$ and $\mathrm{N}_{2}$ in water (mole fraction) in gas and aqueous phases. 


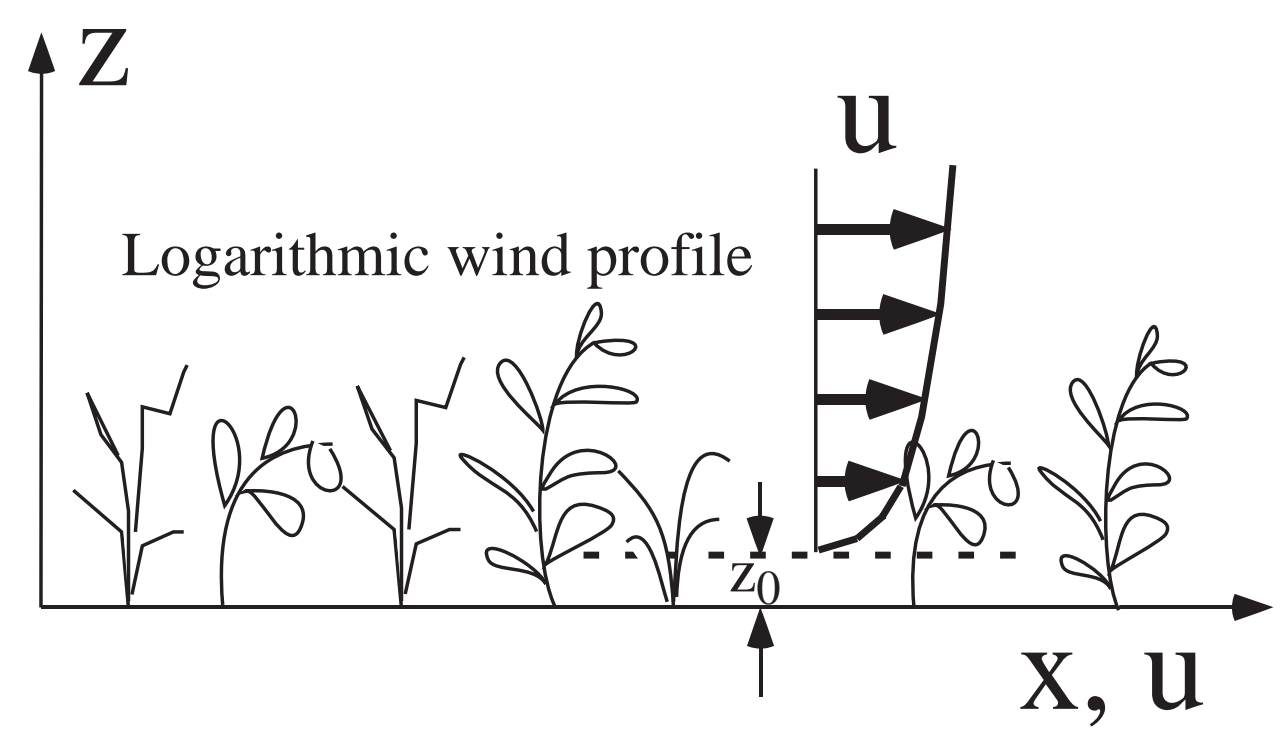

Figure 4.1 Logarithmic velocity profile for atmospheric surface layer. 


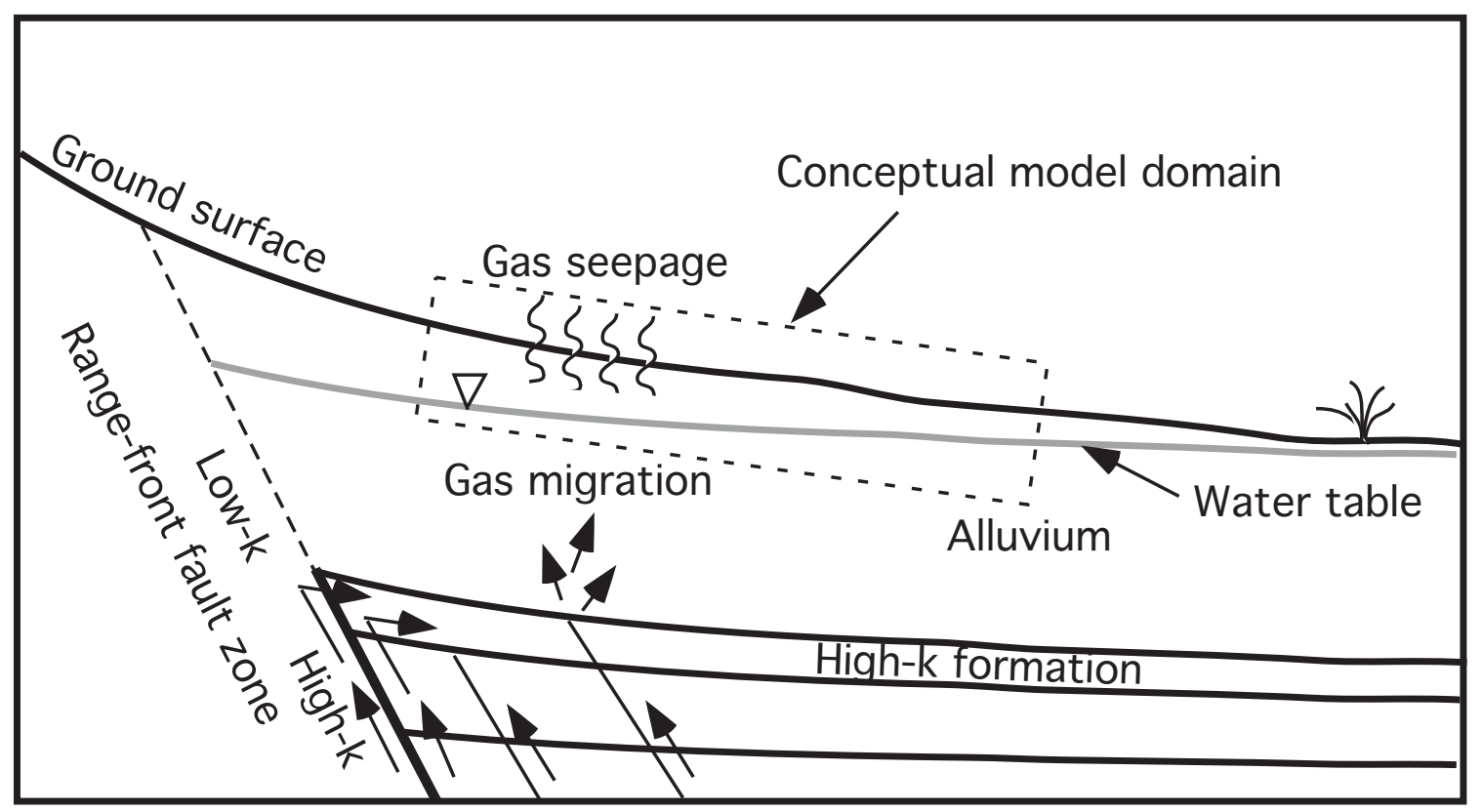

Figure 4.2. Conceptual model for gas migration from a deep hidden geothermal system. 


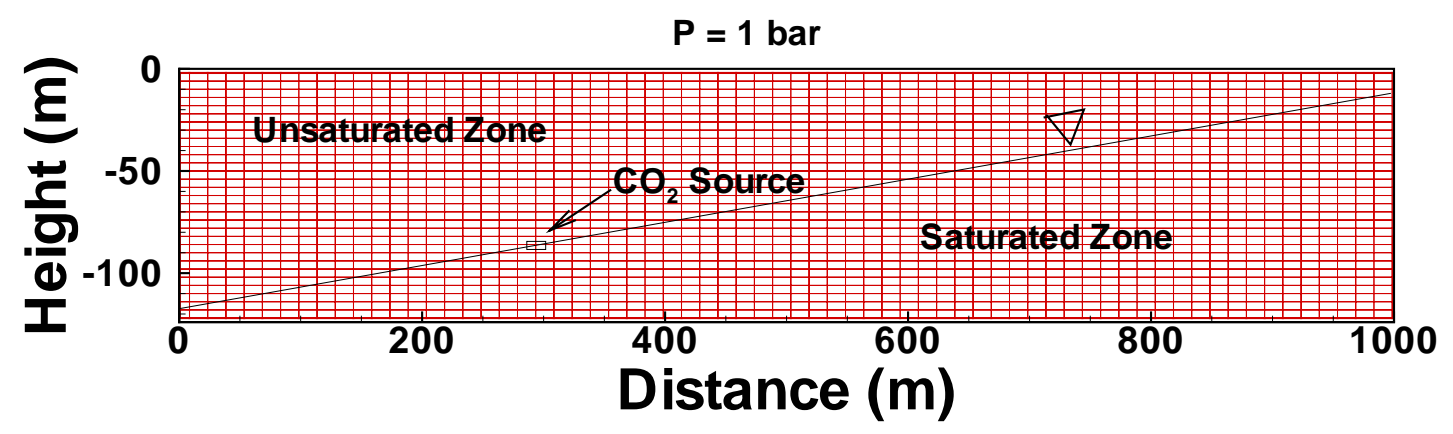

Figure 4.3. Grid and boundary conditions for the subsurface model system. Note vertical exaggeration, tilt is actually only six degrees relative to horizontal. 

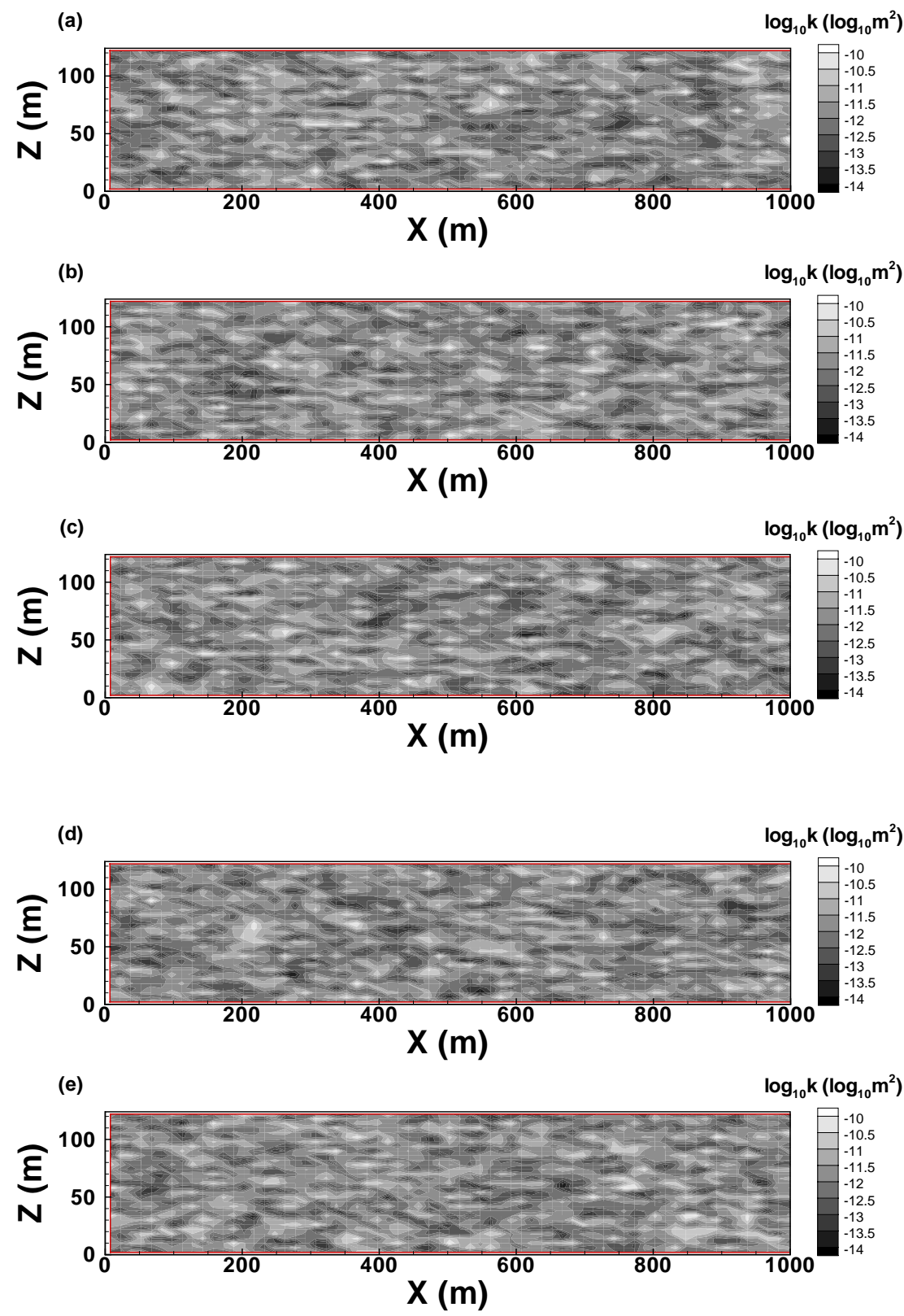

Figure 4.4. Five realizations (A-E) of permeability heterogeneity for the alluvial fan system. 


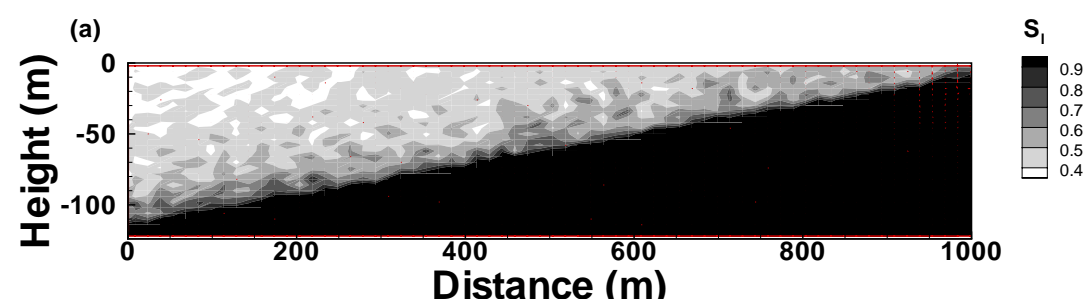

(b) $\mathbf{S}_{1}$
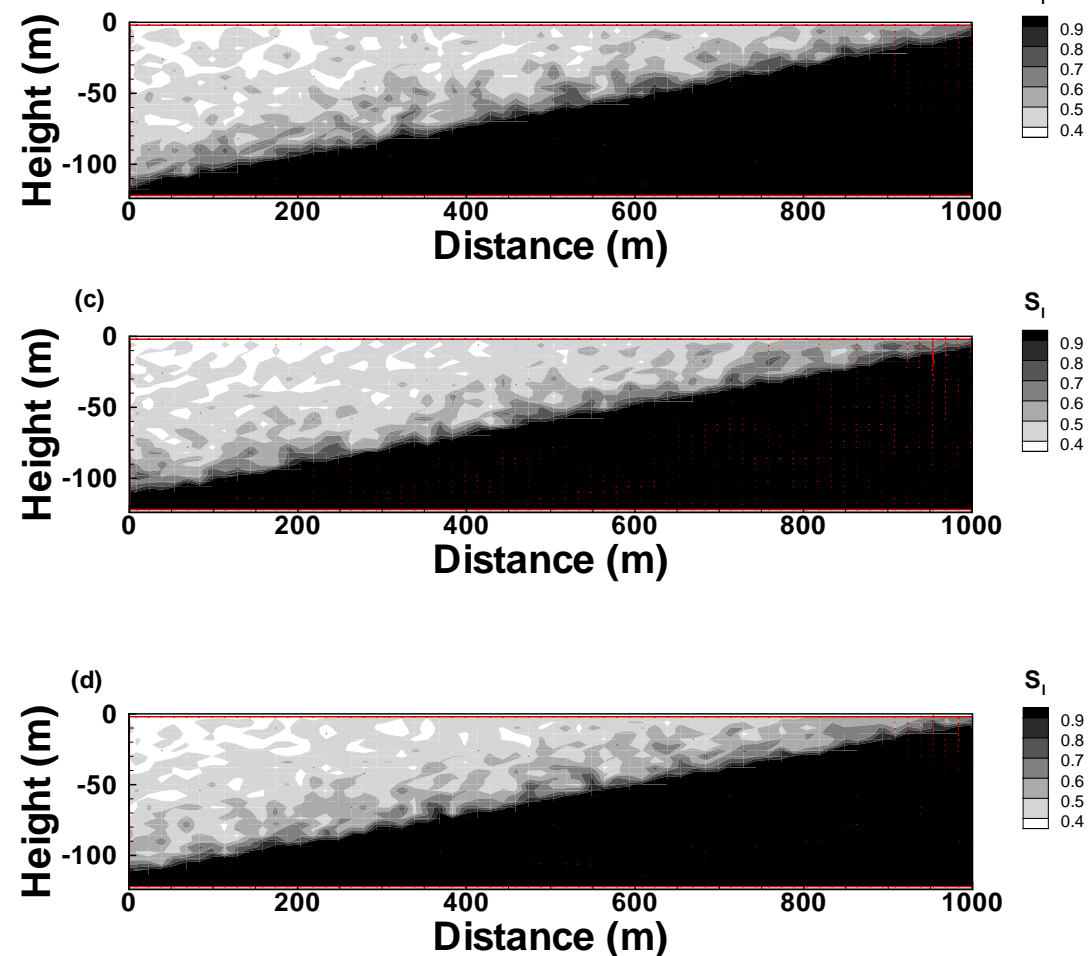

(e)

$\mathbf{S}_{1}$

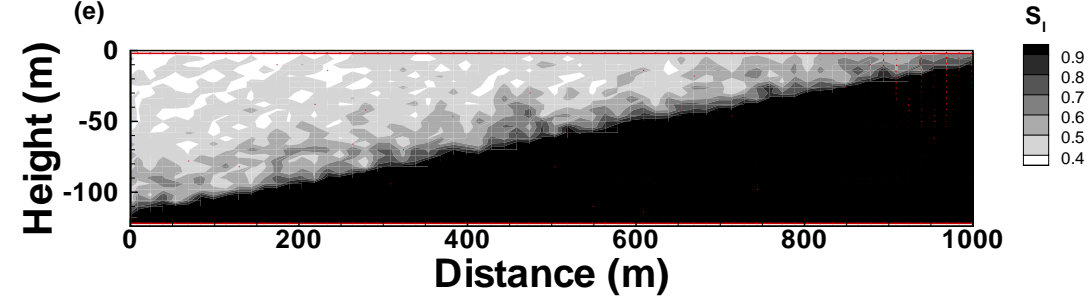

Figure 4.5. Initial liquid saturation for the five realizations (A-E). 


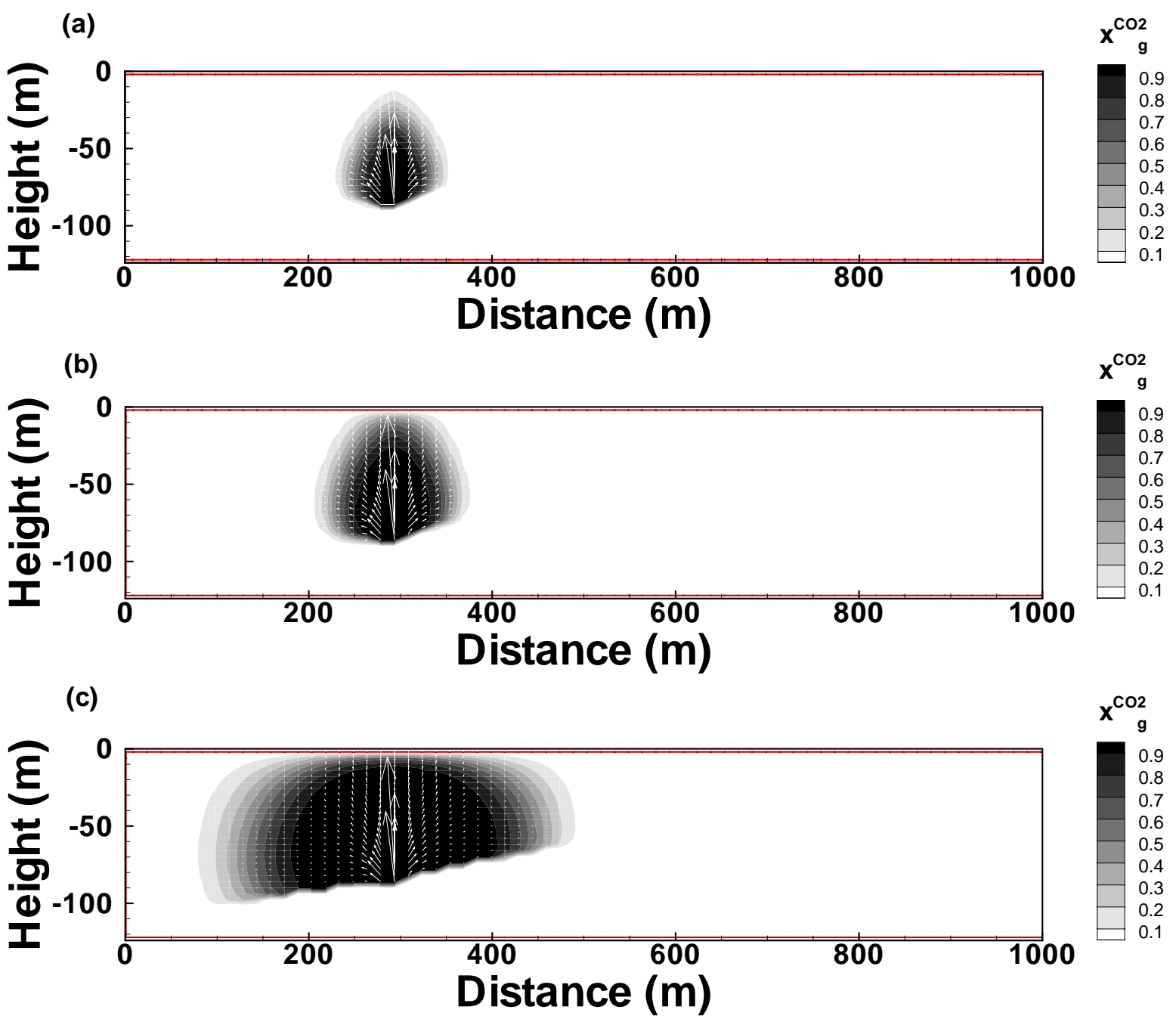

Figure 4.6. Subsurface $\mathrm{CO}_{2}$ concentrations (mole fraction) at $t=(a) 0.5$, (b) one, and (c) ten years for the homogeneous permeability field and high $\mathrm{CO}_{2}$ source flux $\left(576 \mathrm{~g} \mathrm{~m}^{-2} \mathrm{~d}^{-1}\right)$. 


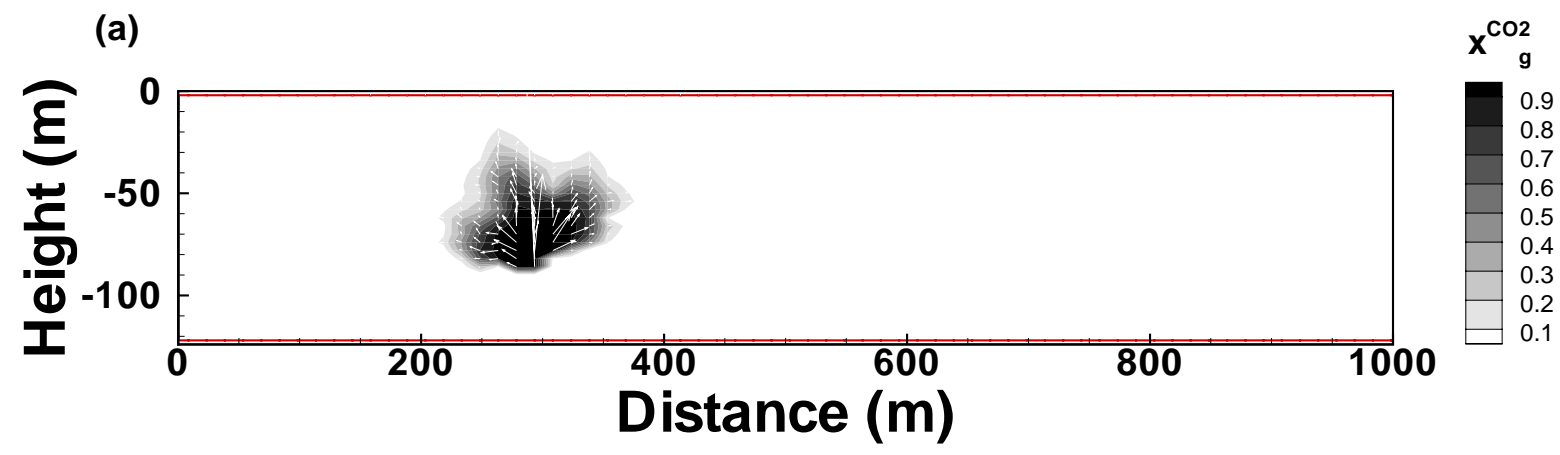

(b)

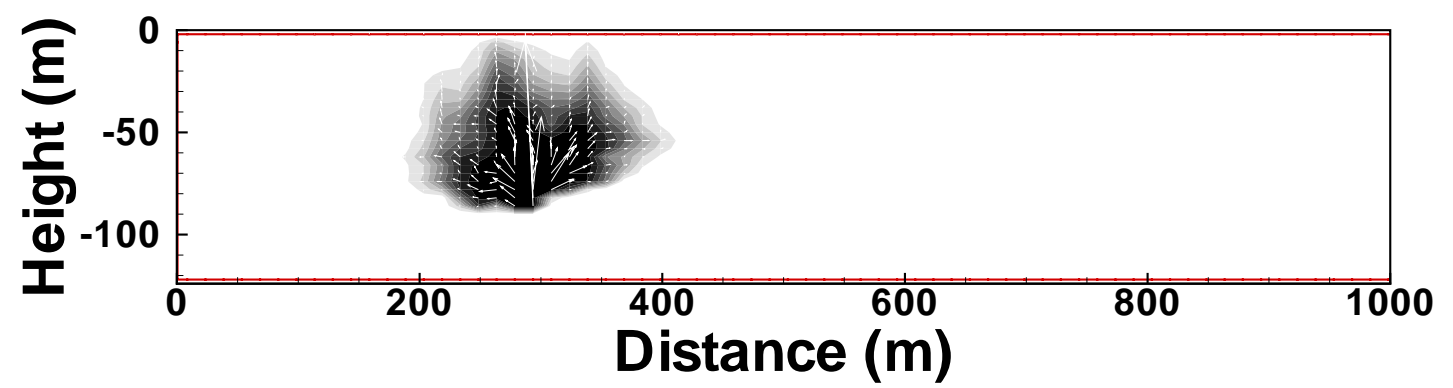

$\mathbf{x}^{\mathrm{CO} 2}$

(c)

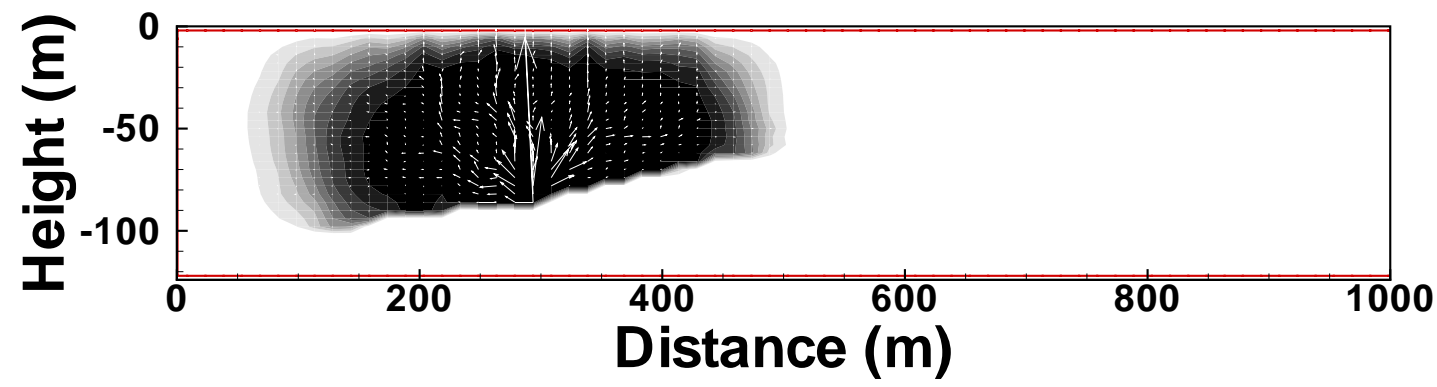

$\mathrm{X}_{\mathrm{g}}^{\mathrm{CO} 2}$

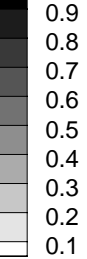

Figure 4.7. Subsurface $\mathrm{CO}_{2}$ concentrations (mole fraction) at $t=$ (a) 0.5, (b) one, and (c) ten years for permeability realization A and high $\mathrm{CO}_{2}$ source flux $\left(576 \mathrm{~g} \mathrm{~m}^{-2} \mathrm{~d}^{-1}\right)$. 
(a)
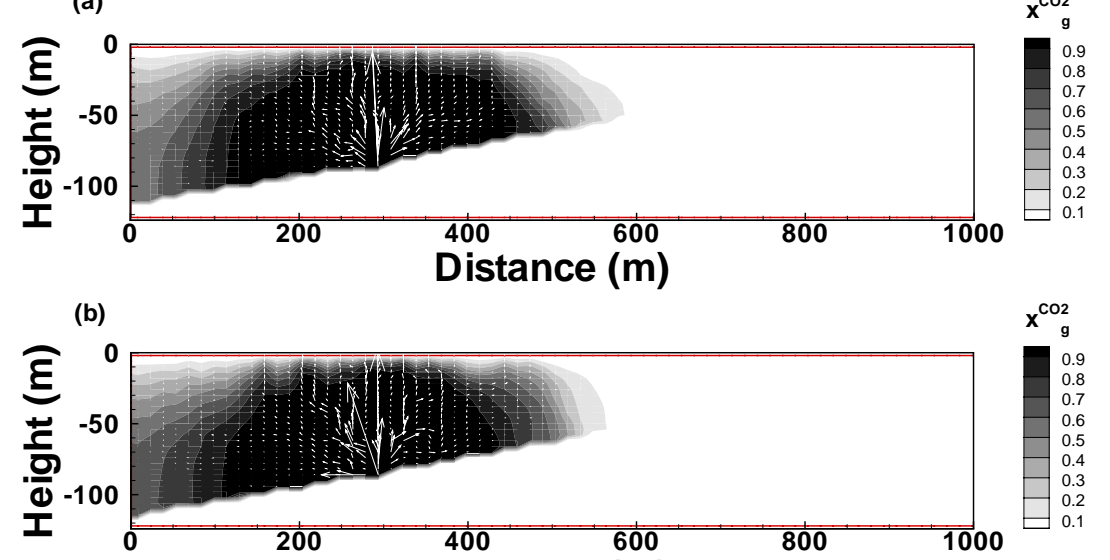

(c)

Distance (m)
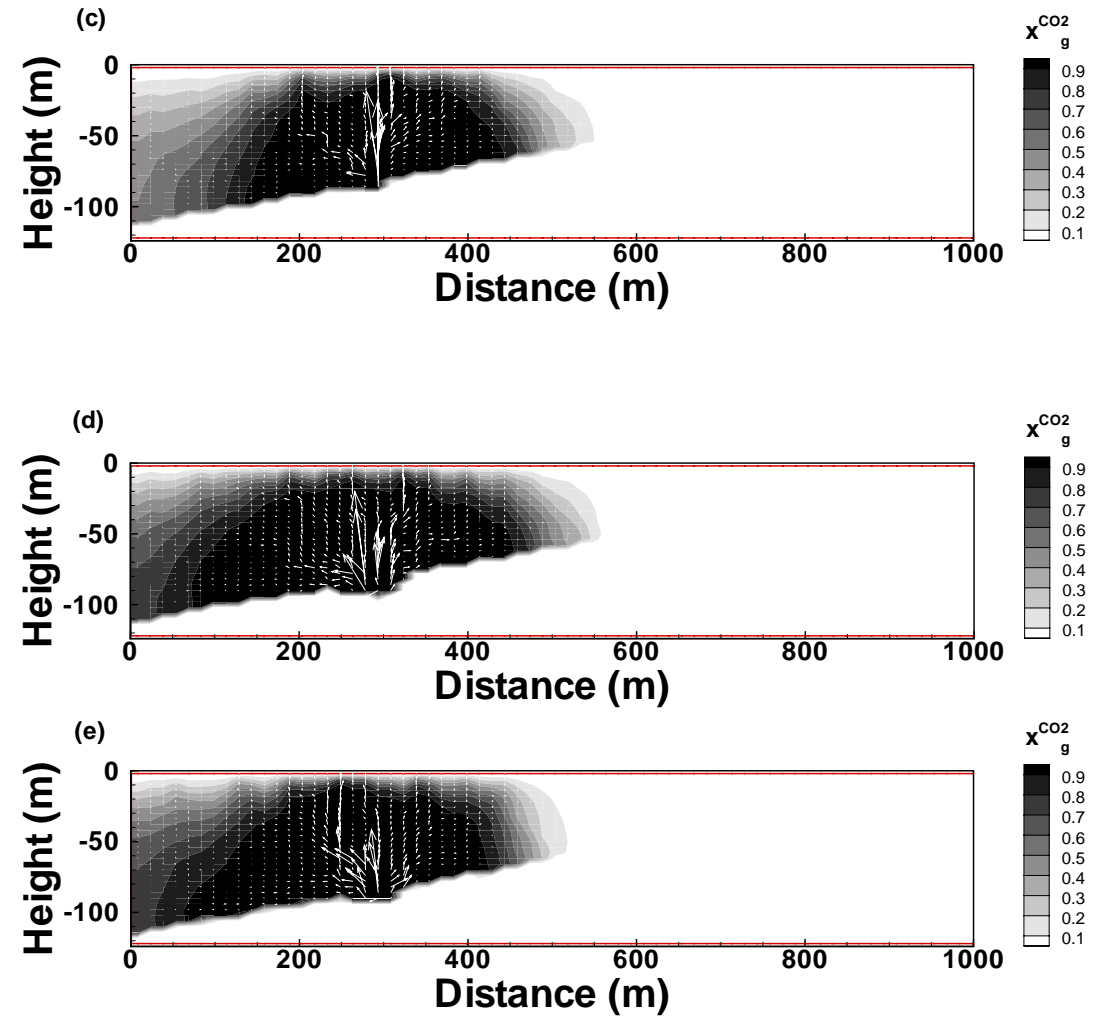

Figure 4.8. Subsurface $\mathrm{CO}_{2}$ concentrations (mole fraction) at $t=200$ years for five permeability realizations (A-E) and high $\mathrm{CO}_{2}$ source flux $\left(576 \mathrm{~g} \mathrm{~m}^{-2} \mathrm{~d}^{-1}\right)$. 


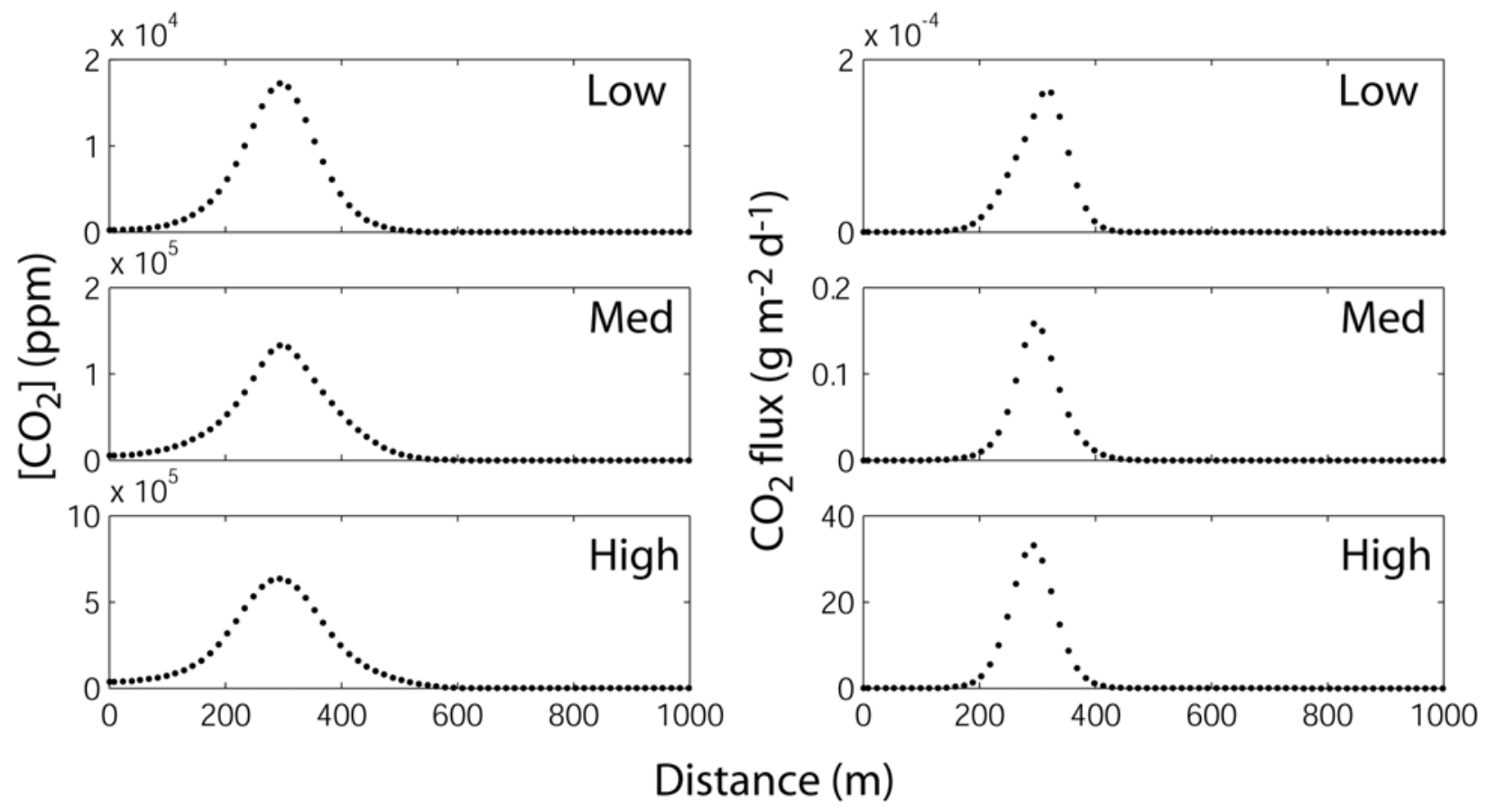

Figure 4.9. Horizontal profiles of shallow subsurface $\mathrm{CO}_{2}$ concentration ( $\left[\mathrm{CO}_{2}\right], 3 \mathrm{~m}$ depth) and surface $\mathrm{CO}_{2}$ flux for low $\left(5.76 \mathrm{~g} \mathrm{~m}^{-2} \mathrm{~d}^{-1}\right)$, medium $\left(57.6 \mathrm{~g} \mathrm{~m}^{-2} \mathrm{~d}^{-1}\right)$, and high $\left(576 \mathrm{~g} \mathrm{~m}^{-2}\right.$ $\left.d^{-1}\right) \mathrm{CO}_{2}$ source fluxes, homogeneous isotropic permeability, and $t=200$ years. 


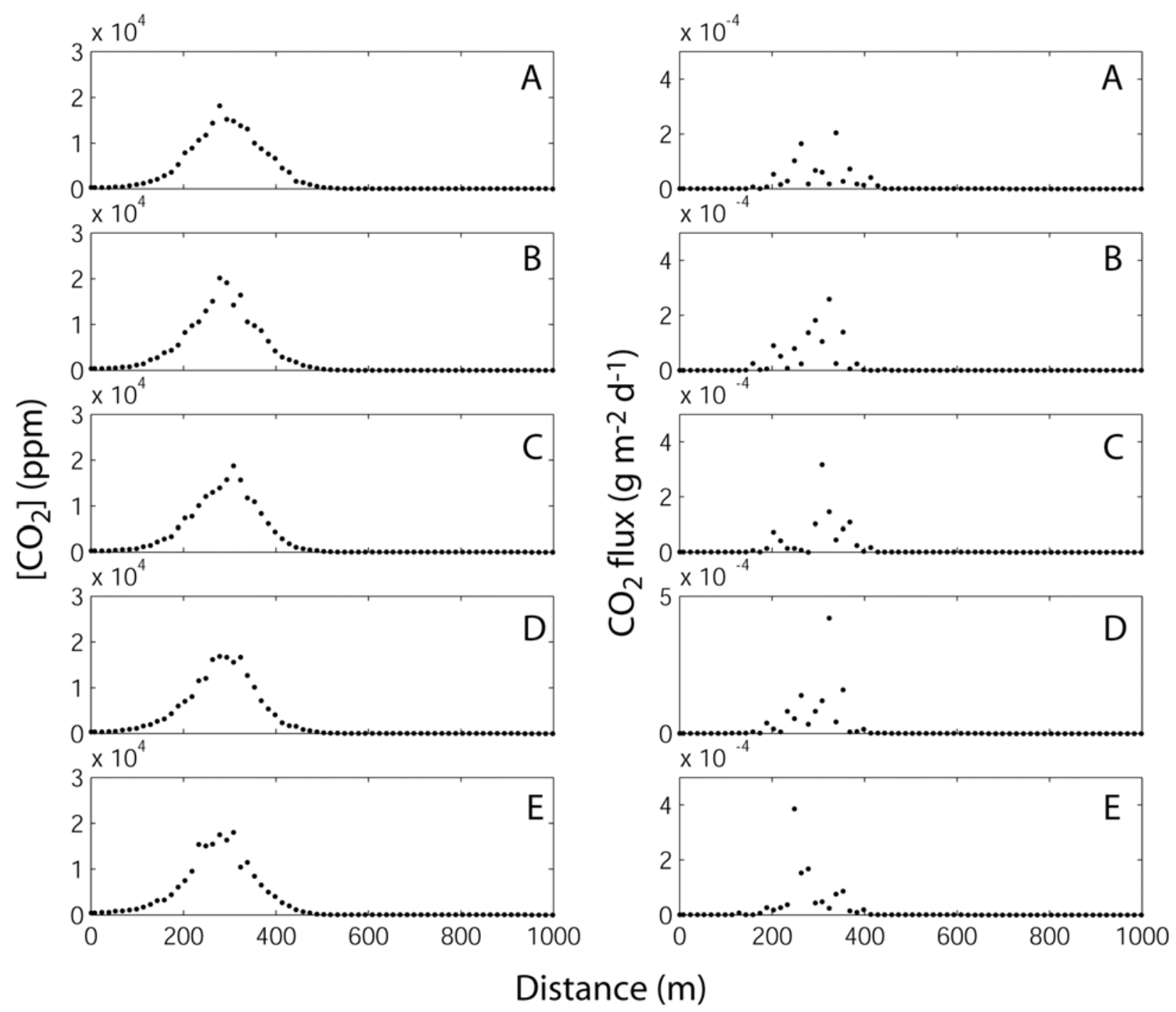

Figure 4.10. Horizontal profiles of shallow subsurface $\mathrm{CO}_{2}$ concentration $\left(\left[\mathrm{CO}_{2}\right], 3 \mathrm{~m}\right.$ depth) and surface $\mathrm{CO}_{2}$ flux for low $\left(5.76 \mathrm{~g} \mathrm{~m}^{-2} \mathrm{~d}^{-1}\right) \mathrm{CO}_{2}$ source flux, heterogeneous isotropic permeability realizations $A-E$, and $t=200$ years. 


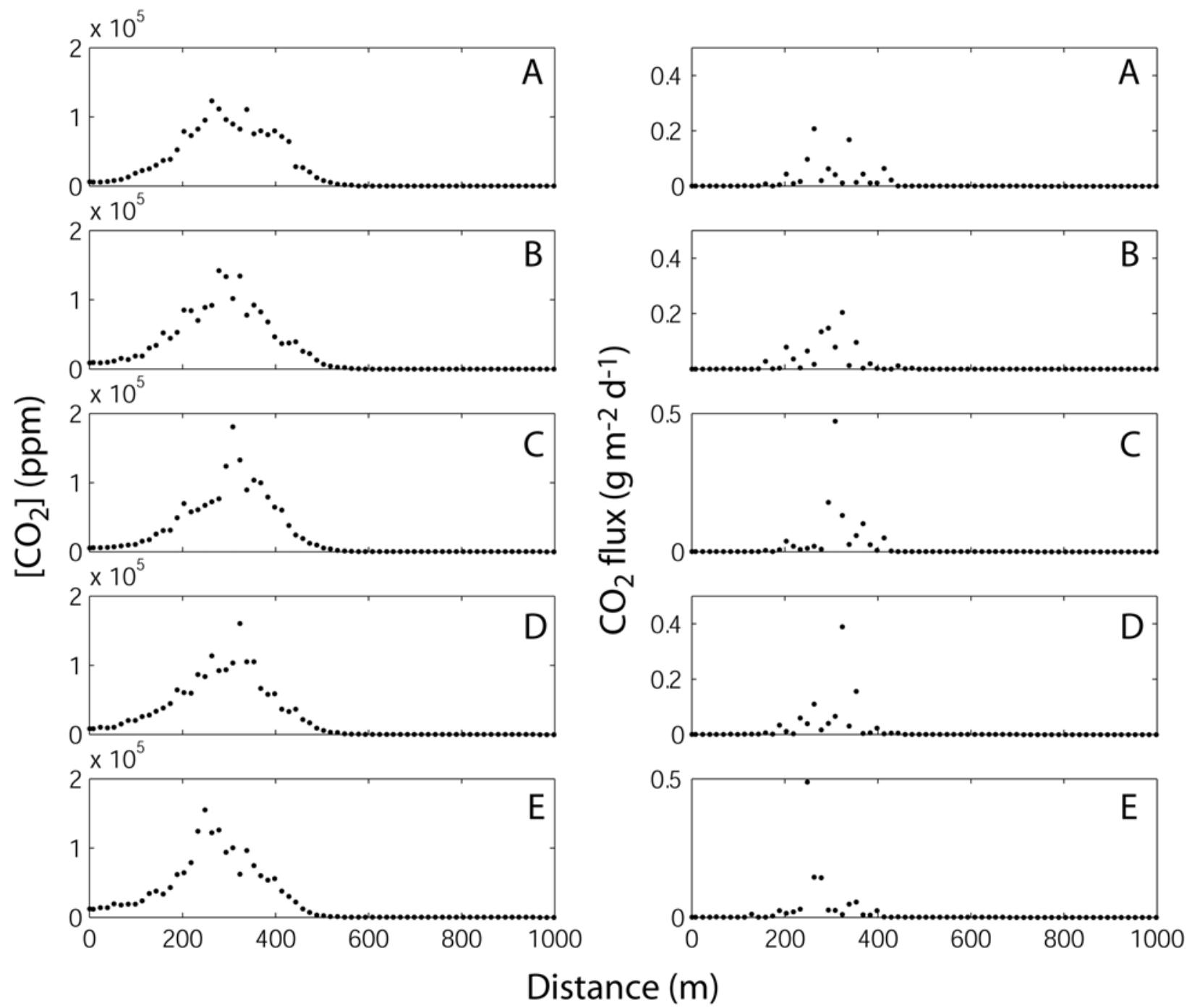

Figure 4.11. Horizontal profiles of shallow subsurface $\mathrm{CO}_{2}$ concentration $\left(\left[\mathrm{CO}_{2}\right], 3 \mathrm{~m}\right.$ depth) and surface $\mathrm{CO}_{2}$ flux for medium (57.6 $\left.\mathrm{g} \mathrm{m}^{-2} \mathrm{~d}^{-1}\right) \mathrm{CO}_{2}$ source flux, heterogeneous isotropic permeability realizations $A-E$, and $t=200$ years. 


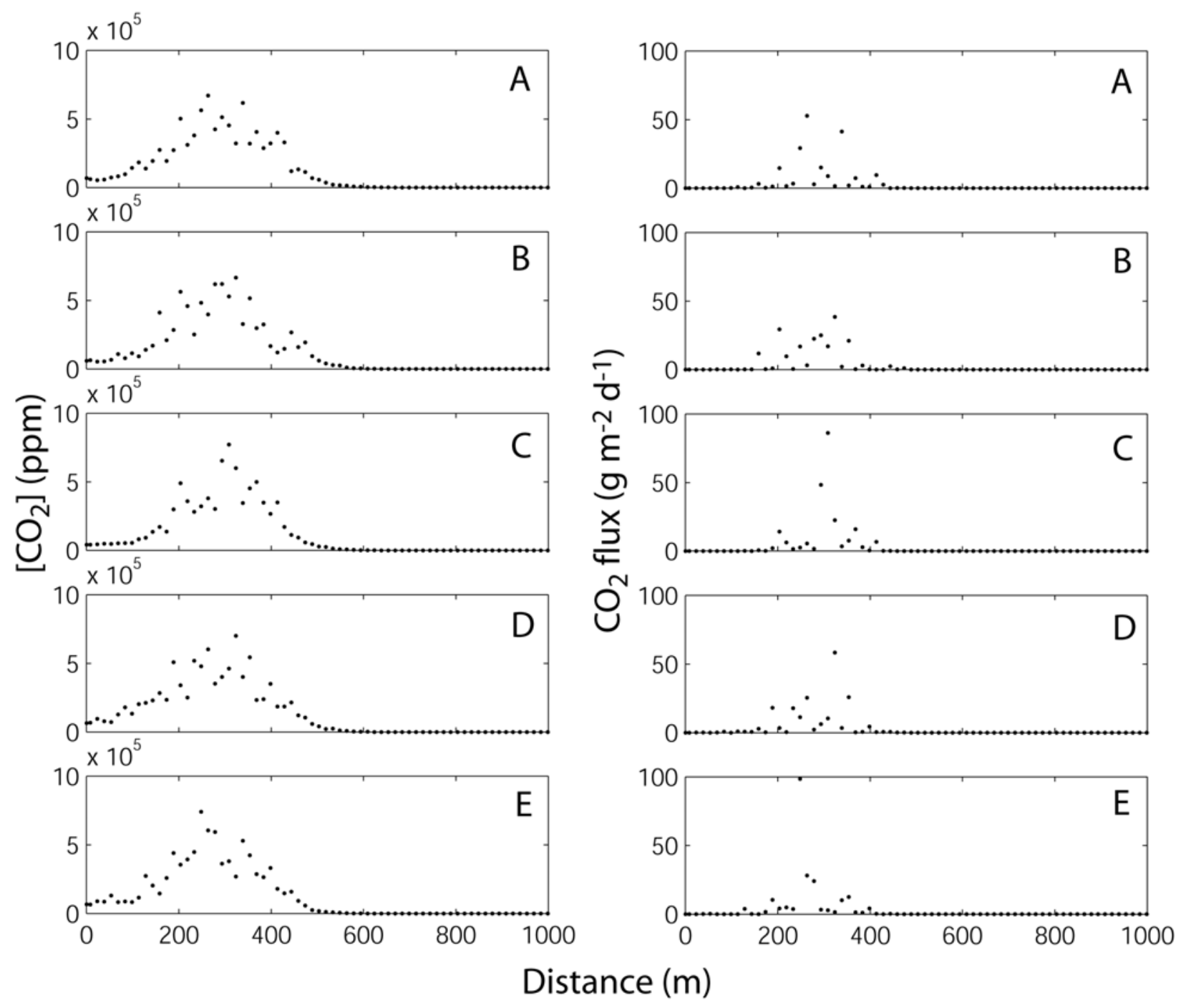

Figure 4.12. Horizontal profiles of shallow subsurface $\mathrm{CO}_{2}$ concentration ([CO $\left.\mathrm{CO}_{2}\right], 3 \mathrm{~m}$ depth) and surface $\mathrm{CO}_{2}$ flux for high (576 $\mathrm{g} \mathrm{m}^{-2} \mathrm{~d}^{-1}$ ) $\mathrm{CO}_{2}$ source flux, heterogeneous isotropic permeability realizations $A-E$, and $t=200$ years. 


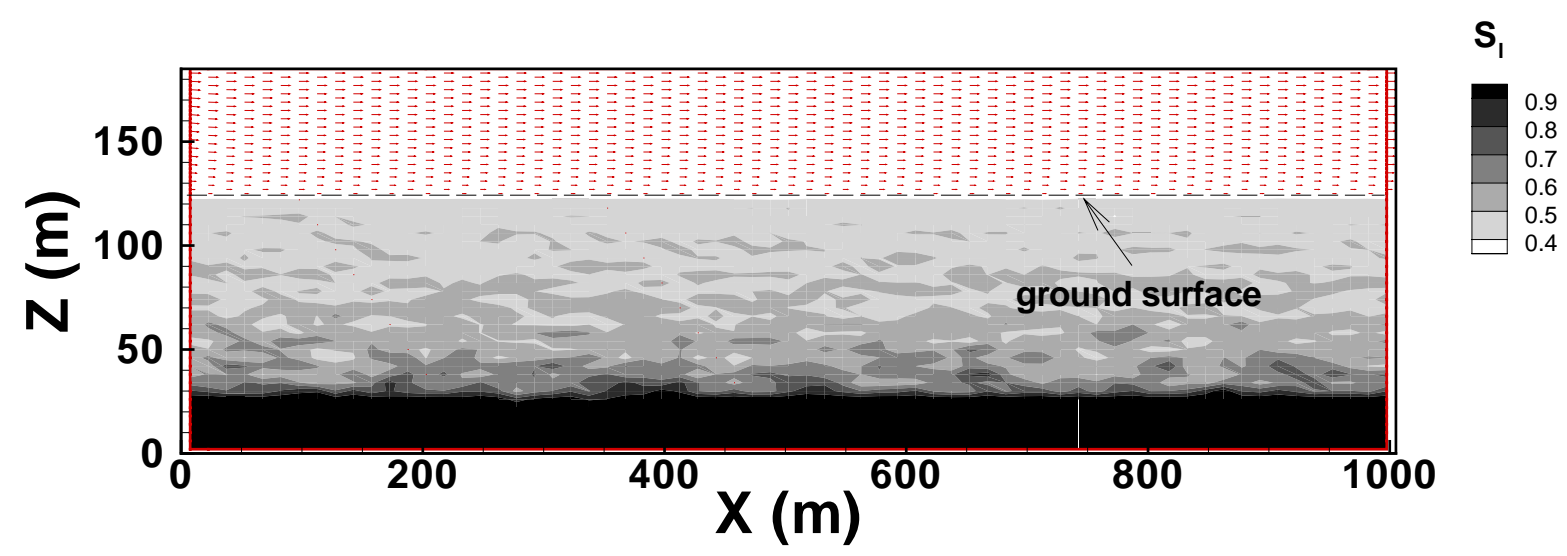

Figure 4.13. Initial liquid saturation and wind velocity for the coupled subsurface-surface layer system with heterogeneous permeability for subsurface. 

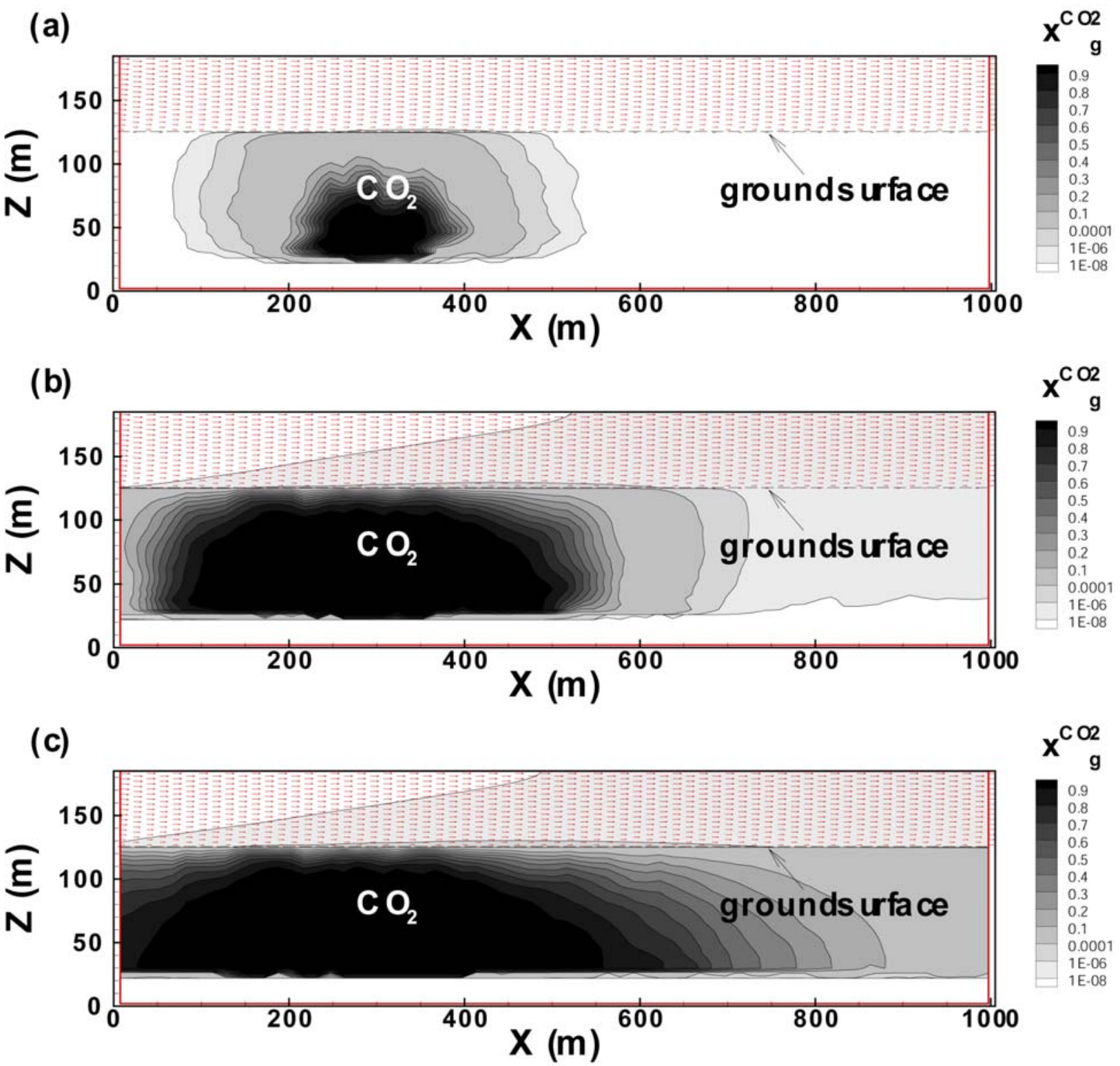

Figure 4.14. Coupled $\mathrm{CO}_{2}$ subsurface migration and surface-layer mixing at 1, 10, and 200 years after $\mathrm{CO}_{2}$ migration begins for wind velocity of $3 \mathrm{~m} \mathrm{~s}^{-1}$ and permeability realization A in a horizontal system. 


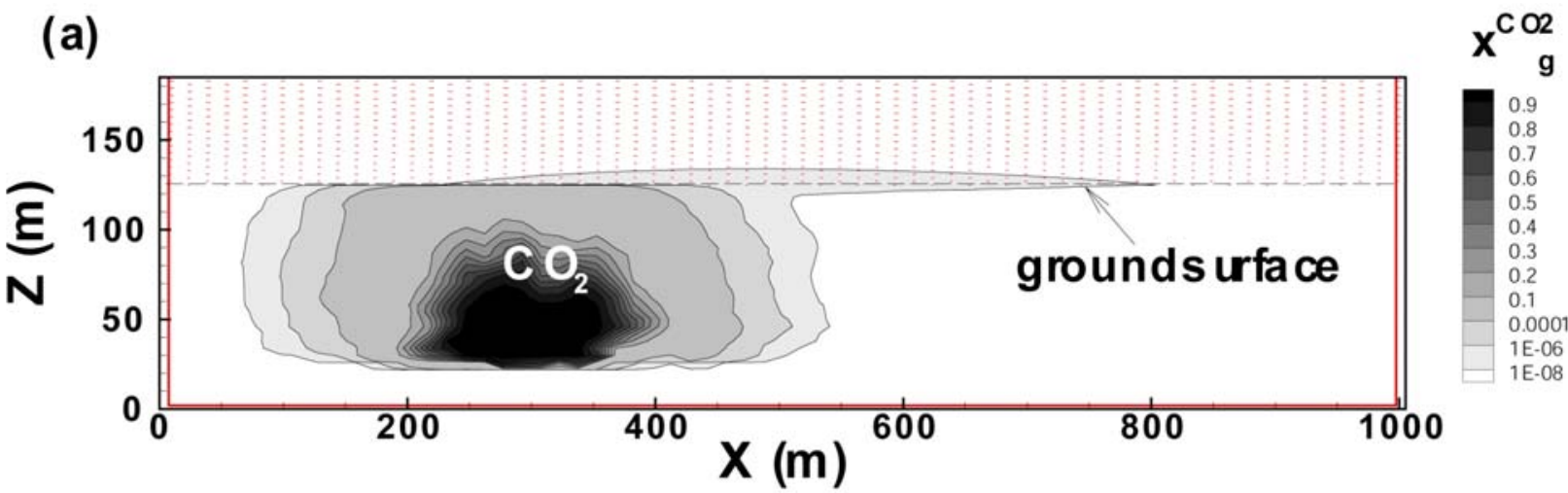

(b)
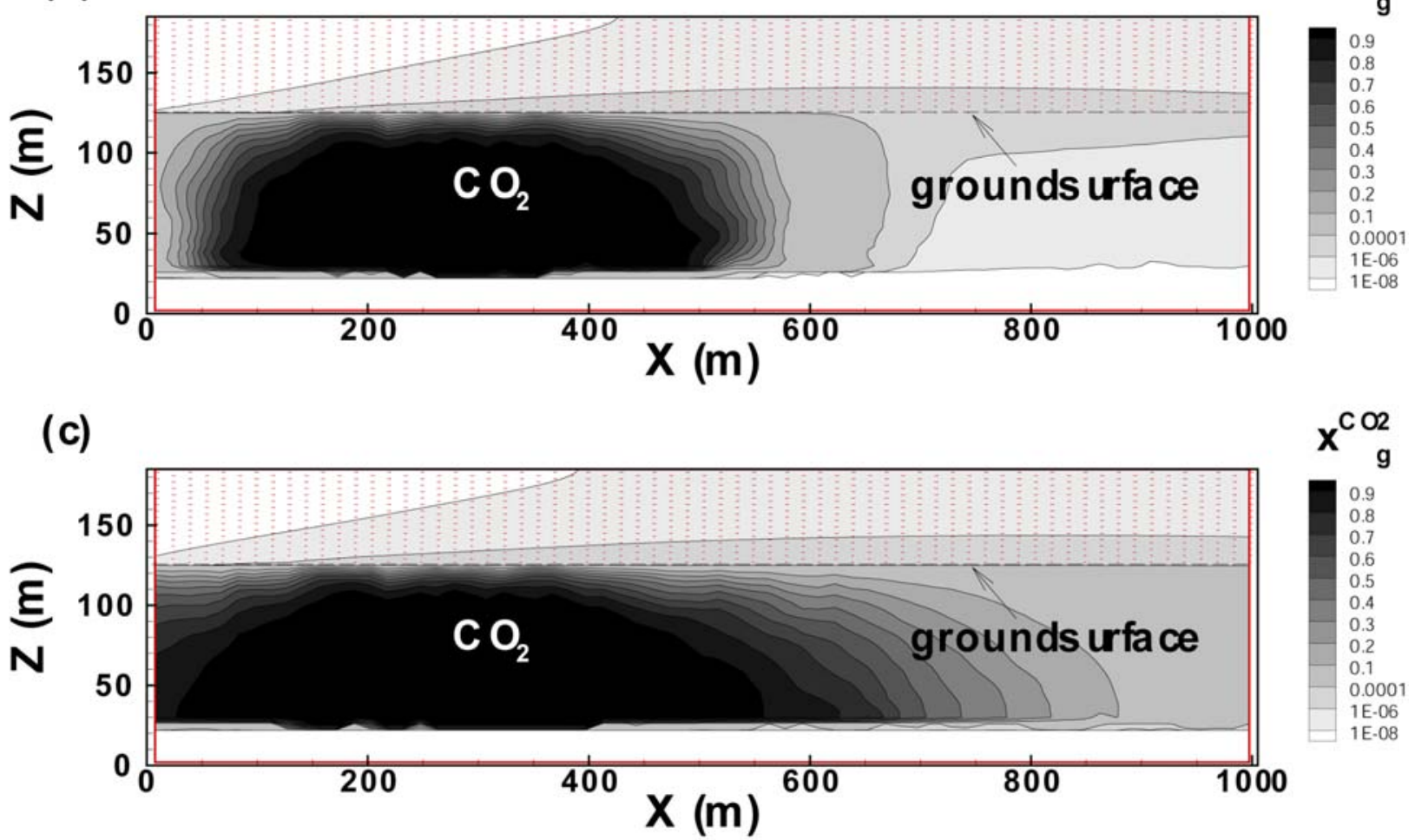

Figure 4.15. Coupled $\mathrm{CO}_{2}$ subsurface migration and surface-layer mixing at 1, 10, and 200 years after $\mathrm{CO}_{2}$ migration begins for wind velocity of $1 \mathrm{~m} \mathrm{~s}^{-1}$ and permeability realization A in a horizontal system. 


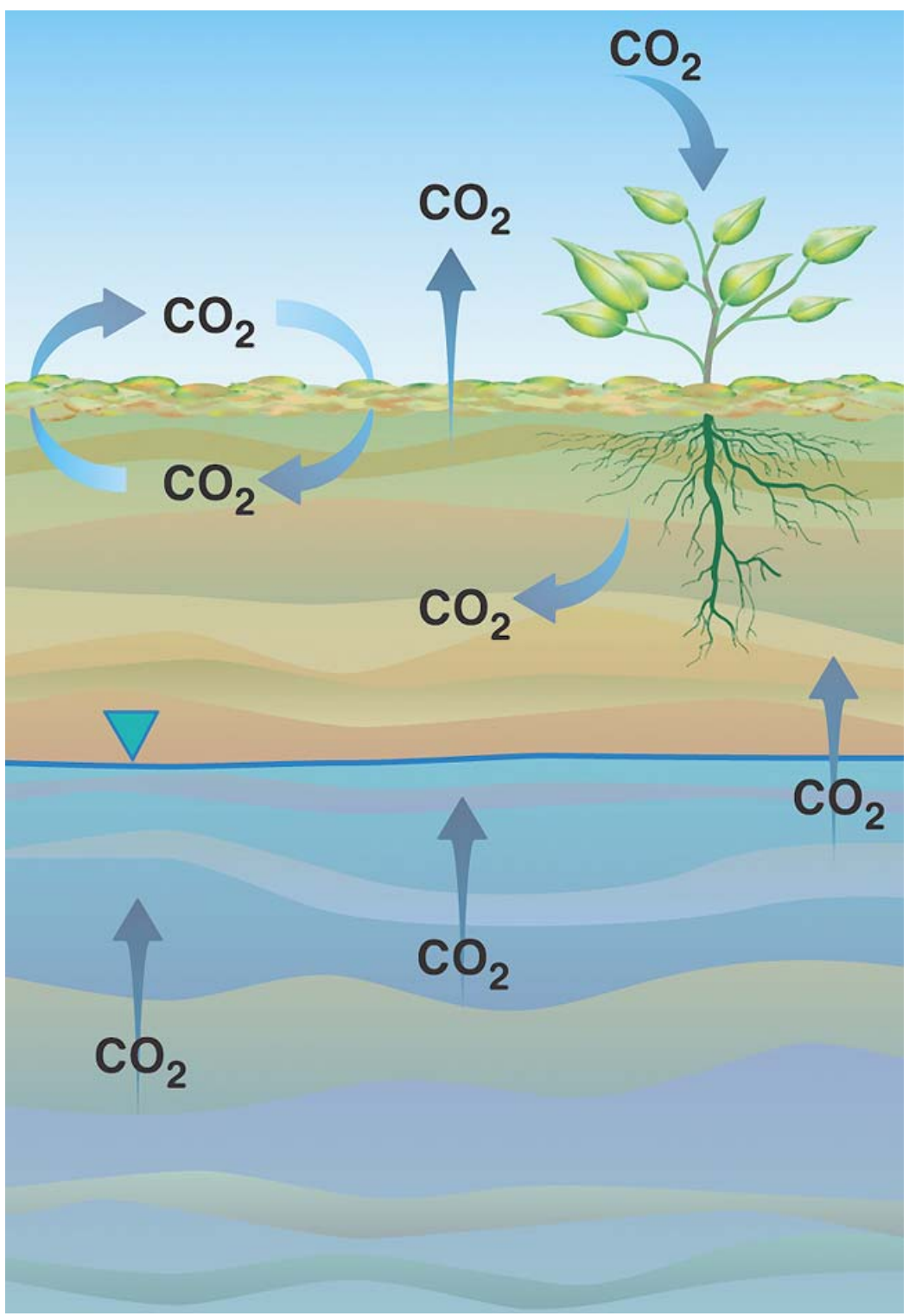

Figure 5.1. Soil $\mathrm{CO}_{2}$ sources and sinks, showing from left-right, top-bottom, exchange with the atmosphere, production by decay of soil organic matter, photosynthetic uptake by plants, and production by root respiration, groundwater degassing, oxidation of subsoil organic matter, and deep degassing. 


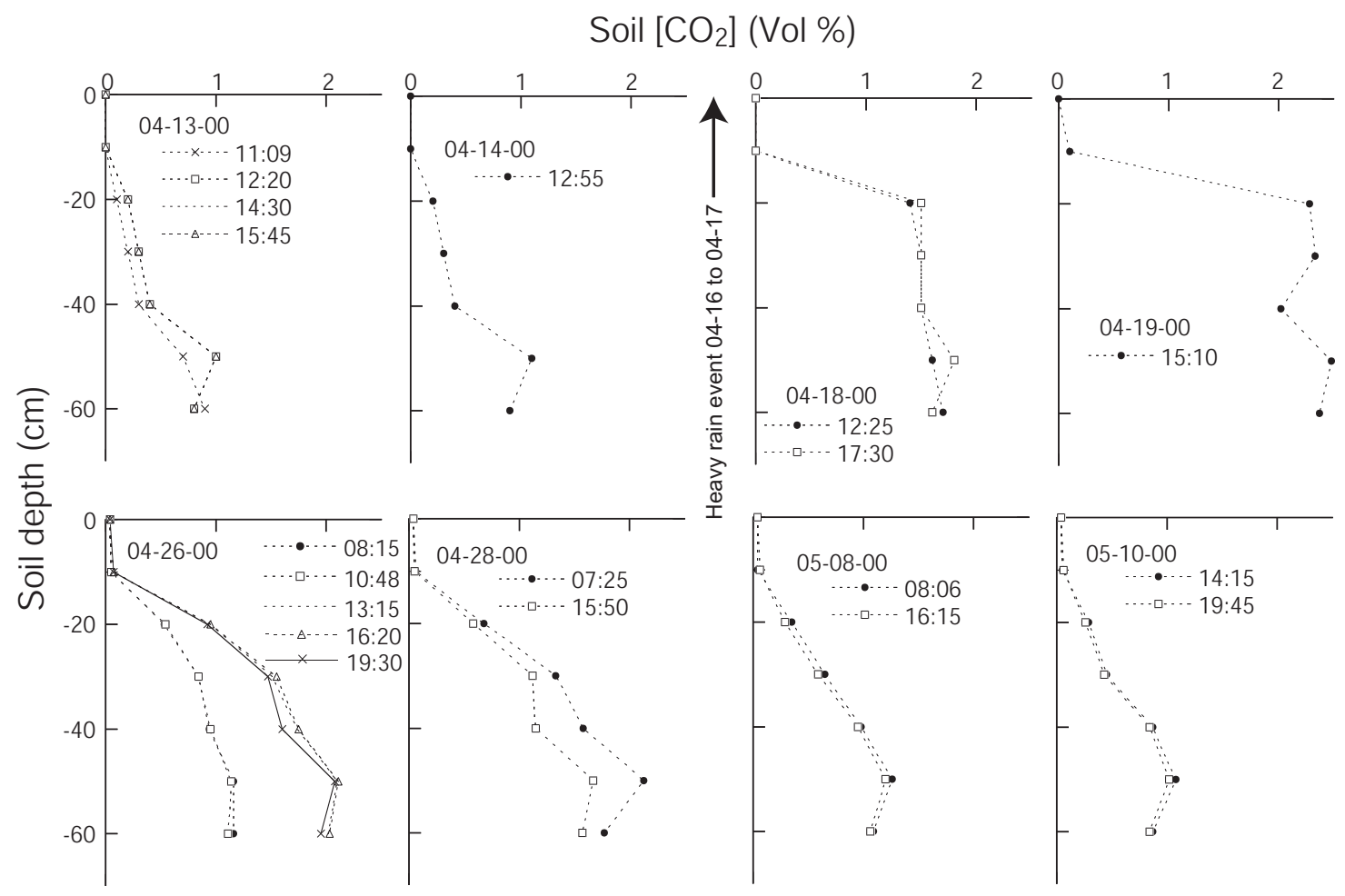

Figure 5.2. Repeated measurements of a soil $\mathrm{CO}_{2}$ concentration profile in central California over a month-long period (modified from Lewicki et al., 2003). Measurement dates and times and the timing of a heavy rain event are shown. Temporal variability of soil $\mathrm{CO}_{2}$ concentration is due to change in soil $\mathrm{CO}_{2}$ production rates due to changes in soil temperature and water content. For example, increase in soil $\mathrm{CO}_{2}$ concentrations is observed each day from morning to afternoon measurement times due to increasing soil respiration rates with soil temperature. Also, soil $\mathrm{CO}_{2}$ concentrations increased following a heavy rain event (04-16-00 to 04-17-00) due to increasing soil respiration rates and/or decreasing loss of $\mathrm{CO}_{2}$ to the atmosphere with increasing soil water content. 


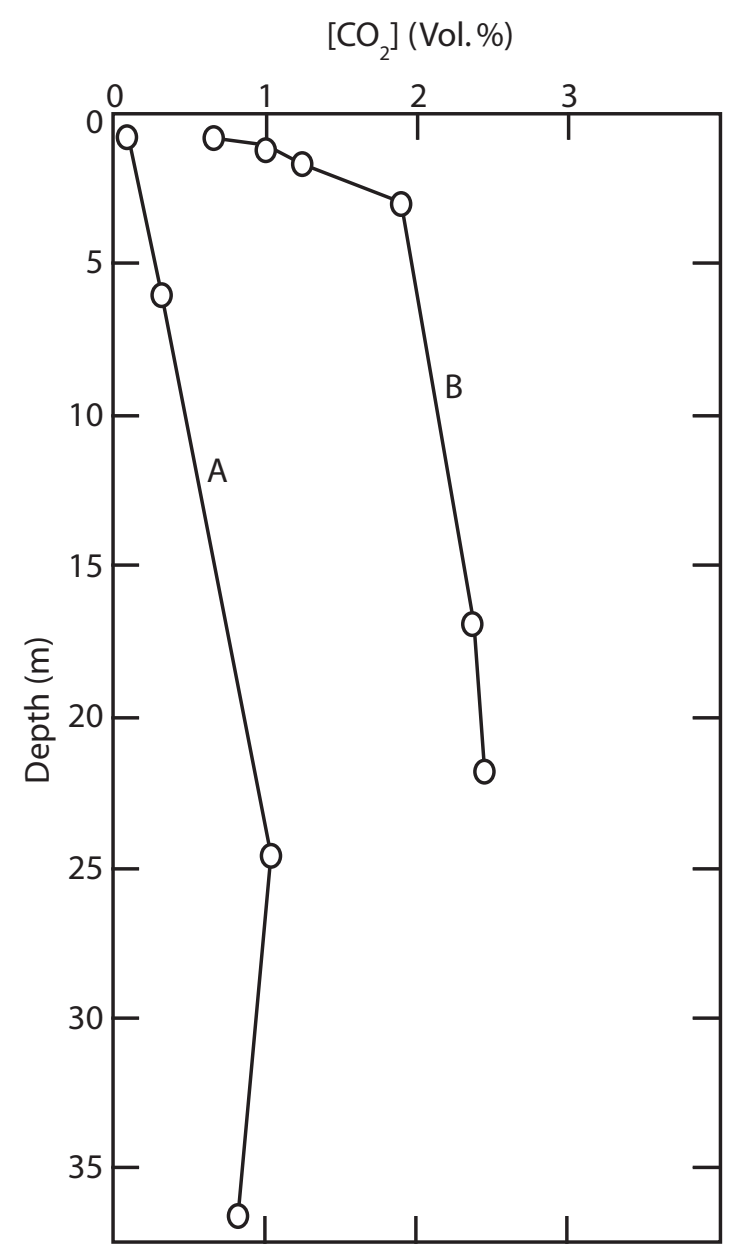

Figure 5.3. Profiles (A and $\mathrm{B}$ ) of $\mathrm{CO}_{2}$ concentration with depth in the unsaturated zone above the Ogallala aquifer system of Texas (modified from Wood and Petraitis, 1984). Increase in $\mathrm{CO}_{2}$ concentration with depth was interpreted to result from production of $\mathrm{CO}_{2}$ by oxidative decay of particulate organic carbon. The water table at sites $A$ and $B$ was $~ 51$ and $77 \mathrm{~m}$ below the surface. 


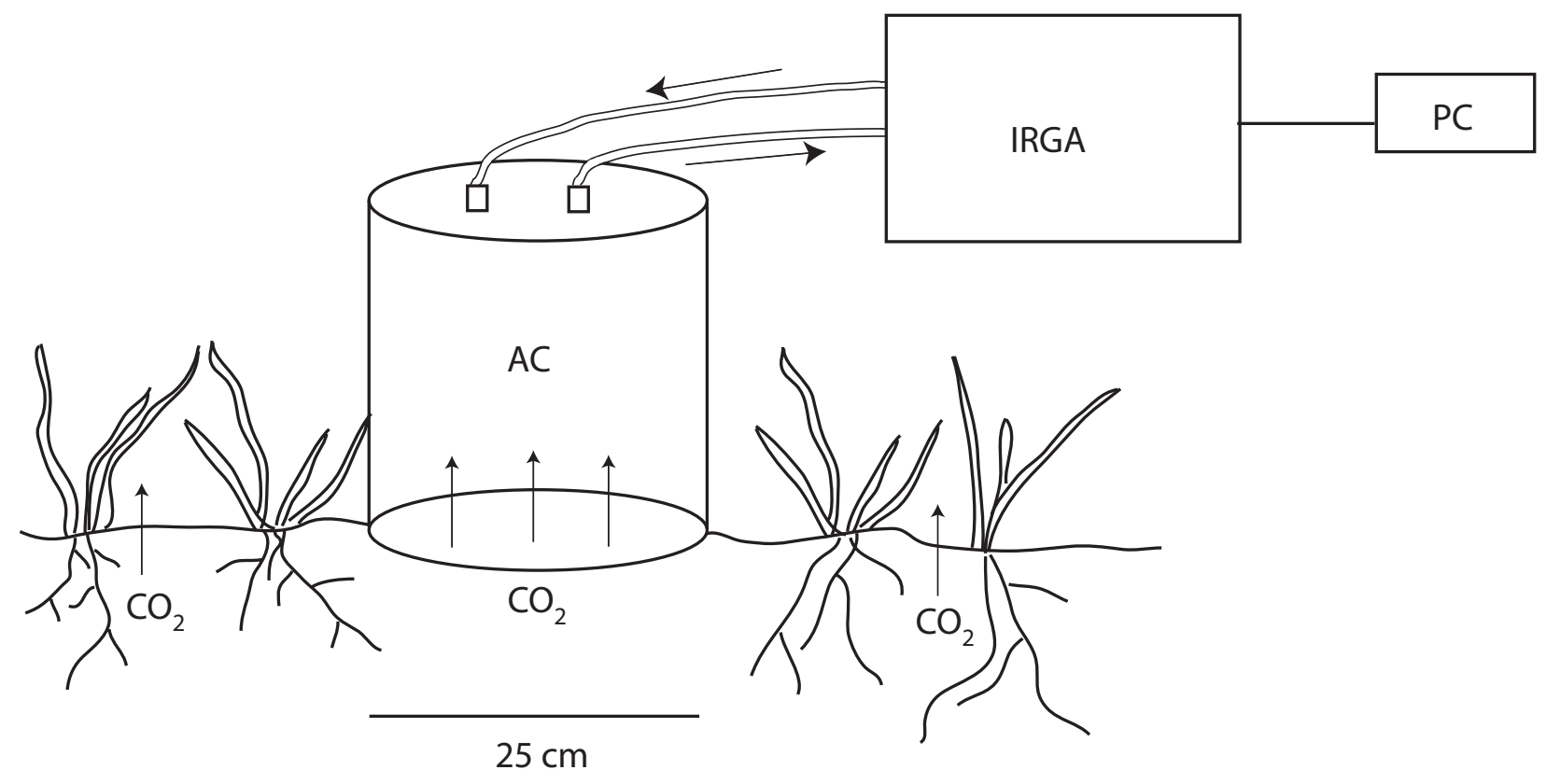

Figure 6.1. Schematic diagram of an accumulation chamber (AC) measurement system of soil $\mathrm{CO}_{2}$ flux. The air contained in the AC is circulated through the AC and the IRGA and the rate of change of $\mathrm{CO}_{2}$ concentration in the $A C$ is measured by the IRGA and recorded by the $P C$. 


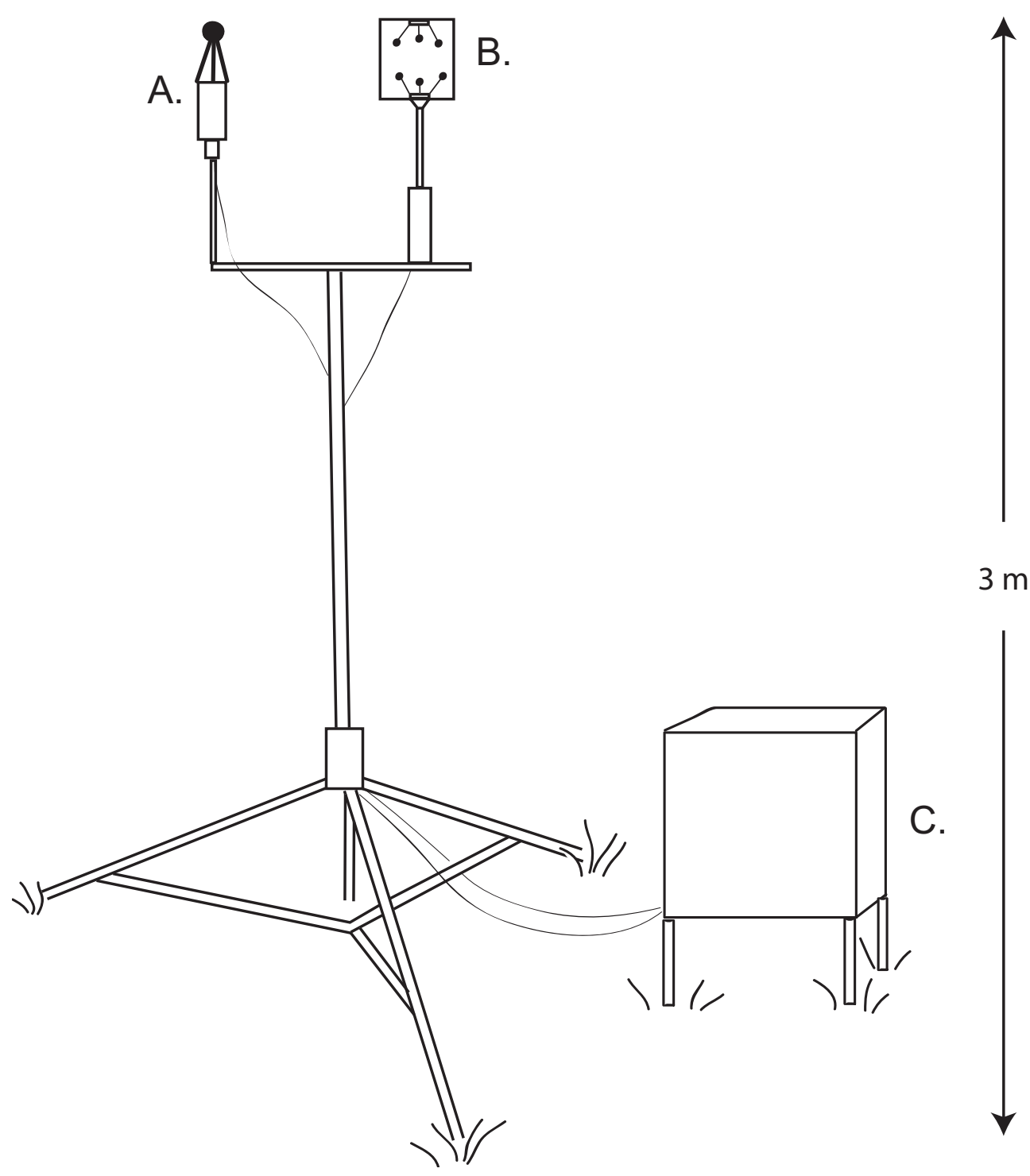

Figure 6.2. Schematic diagram of an eddy correlation (EC) instrumentation tower to measure surface CO2 flux. An (A) open path IRGA, (B) high frequency response sonic anemometer, and $(C)$ box containing power source and datalogger/PC are shown. 


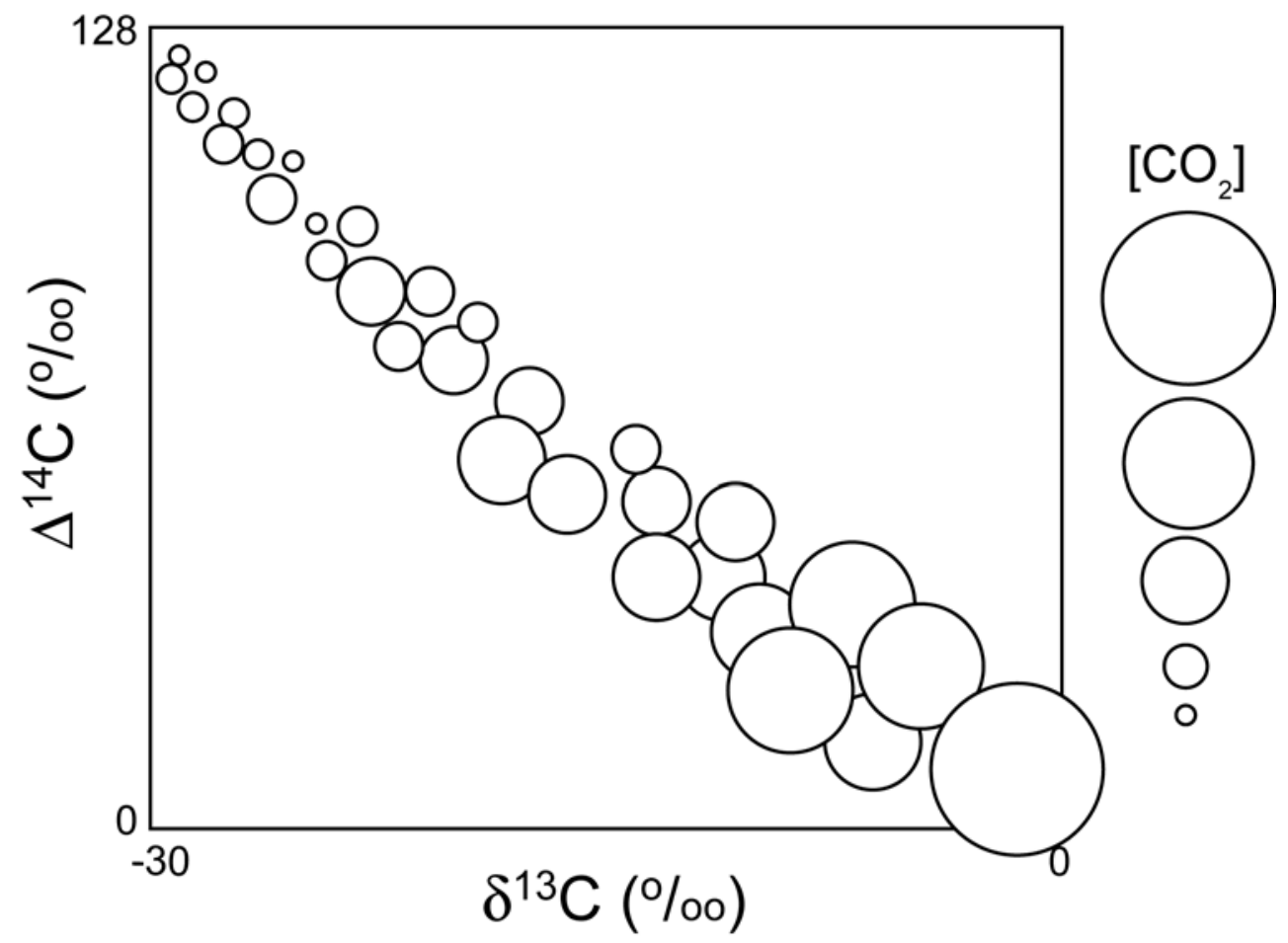

Figure 7.1. Bubble plot of $\Delta^{14} \mathrm{C}$ versus $\delta^{13} \mathrm{C}$ compositions of soil $\mathrm{CO}_{2}$ showing idealized mixing trend between soil gas with relatively low $\mathrm{CO}_{2}$ concentration $\left(\left[\mathrm{CO}_{2}\right]\right)$ and $\delta^{13} \mathrm{C}$ and high $\Delta^{14} C$ (young biogenic carbon dominated) and soil gas with relatively high $\mathrm{CO}_{2}$ concentration, $\delta^{13} \mathrm{C}$ and low $\Delta^{14} \mathrm{C}$ (geothermal carbon dominated). Bubble size scales with soil gas $\mathrm{CO}_{2}$ concentration. 

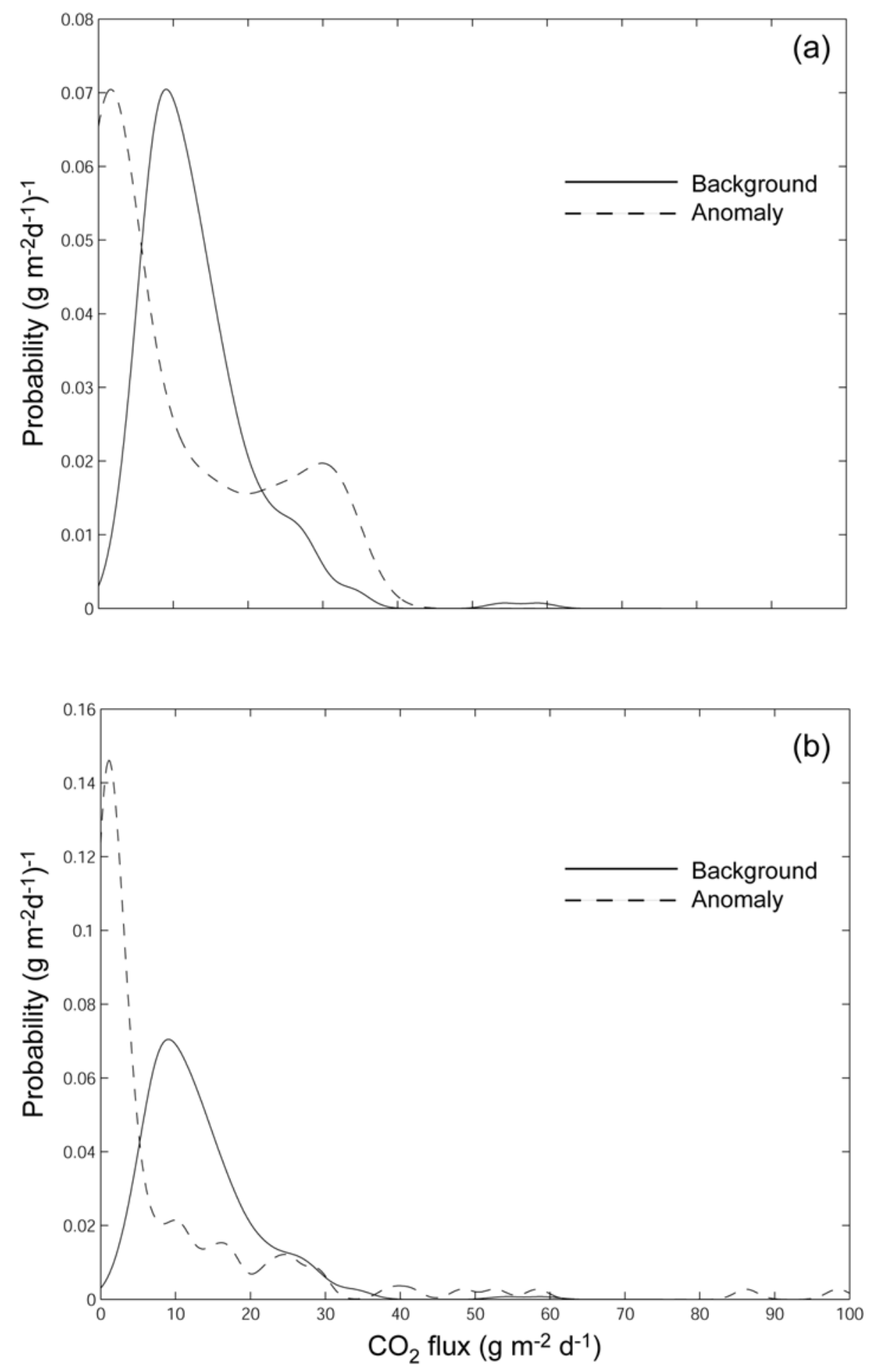

Figure 7.2. Probability density functions of background central California soil $\mathrm{CO}_{2}$ flux and anomalous $\mathrm{CO}_{2}$ flux associated with (a) homogeneous isotropic (see Figure 4.9 for surface $\mathrm{CO}_{2}$ flux profile associated with high source geothermal $\mathrm{CO}_{2}$ flux) and (b) heterogeneous isotropic (see Figure 4.12 for surface $\mathrm{CO}_{2}$ flux profile associated with high source geothermal $\mathrm{CO}_{2}$ flux) permeability structures. 

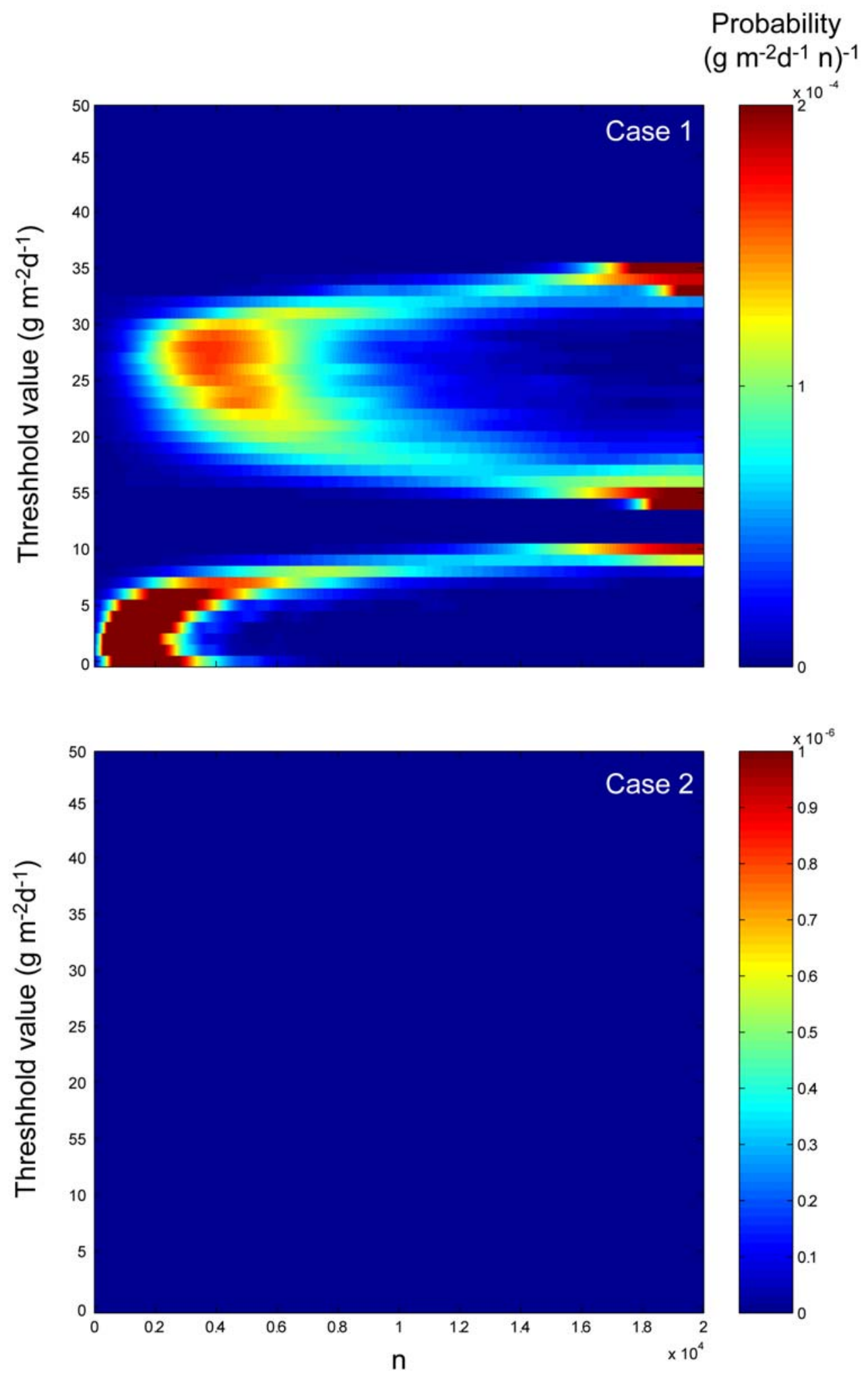

Figure 7.3. Probability image plots for Cases 1 and 2 Monte Carlo simulations (see Table 7.2). 


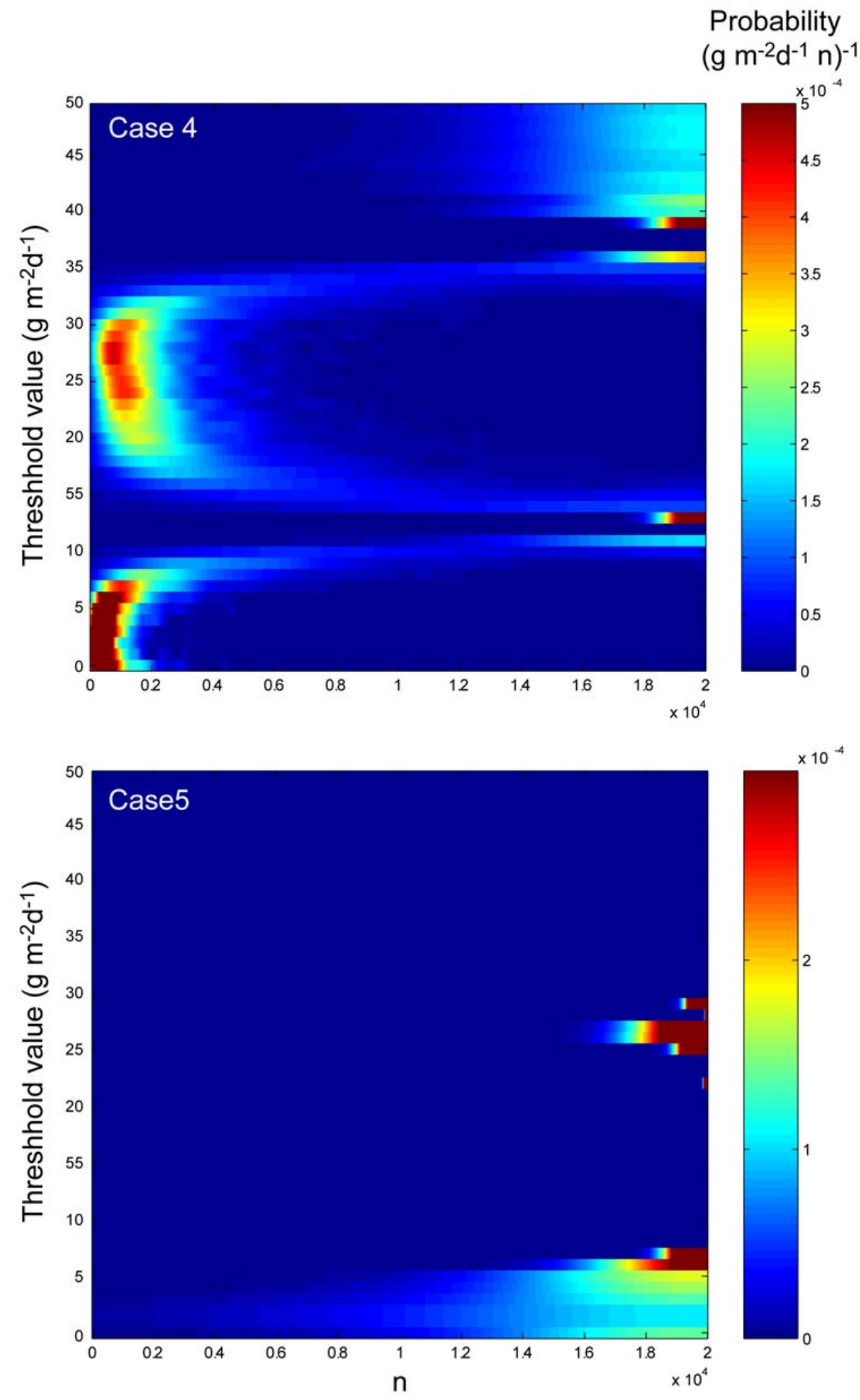

Figure 7.4. Probability image plots for Cases 4 and 5 Monte Carlo simulations (see Table 7.2). 

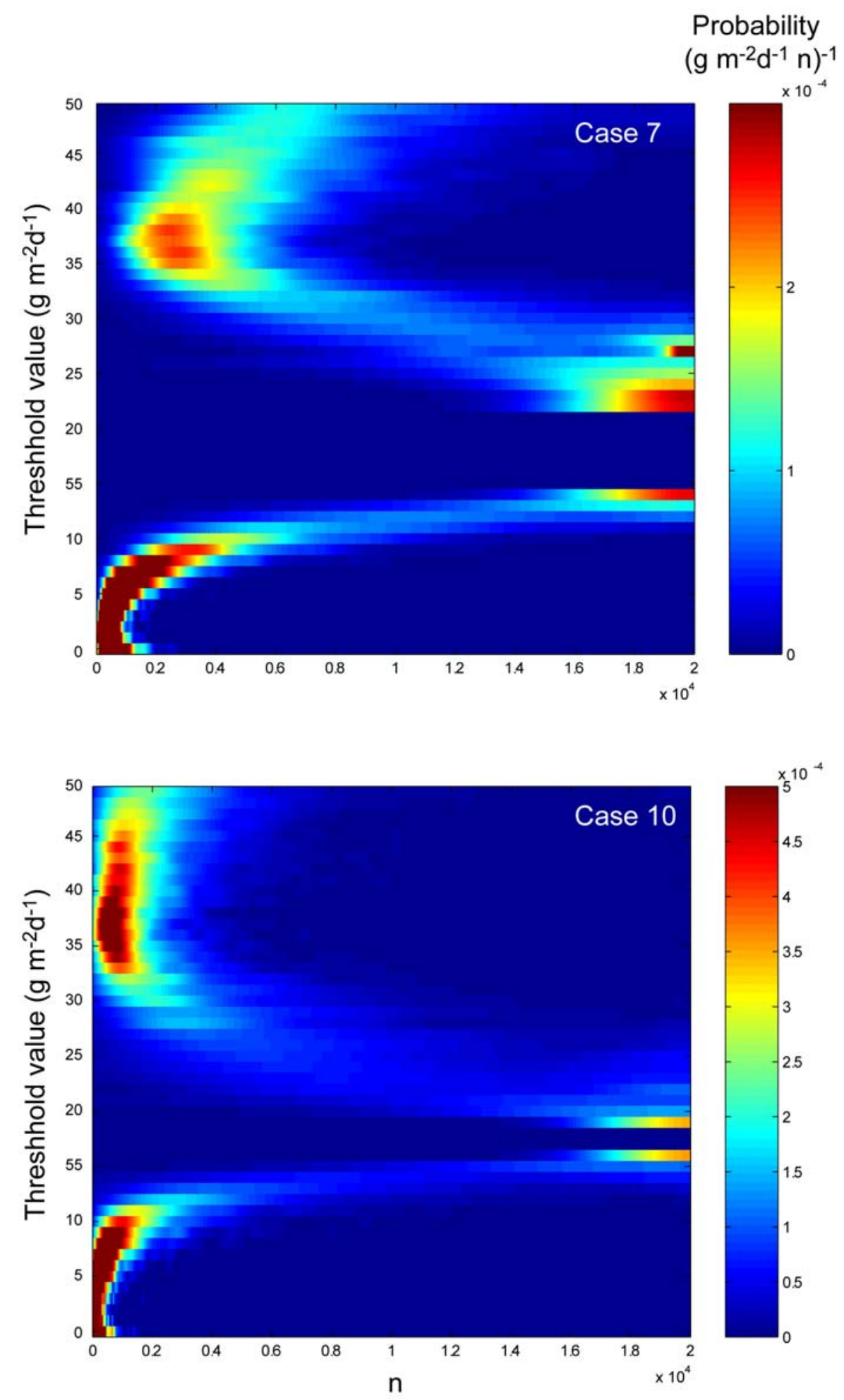

Figure 7.5. Probability image plots for Cases 7 and 10 Monte Carlo simulations (see Table 7.2). 


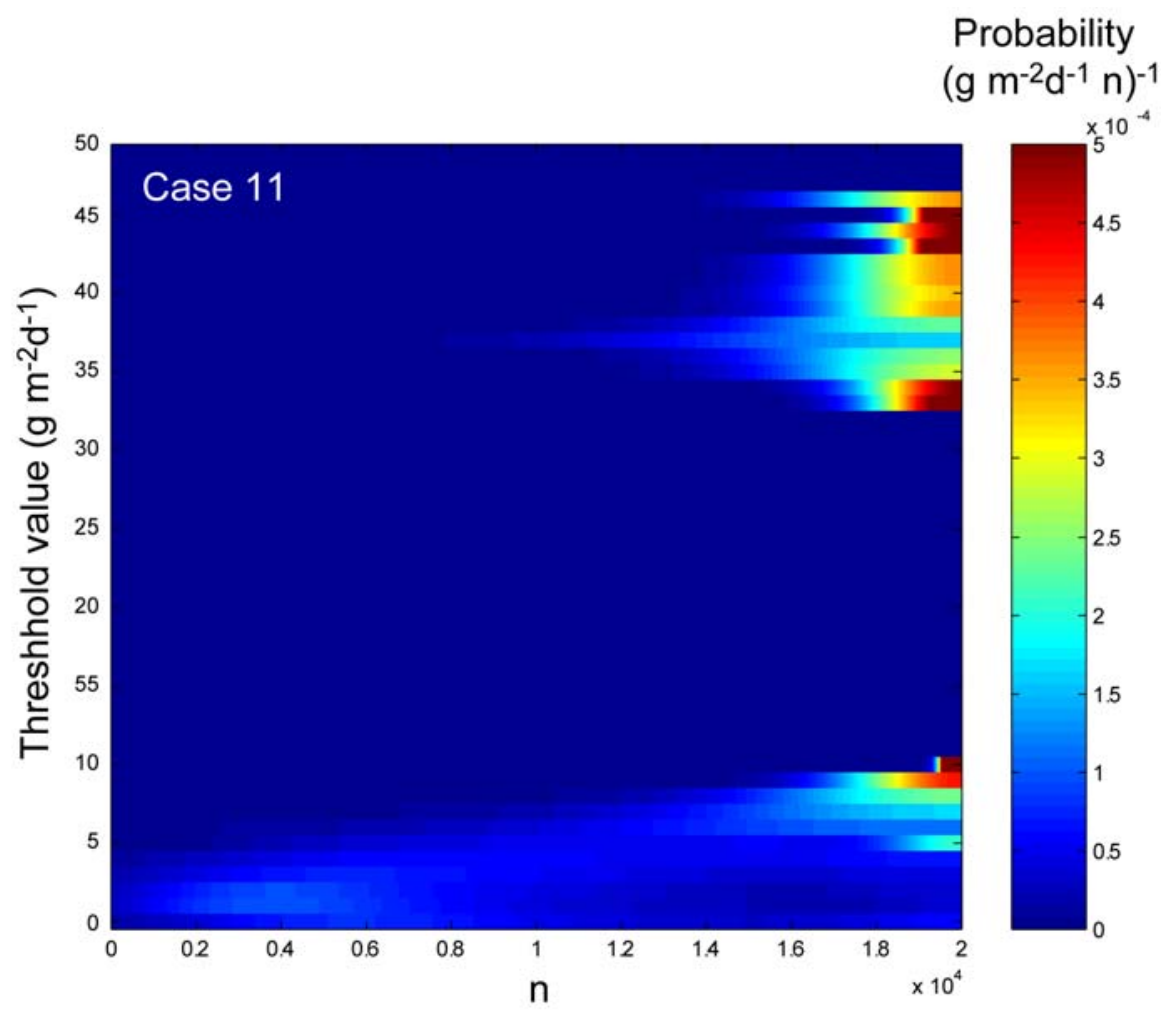

Figure 7.6. Probability image plots for Case 11 Monte Carlo simulation (see Table 7.2). 